\title{
PRACTICES AND PREFERENCES AMONG STUDENTS WHO READ BRAILLE AND USE ASSISTIVE TECHNOLOGY
}

\author{
by \\ Frances Mary D'Andrea \\ Bachelor of Science, George Peabody College for Teachers, 1982 \\ Master of Education, Georgia State University, 1996
}

\author{
Submitted to the Graduate Faculty of \\ The School of Education in partial fulfillment \\ of the requirements for the degree of \\ Doctor of Philosophy
}

University of Pittsburgh 


\section{UNIVERSITY OF PITTSBURGH \\ SCHOOL OF EDUCATION}

This dissertation was presented

by

Frances Mary D'Andrea

It was defended on

June 15, 2010

and approved by

Amanda J. Godley, PhD, Associate Professor, Department of Instruction and Learning, University of Pittsburgh

M. Cay Holbrook, PhD, Associate Professor, Educational \& Counseling Psychology \& Special Education, University of British Columbia

Linda Kucan, PhD, Assistant Professor

Department of Instruction and Learning, University of Pittsburgh

Christopher Lemons, PhD, Assistant Professor

Department of Instruction and Learning, University of Pittsburgh

Dissertation Advisor: George J. Zimmerman, PhD, Associate Professor

Department of Instruction and Learning, University of Pittsburgh 
Copyright (C by Frances Mary D'Andrea

2010 


\title{
PREFERENCES AND PRACTICES AMONG STUDENTS WHO READ BRAILLE AND USE ASSISTIVE TECHNOLOGY
}

\author{
Frances Mary D'Andrea, $\mathrm{PhD}$ \\ University of Pittsburgh, 2010
}

An increased emphasis on the use of technology and the focus on "multiliteracies" in the classroom has great implications for both teachers and students regarding the expectation that all students will become skilled and critical users of computers and other technology for literacy-related tasks.

Students who are braille readers use assistive technology not only to engage in literacy tasks (such as creating print documents) but also to access the general curriculum. For all of its acknowledged importance, there is little research on the ways that technology has changed the reading and writing practices of students who use braille, nor is there much research on how assistive technology is learned by students with visual impairments.

A mixed methods study was conducted to investigate current use of paper braille and assistive technology among students aged 16-22 who read braille, and the students' attitudes toward braille and technology as tools for classroom learning in high school and college. The first phase of the study consisted of 12 semi-structured interviews of students around the United States. These interviews were coded for themes, and quotes from the interviews were used to create a Likert-scale survey. In the second phase of the study, 77 students participated in the survey, indicating their agreement or 
disagreement with the statements on the survey. Survey data were analyzed for frequencies and percentages of responses, and relationships between variables such as grade level, age, primary medium, and other factors were explored.

Results of the study indicated the changing nature of how students use various tools and select approaches to completing their class work, and the importance for students of being able to make choices regarding tools and strategies. Implications for teacher preparation and suggestions for future research are discussed. 


\section{TABLE OF CONTENTS}

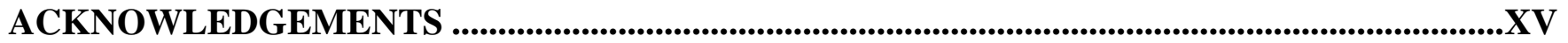

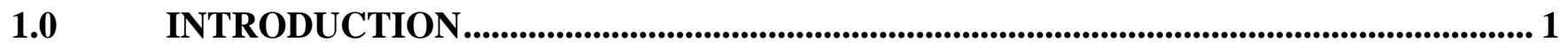

1.1 RELEVANCE OF THE STUDY ............................................................................ 3

1.2 SIGNIFICANCE OF THE PROBLEM....................................................................... 4

1.3 RESEARCH QUESTIONS.......................................................................................... 5

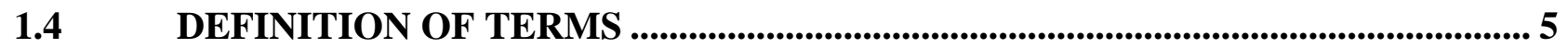

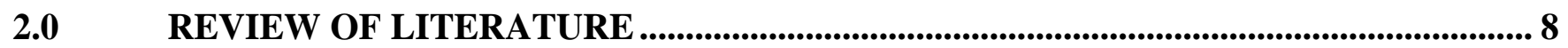

2.1 THE “BRAVE NEW WORLD” OF TECHNOLOGY IN SCHOOLS ......................... 8

2.2 STUDENTS WITH DISABILITIES AND THE USE OF TECHNOLOGY ............ 12

2.3 READING AND WRITING FOR STUDENTS WHO ARE BLIND ......................... 15

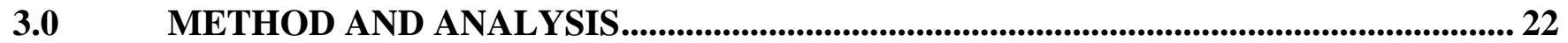

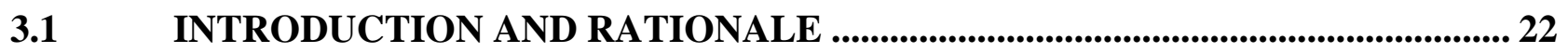

PHASE I: QUALITATIVE........................................................................................ 23

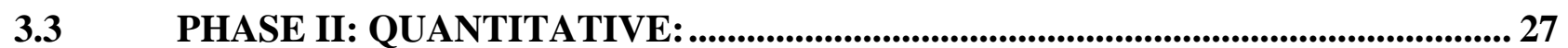

3.3.1 Survey Development ................................................................................................................... 27

3.3.2 The Survey Design ............................................................................................................ 28

3.3.3 The Pilot .................................................................................................................................. 31

3.3.4 Survey Dissemination ............................................................................................................. 32

3.4 RECRUITMENT AND SELECTION OF PARTICIPANTS ....................................... 34

4.0 RESULTS ......................................................................................................................... 39

4.1 PHASE I: FOCUSED INTERVIEWS ................................................................... 39

4.1.1 Basic Descriptive Data of Participants................................................................................ 40 
4.1.2 Learning to Read and Write Braille........................................................................... 41

4.1.3 Current Practices for Reading and Writing................................................................ 45

4.1.3.1 The devices and tools students used for reading and writing ...................... 46

4.1.3.2 Tasks performed by students using braille and technology ........................... 50

4.1.3.3 How students learn to use technology for school tasks.................................... 62

4.1.4 Preferences and Opinions About Braille and Technology ……................................ 65

4.1.4.1 Opinions about selecting a particular device....................................................... 65

4.1.4.2 Opinions about specific tasks and access to information ................................ 69

4.1.4.3 Opinions about the role of TVIs ......................................................................... 79

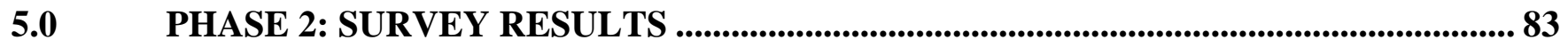

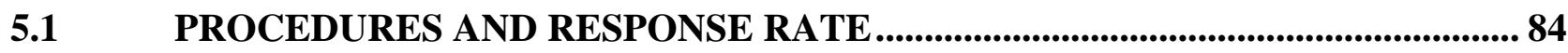

5.1.1 Demographic information ..................................................................................................... 86

5.2 STUDENT PRACTICES FOR USING BRAILLE AND TECHNOLOGY ............92

5.2.1 Use of paper and electronic braille .................................................................................... 93

5.2.2 Use of speech access and other electronic methods....................................................... 97

5.2.3 Mathematics and foreign language materials ............................................................ 101

5.2.4 Use of the Slate and stylus ...................................................................................... 103

5.2.5 Engaging in Specific multiliteracy tasks ..................................................................... 105

5.3 HOW DO STUDENTS LEARN THESE PRACTICES?............................................. 108

5.3.1 How they learned ...................................................................................................................... 108

5.3.1.1 Role of TVI ............................................................................................................... 113

5.4 PREFERENCES RELATED TO BRAILLE AND TECHNOLOGY ................... 116

5.4.1 Preferences for braille...................................................................................................... 117 
5.4.2 Preferences regarding speech and other technology ................................................. 121

5.4.3 Preferences for the slate and stylus ................................................................................... 125

5.4.4 Preferences for mathematics .................................................................................... 127

5.4.5 Accessing information in general..................................................................... 129

$5.5 \quad$ RELATIONSHIPS BETWEEN VARIABLES ......................................................... 133

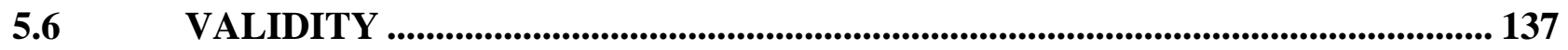

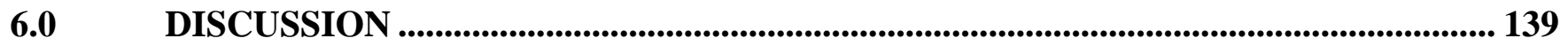

6.1 THE CHANGING NATURE OF READING ............................................................. 140

6.2 THE IMPORTANCE OF CHOICE IN STUDENTS' LIVES.................................. 142

6.3 TEACHER PREPARATION AND INSTRUCTION ................................................... 145

6.4 CHALLENGES ASSOCIATED WITH THIS STUDY ............................................ 148

6.5 LIMITATIONS OF THIS STUDY ............................................................................ 152

6.6 NEED FOR ADDITIONAL RESEARCH................................................................... 154

$6.8 \quad$ CONCLUDING THOUGHTS....................................................................................... 157

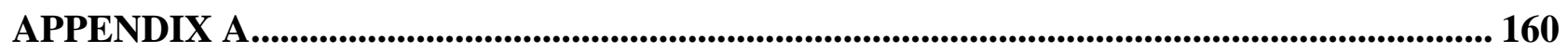

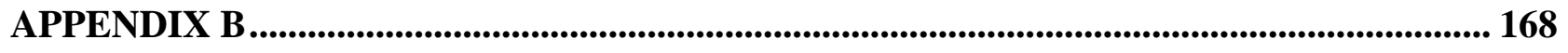

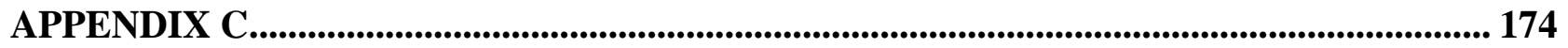

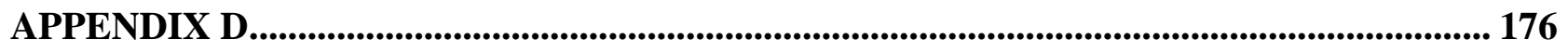

APPENDIX E .................................................................................................................................. 178

APPENDIX F ..................................................................................................................................... 182

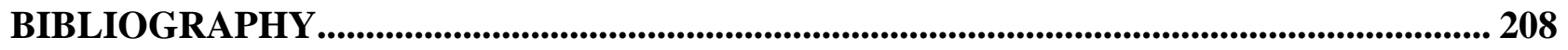




\section{LIST OF TABLES}

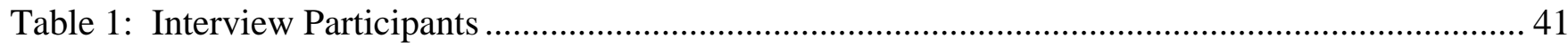

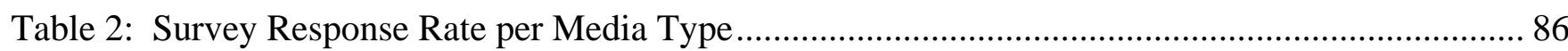

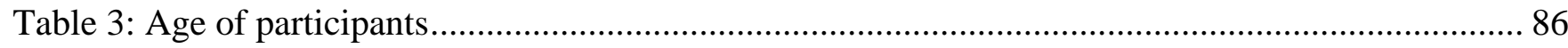

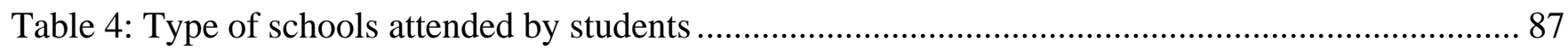

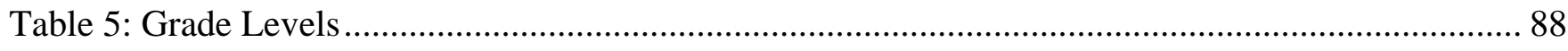

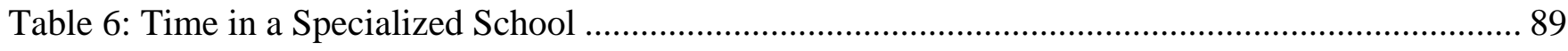

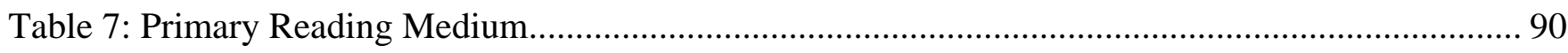

Table 8: Age students began to use technology for schoolwork ............................................................ 92

Table 9: Question 1: I use a portable braille notetaker to do most of my schoolwork .............................. 93

Table 10: Question 3: All of my textbooks are in paper braille................................................................. 94

Table 11: Question 10: When I'm listening my mind kind of zones out sometimes, so when I study I use

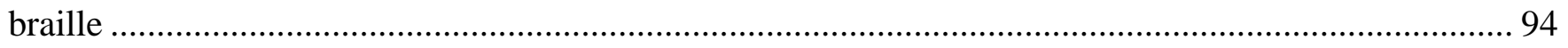

Table 12: Question 11: If it's a really difficult assignment I like to have the braille.................................. 95

Table 13: Question 13: I read with the refreshable braille display all day long ...................................... 95

Table 14: Question 14: I don't like to read long books on a 32-cell braille display ................................. 96

Table 15: Question 2: I use a computer with speech to do most of my work........................................... 97

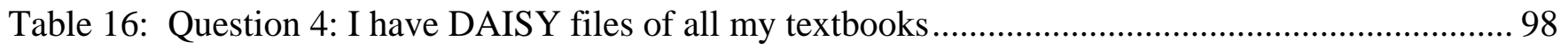


Table 17: Question 5: I'm finding that I'm reading fewer and fewer books tactually; I don't really use

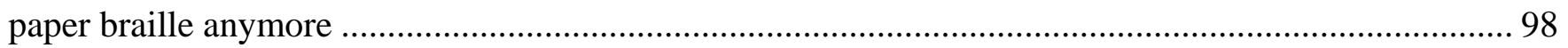

Table 18: Question 9: If I want to read something long it's going to be time consuming, so I'll just listen to it 99

Table 19: Question 12: I found that using speech was a lot faster than trying to read the braille with the display 99

Table 20: Question 15: I base what device to use on the particular assignment 100

Table 21: Question 6: Any of my math books are going to be paper braille 101

Table 22: Question 7: I find it easier to use my computer and listen to math 102

Table 23: Question 8: Whenever I do foreign languages then it's essential to have paper braille 102

Table 24: Question 16: I've never had any practical use for the slate and stylus 104

Table 25: Question 17: I use the slate and stylus for short tasks like taking down people's phone numbers 104

Table 26: Question 25: I usually had to have some help from a sighted person when using PowerPoint 105

Table 27: Question 26: I managed to do PowerPoint by myself with no problem.............................. 106

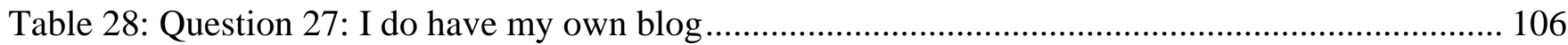

Table 29: Question 28: My teachers email me my assignments.................................................. 107

Table 30: Question 18: I learned the bulk of the technology I use all by myself ................................ 109

Table 31: Question 19: The technology specialist from the school for the blind taught me technology 109

Table 32: Question 20: My TVI got me started on technology ................................................... 110

Table 33: Question 21: I didn't learn technology in school, I went to a center ................................. 110 
Table 34: Question 22: I have friends who know their technology better than me so I'll just ask them how to do something

Table 35: Question 23: My TVI taught me everything I know about technology.....

Table 36: Question 24: I don't really have any blind friends to ask about technology

Table 37: Question 53: TVIs should do their research before buying any sort of assistive technology for a student because a kid doesn't really know all the options available

Table 38: Question 54: I think that it's important that the students have a say in the technology bought for them even if they're really young 114

Table 39: Question 55: TVIs should only know about the most popular devices so they can teach their students how to use them 115

Table 40: Question 56: I think that TVIs should know about every technology device that's out there and keep up with it 115

Table 41: Question 29: I wasn't very enthusiastic about learning braille 117

Table 42: Question 30: I love reading and writing braille and that's how I work best 118

Table 43: Question 31: I try to use braille as little as I can 118

Table 44: Question 32: Braille is the foundation of a blind person's education 118

Table 45: Question 33: I didn't like to read braille because I thought it was slow and inefficient. 119

Table 46: Question 34: I find that when I'm reading braille I process and comprehend things better than when I'm listening 119

Table 47: Question 36: I think reading braille is a lot slower than using speech software 120

Table 48: Question 49: It's important to read braille because it teaches you how to spell and punctuate 120

Table 49: Question 35: Speech allows me to focus on the story more 122 
Table 50: Question 37: I don't really like to listen to synthetic speech

Table 51: Question 38: I'm a huge supporter of mainstream products rather than devices designed for blind people. 122

Table 52: Question 39: I think these new netbooks are taking the place of braille notetakers.............. 123

Table 53: Question 40: I don't like PowerPoint because I have to rely on other people to use it........... 123

Table 54: Question 41: It's gotten a lot easier to do PowerPoint with speech now than it used to ........ 123

Table 55: Question 42: PowerPoint with WindowEyes or JAWS is just too hard .............................. 124

Table 56: Question 43: I don't like the slate because it's much slower............................................ 125

Table 57: Question 44: I'll never reject the importance of the slate and stylus ................................. 126

Table 58: Question 45: I can't imagine how I would do math on the computer .................................. 127

Table 59: Question 46: For my math class I haven't felt the need for braille--speech is fine................ 127

Table 60: Question 47: A part of me still really misses reading the hard copy braille books but it's just not practical

Table 61: Question 48: I'm not a computer person even though I use it all the time 129

Table 62: Question 50: If I can read the menu online I don't care if I have a braille menu or not ......... 130

Table 63: Question 51: When you use technology it's going to make things easier. 130

Table 64: Question 52: Once students get into high school and as they get closer to college you need to start taking the braille away from them and forcing them to use speech. 130

Table 65: Spearman's correlation between grade level and use of braille 133

Table 66: Spearman's correlation between age and use of braille 134

Table 67: Spearman's correlation between time reading braille and usage 134

Table 68: Spearman's correlation between time at specialized school and braille usage 135

Table 69: Spearman's correlation between age and practicality of braille. 135 
Table 70: Spearman's correlation between enthusiasm and years knowing braille............................ 136 


\section{LIST OF FIGURES}

Figure 1: Tools used by students to complete school work ................................................................... 46

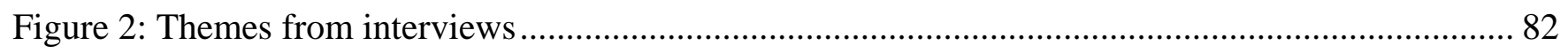

Figure 3: The effect of more choices on future success..................................................................... 159 


\section{ACKNOWLEDGEMENTS}

Any dissertation can only be completed with the help of many people, and this project is no exception. First, I must thank the National Center for Leadership in Visual Impairment (NCLVI) and the U.S. Department of Education, Office of Special Education Programs (OSEP) Cooperative Agreement H325U040001 for the financial support that made it possible for me to go back to school as a full-time student. I am also grateful to the University of Pittsburgh School of Education Alumni Society for awarding me an Alumni Doctoral Fellowship to complete this research.

I would also like to thank my committee, each of whom played an essential role in the development of this research study. My advisor, Dr. George Zimmerman, was a wonderful source of support and assistance, and the expertise of Dr. Amanda Godley, Dr. Cay Holbrook, Dr. Linda Kucan, and Dr. Chris Lemons made this study stronger than it would have been. Thanks to the staff in the department of Instruction and Learning who made sure I always had the correct forms, and special thanks to Suzanne Puskar who helped me keep up with all the consent forms sent to the university.

I have been extremely fortunate in my friends, including my colleagues in the two NCLVI cohorts who provided a model and a dose of reality to the process of completing a dissertation. Thanks to Melissa Brydon, Lynn Fox, Rebecca Renshaw, Kelly Romano, Ruby Ryles, Megan Spence, Diane Wormsley, Tessa Wright, and Kim Zebahazy all of whom said just the right things at just the right 
times. Thanks also to Mark Riccobono and Judith Chwalow at the National Federation of the Blind for their help and support of this project.

I particularly want to thank my family, my mother Margaret F. D'Andrea, and my brothers John, Tom, and Paul and their families. Extra special thanks to my husband Stephen D'Andrea who uprooted his life to move to Pittsburgh with me and has been an unflagging source of support over these past four years (and for many more years than that). This dissertation is dedicated to them. With a cheering section like this, who could miss? I love you all. 


\subsection{INTRODUCTION}

A rapid and accelerating pace of change for all aspects of American life in the use of technology is a defining characteristic of the past four decades. People use technology to communicate, to work more efficiently, and to engage in leisure activities. Seventy-seven percent of American households have a computer (Kennedy, Smith, Wells, \& Wellman, 2007), and by 2004, 75\% of American households had Internet access as well (Nielsen//NetRatings, 2004). Half of Americans report frequent use of the Internet during a typical day and that number is growing (Gallup, 2008). The popularity and seeming ubiquity of the Internet and World Wide Web have changed the behavior of many Americans. Nowadays, people turn to online resources to get news and information, to shop, make travel reservations, socialize with friends who live both far and near, watch their favorite television shows and movies, and play games with people who live far from their communities and whom they may have never met in person.

However, technology use is not confined to adults. Children and youth have embraced new technologies, and frequently engage in high-tech activities such as sending email, text messaging and instant messaging, creating and listening to podcasts, participating in social network sites and online gaming, web surfing, creating videos for public viewing on web sites, downloading music, creating blogs and wikis, uploading photographs, and looking at the photos of others. Prensky (2001) refers to today's children as "digital natives”: They are completely at home in a digital environment, using computers, playing video games, and surfing the Web. Truly, electronic devices are more than simply tools, but have become an electronic culture for youth (Ito, Horst, Bittani, boyd, Herr-Stephenson, Lange, Pascoe, Robinson, 2008). 
As a result of the influx of electronic media, schools have necessarily changed over time. A huge outlay of funding for technology in schools started in the late 1980s. By 1999, 84\% of public school teachers in the United States reported having at least one computer in their classroom, and virtually all teachers (99\%) reported having a computer somewhere in the school that they could use (NCES, 2000). Just a few years later, 99\% of American schools reported having Internet access, with access reported in 92\% of individual classrooms (U.S. Department of Education, 2004). The proliferation of educational technology has led to new expectations for teacher performance and for student outcomes. While students are using technology extensively for many literacy tasks, some educators feel it is the schools’ responsibility for students to become critical users of electronic information (Withrow, 2004). If schools take on this role, teachers will need to be proficient users of technology, as well as instructors for its use.

The use of technology has had a significant impact on the lives of students with disabilities as well, including those who are educated in mainstream settings. The wide variety of assistive technology now available means that more students than ever before are able to use computers to communicate, access information, and produce written and multimedia materials. Students who are blind or visually impaired, for example, can now use software that enlarges images on the computer monitor, and that can "read" aloud the information shown on the screen. Stand-alone electronic devices can be used for note taking, downloading books from the Internet, composing written assignments, and sending and receiving email, among other tasks. The promise of assistive technology in the lives of students who are blind has led to new opportunities and new challenges.

This study investigates these new opportunities and new challenges, specifically the use of technology by students who are blind and use braille, and students' practices and attitudes regarding both braille and assistive technology devices. First, an examination of technology use and the "new literacies" in the classroom are presented with the implications for both teachers and students related to the 
expectation that students will become skilled and critical users of technology for literacy-related tasks. The important role of assistive technology is then highlighted, and how its use facilitates literacy learning for students with disabilities. Specific emphasis is on the use of technology for students who use braille for reading and writing, and the impact of technology on both students who are visually impaired and their teachers. In the course of this study, several questions arise: 1 . How are students who read braille using paper braille and technology for literacy tasks in classrooms? 2. How did they learn these skills?

\subsection{RELEVANCE OF THE STUDY}

For more than 100 years braille literacy has been the key to independent reading and academic success for students who are blind. Over the years many changes in educational practices and tools have altered the way that braille instruction is delivered to students and the format in which students access educational materials. New technology has been developed making access to information by means other than braille available to students who are blind. For instance, assistive technology gives students who read braille access to the Internet, to electronic and digital audio books, and more expedient means to produce hard-copy braille, that is, braille embossed on paper.

While many of these devices have existed for over a decade, there is very little research into the practices of young adults between the ages of 16 and 22 years who are blind, such as how they generally access information, communicate with teachers and with friends both on paper and electronically, and produce classroom assignments. Are they primarily using paper braille or are they using electronic means, such as computers with speech access or portable braille devices, to read and write, and how do they choose which method they use? How do they participate in classroom activities that require the use 
of "new literacy" skills? This study seeks to fill these gaps in the research to get a better picture of the contemporary literacy practices of students who use braille so that teachers of students with visual impairments can be better prepared by university teacher education programs to meet their students' needs.

Federal legislation supports the use of assistive technology for all students with disabilities, but national studies (Kelly, 2008; Levine, Marder, \& Wagner, 2004) indicate that half of high school students with visual impairments are not being provided assistive technology services. It is unclear as to why these students do not receive these federally mandated services. There is little research regarding the implementation of federal regulations governing the provision of AT services and devices and instruction to students with visual impairments. The studies discussed in chapter 2 indicated that close to $10 \%$ of students learn to use technology skills outside of school. Where then are students learning AT skills and who is teaching them? There is also no information as to whether states are tracking the outcomes of these students, such as a possible relationship between students who have received instruction in the use of AT devices and success in post-high school settings, particularly in higher education and employment.

\subsection{SIGNIFICANCE OF THE PROBLEM}

For all of its acknowledged importance, there is little research on the ways that technology has changed literacy acquisition or the reading and writing practices of students who use braille (Ferrell, n.d.), and very little inquiry about how students are engaging in the new literacies, like social networking sites, wikis, document sharing, etc. Advances in assistive technology allow students greater access to texts, especially digital texts, and greater opportunities for electronic communication, but it is unknown 
precisely what effect these advances have had on students who use braille for reading and writing. There are no data that indicate the extent to which paper braille is used by young people who are blind, or if electronic and audio formats have become more prevalent. Studies exist that indicate students who are blind use AT for access to computers for various classroom tasks (Corn \& Wall, 2002; Farnsworth, 2008; Fellenius, 1999), but it is unclear for what purposes young people are using electronic devices as opposed to paper braille for completing classroom assignments, such as using textbooks, conducting research, writing papers, and creating presentations. It is also unclear how students are acquiring these skills and other $21^{\text {st }}$ century skills.

\subsection{RESEARCH QUESTIONS}

The following research questions were addressed in this study:

1. How do young adults (ages 16-22) who are braille readers use braille, audio, and electronic materials and tools for educational purposes?

2. How do young adults who are blind learn new literacy practices using assistive technology?

3. What are the attitudes of young adults towards hard-copy (paper) braille, and toward access technology?

\subsection{DEFINITION OF TERMS}

A number of terms need to be defined to more clearly describe the terminology used in this study.

1. Blind or blindness: considered to be a functional inability to see. 
2. Braille: a system for reading tactually by use of patterns of dots displayed in a six-dot cell.

3. Braille PDA (personal data assistant): a small portable electronic device with a refreshable braille display that is used like a portable computer for people who are blind; the device is often referred to as a "notetaker" or a "braille notetaker."

4. DAISY: stands for Digital Accessible Information System, and refers to an electronic file format that contains audio in human voice, and most or all of the text, and is easily navigable that is, easy to move through, by readers with print disabilities.

5. Legal blindness: a medical term that defines blindness as a visual impairment in which distance acuity is 20/200 or worse in the better eye after best correction, or a visual field restriction of 20 degrees or less.

6. Low vision: a visual impairment after correction but with the potential for use of available vision with modifications, devices, and strategies.

7. Refreshable braille display, dynamic braille display: a feature on a PDA or a small standalone device that connects to a personal computer in which a row of plastic pins move up and down to create braille words generated electronically from a word processing document, a web site, an electronic book, etc. that can be read by the user. After reading the single row of braille, the user pushes a button on the device for the next row of braille symbols to appear. 
8. Text to speech: computer software or hardware that converts the text on the monitor into spoken language. This software is often referred to as "screen reading software."

9. Visual impairment, visually impaired, visual disability: general terms all used to describe individuals who have any degree of vision loss that affects the ability to perform the tasks of daily life. 


\subsection{REVIEW OF LITERATURE}

\subsection{THE “BRAVE NEW WORLD” OF TECHNOLOGY IN SCHOOLS}

Reading instruction over the ages has changed greatly. For centuries there was no expectation that everyone would become literate; the ability to read and write was primarily the privilege of the wealthy. Changes in society with increased industrialization in the late $1800 \mathrm{~s}$ and into the $20^{\text {th }}$ century created the need to make more people achieve at least a basic literacy level. Around the time of World War I, the military discovered that many soldiers could not read well enough to follow directions. This caused vigorous discussion and debate in education circles about how to improve reading instruction (Smith, 2002). This was also the time of growth in educational psychology and the first scientific studies of reading.

An examination of reading instructional practices in the $20^{\text {th }}$ century reveals changing expectations for what it means to be literate as social structures moved from local and rural to more global and urban settings. The second half of the $20^{\text {th }}$ century was a time of great technological advancement and changes in societal expectations for schooling. When the satellite Sputnik was launched in 1957 by Russia, there was enormous concern about the overall state of American education and whether the United States would fall behind other nations economically and intellectually. This led to a number of programs being initiated by the federal government to improve American education. Instructional methods for reading in 
particular were criticized, resulting in a critical examination of instructional methodologies and new efforts for educational research in reading (Smith, 2002).

In addition to shifting societal needs and increasing pressures of a global society, the traditional tools for reading instruction expanded greatly at the end of the $20^{\text {th }}$ century. The typical paper-based tools of textbooks and workbooks have given way to electronic devices such as smart boards, CDROMs, multimedia educational materials, and computers with access to the Internet and its array of resources, such as online encyclopedias, video demonstrations, and search features (Presley \& D’Andrea, 2009). In light of the increased use of new tools and new tasks, definitions of literacy have changed and expanded. The simple dictionary definition of literacy is "the ability to read and write" (Merriam-Webster, 2003). Current definitions incorporate broader views of literacy, including social significance and use of texts from various sources, including electronic media. The PIRLS [Progress in International Literacy Study] (Mullis, Kennedy, Martin, Sainsbury, 2006), for example, defines literacy as follows:

For PIRLS, reading literacy is defined as the ability to understand and use those written language forms required by society and/or valued by the individual. Young readers can construct meaning from a variety of texts. They read to learn, to participate in communities of readers in school and everyday life, and for enjoyment. (p. 3)

In most schools in the United States, the technology tools mentioned above are widely available and there is now an expectation that students will finish school adept in their use. These skills are referred to variously as new literacies, multiple or multiliteracies or as $21^{\text {st }}$ century skills (Anstey \& Bull, 2006; Karchmer, Mallette, Kara-Soteriou, Leu,., 2005; Taffe \& Gwinn, 2007). The National Council of Teachers of English (NCTE, 2008) has adopted a position statement related to $21^{\text {st }}$ Century Literacies that includes the following: 
Twenty-first century readers and writers need to

- develop proficiency with the tools of technology;

- build relationships with others to pose and solve problems collaboratively and cross-culturally;

- design and share information for global communities to meet a variety of purposes;

- manage, analyze and synthesize multiple streams of simultaneous information;

- create, critique, analyze, and evaluate multi-media texts; and

- attend to the ethical responsibilities required by these complex environments. ( $₫$ 2)

The International Society for Technology in Education has developed the National Educational Technology Standards for Students (NETS) (ISTE, 2007), which outlines critical skills that students should develop to be prepared for the future. These standards describe "What students should know and be able to do to learn effectively and live productively in an increasingly digital world,” (p. 1) which includes skills and dispositions such as: (a) creativity and innovation, (b) communication and collaboration, (c) research and information fluency, (d) critical thinking, problem solving, and decision making; (e) digital citizenship, and (f) technology operations and concepts (ISTE, 2007). Further illustrating the increased value that technology skills play in school, the National Assessment of Educational Progress (NAEP), often referred to as “the nation's report card," is adding a test for technological literacy as a special study in 2012 (MacMillan, 2008).

Schools have been under increasing pressure from businesses to prepare technology-literate students who are ready for the work force. The U.S. Department of Labor projects that by 2012, 10.5\% of total employment will be high tech jobs (Hecker, 2005). However, even low tech jobs often require 
the use of computers and other technology. As the U.S. Department of Labor stated in chapter 6 of their report futurework:

It is rare to find a job that does not require some knowledge of computers or computer-based systems . . . Most workers will need basic computer skills to enter their chosen occupations and additional specialized training in field-specific applications to advance. (p. 6)

Indeed, in 2003 55.5\% of U.S. workers used a computer at work (Bureau of Labor Statistics, 2005). The trend for the past 20 years has been an increasing use of technology on the job.

The use of digital tools like the Internet means more information is available and is easier to get than ever before. The plethora of conveniently obtained material is a boon, but students need to develop skills to critically evaluate the vast quantities of information to find what is useful. These skills go beyond traditional reading comprehension. Studies indicate that students need instruction in the use of tools, such as search engines, to find and review material found on the Internet more efficiently (CIBER, 2008). The wide availability of technology in and of itself does not lead automatically to efficient use of it; schools have a leading role in instructing students to use new technologies wisely and critically (The Future of Children, 2000; CIBER, 2008).

Simply because educators have technology in their classrooms and acknowledge that students need to learn to use it does not ensure that teachers are actually changing instructional practices to include technology. In fact, numerous studies indicated that teachers are not incorporating technology into the reading curriculum (Leu, Hillinger, Loseby, Balcom, Dinkin, Eckels, Johnson, Mathews, Raegler, 1998; NEA, 2008; NCES, 2000; Rozema \& Webb, 2008; Wenglinsky, 2005). Students aged 12-17 reported using the Internet mostly from home; only 11\% reported using the Internet most often from school (U.S. Department of Education, n.d.). Many reasons are suggested for why this may be, such as lack of teacher training, both pre-service and in-service, lack of technical support, lack of educational software, lack of 
time during the school day, and a perceived lack of a match between available educational software and the curriculum (Leu et al., 1998; NEA, 2008). Another hypothesis is generational in nature: If youth today are digital natives, many teachers can be considered “digital immigrants” (Prensky, 2001), and as such, have varying abilities to quickly learn to use new technology devices. It is a common joke among teachers that if they do not know how to use the technology in their classrooms, they can ask one of their students to make it work correctly.

The consequences of inadequate technological preparation are potentially serious, however, based on the importance with which $21^{\text {st }}$ Century Skills are perceived by educational institutions, the business community, and state and federal leaders. The 2001 reauthorization of the Elementary and Secondary Education Act, referred to as No Child Left Behind (NCLB), included funding for states specifically for educational technology (SETDA, 2008). In addition, 45 states have established technology standards for teachers, although only half require some measure of competency in the use of technology for initial certification, and only nine require teachers to demonstrate competency for recertification (Bausell \& Klemick, 2007).

\subsection{STUDENTS WITH DISABILITIES AND THE USE OF TECHNOLOGY}

Students with disabilities have also been the beneficiaries of technological innovation. The advent of assistive technology in the past two decades has allowed children with disabilities greater opportunities to communicate, travel, and function with more independence than ever before. Assistive technology (AT) can be defined as "any item, piece of equipment, or product system that is used to increase, maintain, or improve functional capabilities of individuals with disabilities” (Wepner \& Bowes, 2004, p 219). While some people may assume that assistive technology only refers to complex high-tech 
electronic systems, in fact, many useful AT solutions are decidedly low tech. Assistive technology can be as simple as a rubber grip that makes it easier for students with mild cerebral palsy to use a pencil, or a book stand that holds a textbook at a comfortable position so a student with a visual impairment does not have to bend over the desk to read. The range of what is considered AT goes from these simple devices all the way to advanced computer systems with screen reading and voice recognition software for students who have difficulty both seeing the screen and using the keyboard.

The use of AT is recognized as essential to special education. The Individuals with Disabilities Education Act (IDEA) as reauthorized in 1997 and again in 2004 as the Individuals with Disabilities Education Improvement Act, or IDEIA, includes strong provisions requiring school systems to assess students for use of AT devices and provide them if deemed educationally necessary. The language in the Act is unequivocal:

Assistive technology device: Assistive technology device means any item, piece of equipment, or product system, whether acquired commercially off the shelf, modified, or customized, that is used to increase, maintain, or improve the functional capabilities of a child with a disability. The term does not include a medical device that is surgically implanted, or the replacement of such device. (§300.5)

Assistive technology service: Assistive technology service means any service that directly assists a child with a disability in the selection, acquisition, or use of an assistive technology device. (§300.6) The term includes:

(a) the evaluation of the needs of a child with a disability, including a functional evaluation of the child in the child's customary environment;

(b) purchasing, leasing, or otherwise providing for the acquisition of assistive technology devices by children with disabilities; 
(c) selecting, designing, fitting, customizing, adapting, applying, maintaining, repairing, or replacing assistive technology devices;

(d) coordinating and using other therapies, interventions, or services with assistive technology devices, such as those associated with existing education and rehabilitation plans and programs;

(e) training or technical assistance for a child with a disability or, if appropriate, that child's family; and

(f) training or technical assistance for professionals (including individuals providing education or rehabilitation services), employers, or other individuals who provide services to, employ, or are otherwise substantially involved in the major life functions of that child. (OSERS, 2006)

It is obvious that strong federal support exists for the provision of assistive technology for students with disabilities. There is recognition that technology tools are useful to many students with intellectual, behavioral, and physical disabilities. One area in which technology has been particularly helpful is in adapting materials and providing access to literacy activities. A literature review by Strangman and Dalton (2005) found a wide variety of accessible software programs and assistive technology solutions designed for struggling readers that focus on the essential elements of reading instruction: (a) phonemic awareness, (b) phonics/word recognition, (c) vocabulary, (d) fluency, and (e) comprehension, although studies investigating the effects of this software have mixed results. Other studies have looked at specific types of AT, such as text to speech and supported hyperlinks-again with mixed results. Strangman and Dalton (2005) caution practitioners from assuming that any one type of AT device or software solution will work with all students who have a disability; instead, they advocate an approach of “universal design for learning” (p. 561) to meet the needs of individual students. 
In fact, much of the general educational software and other technology devices available in schools are not accessible for students who are visually impaired. While text-to-speech is incorporated into some software, especially for younger students, the menus and settings do not provide audio output, so students who cannot see the screen are unable to use the programs independently. A “one-size-fitsall” response to providing assistive technology is not appropriate for students with visual impairments. The next section will look specifically into the issues of literacy and technology for students who are blind or visually impaired.

\subsection{READING AND WRITING FOR STUDENTS WHO ARE BLIND}

Students who are blind or visually impaired are a heterogeneous group comprising a variety of etiologies, levels of visual and physical functioning, and needs. Generally speaking, the term visual impairments is used to describe any child with a functional disability in vision; other terms include low vision and visual disability. The term blindness generally refers to students who have no or very little use of vision for functional tasks. In this paper, the terms are used more or less interchangeably, as both students who are blind or visually impaired may use braille, depending on their visual functioning.

Visual impairment is considered a low-incidence disability in children, comprising less than $1 \%$ of students who receive special education services (U.S. Department of Education, 2003). It is difficult to ascertain the exact number of students who are visually impaired or blind in part because the federal child count vastly undercounts students with visual impairments. The states only report students receiving special education services by primary disability and many students who are visually impaired have additional disabilities (Mason \& Davidson, 2000). Thus, students who have severe cognitive disabilities and a visual impairment may only be reported as receiving services for their developmental 
delay and not for services related to their visual disability. In addition to the federal child count, the American Printing House for the Blind (APH) does an annual registration of students who are legally blind served in programs up through $12^{\text {th }}$ grade level across the United States. The APH statistics, which only include the students with more severe visual impairments, are higher than the federal child count, which supposedly includes all students with visual impairments, not just legal blindness.

APH includes an additional component to their annual registration: the number of students who use various media for reading. The categories listed are visual readers, braille readers, auditory readers, prereaders, and nonreaders (APH, 2007). In this way, APH reports the numbers and percentages of students who read braille as their primary medium. In Fiscal Year 2007, the latest for which data are available, the largest category was nonreaders (34\%) while the second largest category was pre-readers (24\%); braille readers were listed as $10 \%$ of the total registered students. However, if the numbers of prereaders and nonreaders are removed from the count of the legally blind students who use print, braille, or audio in K-12 programs, $26 \%$ used braille as their primary medium. In 2007, that was 5,626 students in the United States. APH has also started collecting information on students who use braille as a secondary medium; those data have not yet been published.

People are often surprised to discover not only the small number of students who read braille, but also that the current braille code in the United States is a relatively recent invention. Although Louis Braille, inventor of the code that bears his name, lived in the early 1800s, the braille code as it is used today evolved as a system almost entirely during the 20th century (D’Andrea, 2009). The literary braille code is still evolving as a method of representing printed material, with additional codes, such as the computer braille code, having been added very recently. But in general, for more than a century people who are blind have depended on braille for reading and writing. 
Over the years, many changes in educational practices and tools have altered the way that braille instruction is delivered to students. From the early 1800s through the 1950s, most students with visual impairments or blindness were taught in specialized schools for the blind. Trained and experienced teachers of braille reading and writing were on staff and students had multiple opportunities to learn and use braille throughout the day and receive feedback from adults well versed in the braille code. While some students with visual impairments were also enrolled in their local public schools, the passage in 1975 of P.L.94-142, the Education of All Handicapped Children Act, precipitated the enrollment of the majority of children in their neighborhood schools (Hatlen, 2000). Depending on the data source, it is estimated that between 73\%-96\% of students with visual impairments are now taught in public schools (McMahon, 1998; Mason \& Davidson, 2000).

With the influx of children with visual impairments being served in their neighborhood schools, changes in service delivery occurred. While some children received instruction in separate settings, such as resource rooms, most were served in the general education classroom by an itinerant teacher of students with visual impairments (Spungin \& Taylor, 1986). This alteration in service delivery has often meant less intense instruction in braille reading and writing from an expert braille teacher (Hatlen, 2000). Since the itinerant teacher generally is not able to be at one school all day, reinforcing braille skills all too often is left to someone else, such as the classroom teacher or a paraprofessional, neither of whom could be counted on to be proficient in the code nor knowledgeable about teaching reading and writing through braille. Children were not always able to get timely or accurate feedback on their reading and writing efforts. In some extreme cases, due to a shortage of TVIs and large caseloads of others, paraprofessionals provided instruction despite their lack of training and certification (Forster \& Holbrook, 2005). 
Some people maintain that changes in services are partially responsible for the relatively small number of students who use braille and that more students would use it if instruction was readily available (Spungin \& D’Andrea, 2000). Because of the concern about braille literacy, parents and advocacy groups led the effort to add language to IDEA in 1997 that reinforces the important role that braille plays in the education of students with visual impairments. Specifically, the Individualized Education Plan (IEP )team must consider:

the provision of instruction in braille and the use of braille for a child who is blind or visually impaired, unless the IEP team determines, following evaluation of the child's reading and writing skills, needs, and appropriate media (including future needs for instruction in braille or the use of braille), that such instruction is not appropriate. (34 CFR $§ 300.346$ (a)(2)(v) as quoted in Reed and Bowser, 2005, p. 67)

While this language has been part of IDEA for more than 10 years, there has been no documented increase in the percentage of students on the APH annual registration who use braille as their primary reading medium.

At the same time these changes in service delivery were occurring, new technology emerged making access to information by means other than braille available to students who are blind. Not only did alterations in service delivery and in the braille code itself change how children learned braille but also advances in technology changed both the instructional methods used and the format in which educational materials were now available. In addition to braille texts on paper, also referred to as hard copy braille, students could now use technology that allows greater access to digital texts and for electronic communication. Technology such as audio recordings and digital text offered additional options for access to printed materials. For example, if students were assigned a novel to read for English class, they now had a choice: students could request it from the Library of Congress' National 
Library Service for the Blind and Physically Handicapped (NLS) in paper braille and wait for it to arrive in the mail, or they could download it from NLS' WebBraille service and have it instantly. The electronic file could be stored on a portable device that has a dynamic braille display, also called refreshable braille display, in which a row of plastic pins move up and down to create braille words one line at a time. So students could read the book on the braille display while listening to it as well.

Assistive technology exists that gives students who are blind access to the Internet, to electronic and digital audio books, and even far-easier means to produce hard-copy braille. The use of assistive technology holds great promise for greater access to printed information formerly difficult or timeconsuming to acquire.

These developments are significant because the provision of braille textbooks has been problematic for many years. Students who use braille often do not receive their educational materials at the beginning of the school year, at times waiting months for braille textbooks to arrive (Wall Emerson, Corn, \& Siller, 2006). Unlike print, many braille textbooks are not readily available from multiple sources and may not be available from any source, particularly if they are new editions. If books are not already in braille, certified braille transcribers must create these books and materials, a process that takes time and can cost a significant amount of money depending on the complexity of the book; for example, a high school math book can take months to produce and cost thousands of dollars. Even though the use of available technology, such as braille translation software and electronic braille embossers, have made creating braille books more efficient, preparation of the electronic book file, proofreading, and other production requirements can cause a serious delay in getting the book into the hands of the student who needs it. The fact that students now have other options to receive educational materials in a format they can use is a significant breakthrough. 
It should be noted that electronic books have their limitations as well; significantly, they often do not include charts, tables, graphs, illustrations or their captions, or other information outside the text of the textbook chapter. These features are generally included in paper copies of braille textbooks provided as tactile graphics or as written descriptions prepared by a certified braille transcriber.

One additional factor that has enhanced the ability to provide books in usable formats is the National Instructional Materials Accessibility Standard (NIMAS), a provision in IDEIA, NIMAS, in brief, is a specific standard that textbook publishers must use to create their electronic files so they can easily be converted into print, braille, audio, and other formats (OSEP, n.d.). A central repository of these electronic files has been established at APH, but at the time of this writing, the system is too new to have reliable data as to its efficiency in delivering braille texts to students throughout the United States.

The use of assistive technology by people who are visually impaired or blind has broader implications beyond the classroom. If indeed one goal of schooling is for students to acquire $21^{\text {st }}$ century skills that will enable them to find good jobs and compete in a global market, students with disabilities need the same skills plus the assistive technology skills that enable them to access information and work efficiently. Students with visual impairments are no exception. Several studies indicate that use of technology is related to competitive employment for adults who are blind and that lack of technology skills can be a barrier to employment (Butler, Crudden, Sansing, \& LeJeune, 2002; Fields, 2004).

Yet, a recent analysis of data drawn from the Special Education Elementary Longitudinal Study (SEELS) indicated that the vast majority of students with visual impairments in elementary and middle schools were not using assistive technology (Kelly, 2008). In fact, only between $12 \%$ and $18 \%$ of visually impaired students reportedly used assistive technology and the percentage dropped over the three years of data collection. 
While the picture improves for secondary students, the National Longitudinal Transition Study (NLTS2) indicated that only 57\% of high school students with visual impairments received assistive technology services from any source; fewer than half (48.9\%) received those services in their schools (Levine, Marder, \& Wagner, 2004).

The NLTS2 also compared post-school outcomes of students with various types of disabilities. Students who were visually impaired were $21 \%$ less likely to be employed than students with learning disabilities. While other factors have been identified as roadblocks to employment, such as employer attitudes, lack of transportation, lack of opportunity for job skills training, the rapid pace of technology change (Butler, et al., 2002), the question can be raised: could the demonstrated lack of assistive technology instruction among high school graduates also play a part in the underemployment of students who are blind? And a related question: Would post-school employment rates for students who are blind be higher if they had better technology instruction while in school? 


\subsection{METHOD AND ANALYSIS}

\subsection{INTRODUCTION AND RATIONALE}

This mixed-methods investigation was conducted in two phases. Mixed methods was chosen as the appropriate methodology for this study as it would best answer the specific research questions related both to practices (i.e., what do students actually do) and preferences (i.e., how do they feel about those practices). A mixed-methods approach linking qualitative and quantitative data can clarify and deepen the information gained in both phases of the study (Miles \& Huberman, 1994). In this study, qualitative information was first gathered from students who use both braille and technology, and then this information was tested quantitatively by a larger number of students. This also allowed for triangulation of the data gathered in the first phase (Gray, 2004).

Since so little is known about student practices and preferences, it was logical to start with student interviews and to use them as the basis for the survey. Therefore, in the first phase, the researcher conducted in-depth interviews regarding students' classroom literacy practices. The analysis of the interviews was qualitative and interpretive in nature; information was gathered to understand phenomena and build theory while also reporting general themes that emerged from the students.

In the second phase, a survey instrument with questions designed to investigate how widespread these practices and beliefs were among a larger number of students who use braille and technology was developed based on these themes. 


\subsection{PHASE I: QUALITATIVE}

This phase of the project investigated how advances in technology have influenced literacy practices for young adults who are blind and who use braille and assistive technology by use of elaborated case studies (Rubin \& Rubin, 2005) through focused interviews. This method is particularly useful for topics where little is known about specific practices. Therefore this portion of the study was explanatory and descriptive in nature (Bogdan \& Biklen, 2007; Marshall \& Rossman, 1995). The interview protocol was thus designed to investigate specific issues but to be open-ended enough that new areas of investigation could be explored. The use of such semi-structured interviews is useful in cases where the researcher knows enough about the subject to develop questions but not enough to foresee the responses (Morse \& Richards, 2002).

The questions in the interview protocol were informed by the researcher's experiences in teaching youth who are blind, but also by participation in an Open Forum sponsored by the Braille Authority of North America (BANA) in November of 2008 in the Boston area. BANA is an international non-profit organization that is responsible for setting the rules for the braille codes used in the United States and Canada. (New Zealand is an associate member.) BANA hosts an Open Forum at each of their semiannual meetings as a way for people interested in braille reading and writing, whether as braille readers, teachers, or transcribers, to meet the BANA board, and so people can hear about ongoing BANA projects and give feedback. The researcher is a board member of BANA and is chair of the committee

that plans the Open Forums. This particular Open Forum was attended by a number of braille-reading youth who lived in the area. Many of their questions and comments about their use of braille textbooks and technology made it quite clear that this was an area of rapid change; major shifts were occurring in schools regarding both the materials and activities in which students who are blind were attending. The 
students' comments also provided some thoughtful starting points for developing interview questions, as well as the general research questions, for this study.

As there is little documented knowledge about the practices of young adults who are braille readers and use assistive technology, the interview methodology described above was quite useful for gaining insights into the current classroom literacy practices of youth who are blind. The emerging themes and patterns, it was hoped, would give a deeper understanding of current activities and methods used by youth who are blind, the consumers and users of technology, that have not been documented before. By talking to the students rather than to their parents or teachers, a more direct and richer interchange occurred, and personal preferences and attitudes could be described more fully.

The interviews centered around how paper and electronic braille were used by these young adults, ages 16-22, and for what purposes, as well as how assistive technology was used by these same students and for what purposes. The students were asked to describe the devices they used and the contexts in which they used them, as well as their preferences for using braille and their assistive technology devices. In addition, the interviewer asked how these young adults learned these skills and from whom. The interviews investigated behaviors and practices taking place in naturally occurring everyday situations at school and home, but with the greatest emphasis on classroom learning practices, as opposed to social practices such as online chatting or instant messaging. Questions also probed students' experiences not only with traditional media, like books, but also with multiliteracies in the classroom, such as participation in shared document writing, preparing multimedia presentations, blogs, and so forth. While these questions only scratched the surface of what is contained in the broad topic of new literacies they were a starting place for gathering information as to how widespread these practices are in the classrooms the interviewees attend. 
Finally, the students were asked to give their advice to students their ages about braille and technology, as well as what advice they would give to people who are now studying to become teachers of students with visual impairments. These two advice questions served as summary statements for the interviews, as students could synopsize their own experiences of learning braille and technology to share with others. The interview protocol is attached to this document as Appendix E.

Since this study used an elaborated case study design, where each person interviewed was considered as a separate case and not compared to a norm or standard, a large sample size is generally not needed, as was the case in this study. However, to get a variety of opinions, a sufficient number of interviews were conducted until no new information was gleaned. With grounded theory it is difficult to predict how many interviews will be necessary, but the researcher expected at least eight and perhaps up to 12 students would be adequate for the purposes of this study. As Rubin and Rubin (2005) point out, “A grounded-theory study is complete when new cases produce no change in the themes or hypotheses” (p. 241). As it turned out, 12 students were interviewed.

These 12 high school and college undergraduate students who used braille and assistive technology were asked specifically about their preferences, practices, and experiences with braille and technology. (See section below on participant selection for details about recruitment of participants.) The interviews were originally planned to be conducted in the students' homes, at their college, or in community programs for blind high school students during their after school or weekend programs, as the researcher's preference was to conduct them in person. However, due to the low incidence of students with visual impairments, particularly those who are braille readers and technology users, eligible students who volunteered to participate in this phase were spread over a wide geographic area across the United States and not concentrated in particular areas. It was not feasible, nor desirable, to locate sufficient interviewees only in the local area, nor was it practical to travel to other states to conduct all of 
the interviews. Therefore, in the interest of time and efficiency, telephone interviews were conducted. (See Selection of Participants below and see Chapter 4 for results of Phase I.)

During the interviews, the researcher took notes, and the constant comparative method was used to monitor whether novel responses were being given or if students were giving similar responses to specific questions. Digital recordings of each interview were transcribed and annotated following each of the interviews. The final data record was analyzed through a systematic, inductive process of coding following a grounded theory approach (Bogdan \& Biklen, 2007; Willis, 2007). This process began with open coding with the entire data set being read several times. The intention of this open coding was to explore as many themes and ideas that emerge from the data. Following this coding, a set of broad themes were established and more focused coding occurred. Patterns were examined and sub-themes and topics coded and identified. Grounded theory starts with no preconceived notions; the purpose is one of discovery. As additional interviews were recorded, coded, and analyzed, comparisons were made between the patterns and themes that emerged from successive interviews (Mertens, 1998; Rubin \& Rubin, 2005).

As is typical for interview research, a great deal of data were gathered (Rubin \& Rubin 2005; Miles \& Huberman, 2002). In addition to coding for emerging themes and looking for patterns, responses to specific interview questions were also compared and put into four tables: (a) braille practices, (b) braille preferences, (c) technology practices, and (d) technology preferences. The tables provided an important snapshot of responses to specific questions and enabled the researcher to quickly compare answers to questions that could be probed in subsequent interviews. For example, while a specific question about braille mathematics was not included on the protocol, it was a theme that kept emerging on its own during the first few interviews as indicated on the chart of responses, so it was added as a probe question in subsequent interviews in case a student didn't mention it without a prompt. The tables were also 
useful in designing the survey, as it was obvious which categories of responses were widely varied, which were most frequent, and which were unusual or interesting. The results will be discussed in detail in Chapter 4.

\subsection{PHASE II: QUANTITATIVE:}

\subsubsection{Survey Development}

Themes identified from the interviews helped build understanding of the attitudes toward braille and electronic means for access to print, as well as painted a picture of current classroom practices. Once these themes were identified, a survey was designed with questions based on the themes and their associated practices and attitudes identified in the interviews. The survey, therefore, was not created until after the interviews were completed.

A large amount of data were collected and coded in the interviews, so it was necessary to be selective in designing a survey for students to complete that would not be too time consuming yet would still yield meaningful results (Fowler, 1995).

As stated above, the charts that had been compiled of interview responses were valuable in the process of designing the survey. By perusing the charts for patterns of responses, both typical and surprising answers could be identified. These responses could then be considered for transformation into survey items. In some cases, responses were so paradigmatic that further exploration through the survey would not glean any new knowledge. For example, when asked about the disadvantages of paper braille, every student remarked upon the size and bulk of braille textbooks. This is a well-known characteristic of braille books and no new information was likely to be received through a survey that asked about this 
issue, so it was not included as a survey item. On the other hand, half of the students interviewed reported learning to use braille at a technology center outside of the school setting, such as a rehabilitation center for blind adults, or a special summer program at a technology center. This was new information that had not yet been documented and was worthy of further exploration through the survey. Similarly, every student reported being taught braille by a TVI, but only a few noted that a TVI was the primary instructor of technology; therefore, the survey asked about the TVI 's role in AT instruction but not in braille literacy instruction.

Consideration was also given to items that could best be asked in a survey format with a Likert scale as opposed to other means. For example, the interviews asked students to describe how they prepare papers to hand in to teachers and professors who don't use braille and how they learned to correctly format word processing documents, such as adding headings, styles, etc. The responses to these questions were generally quite lengthy and detailed and would not lend themselves easily to conversion to a single survey question or even a series of survey questions. While the responses were interesting and deserve further exploration, other research methods should be devised to examine these issues further. In fact, many of the interview questions about writing in braille and in print garnered complex responses, so reluctantly, no questions related to writing were added to the survey other than the use of the slate and stylus as a writing tool. (See Chapter 6 for further discussion of this issue). Questions about the slate and stylus were added as a special case because the responses to questions about its use were so surprising to this researcher. Chapter 4 will provide an in-depth analysis of the interview responses.

\subsubsection{The Survey Design}

The survey had three distinct sections. The first section included some background questions, such as basic demographic information as the students' age, and the names of the school they currently attended 
and their level (e.g., high school junior, college sophomore, etc.). Each student was also asked if he or she had attended a school for the blind, and if so, for how long? Students were presented with two multiple choice questions asking how long they had read braille, and their primary reading method during a typical week. Therefore question 8 asked:

I learned to read braille (choose one answer):

a. From early childhood or preschool (I have always read braille);

b. In elementary school (I started with print but switched to braille in school);

c. In middle school (I started with print but switched to braille in school);

d. Along with print throughout school but now I primarily use braille;

e. Other (please explain).

Question 9 asked: "In a typical week I primarily read:
a. braille on paper;
b. braille electronically (with refreshable braille);
c. auditorily (whether on computer, CD, tapes, etc.);
d. print;
e. Other (please explain)."

These questions were asked in a multiple choice format to simplify coding, however past experience with questions of this sort led the researcher to add a text box for other for participants to more fully explain their choices if necessary. Lastly, students were asked a set of questions about their use of technology. They were asked to list all of the technology they used, including mainstream devices, then to list which one or two they used most often. The final question of this section asked students to write how old they were when they first started using technology to complete school work. These last few 
questions were designed as open-ended text boxes rather than pick lists due to accessibility issues and to allow the students to add any comments they wished to share.

Following this set of basic descriptive and demographic questions was an instructions page that gave an overview and directions for completing the next two sets of questions. The survey questions used Likert-scale responses so the students could rate their agreement to various statements. For the set of statements related to practices, students chose one of the following rankings:
a. This is very much like me.
b. This is sort of like me.
c. This is neither like me nor unlike me.
d. This is somewhat unlike me.
e. This is very unlike me.

Other survey questions related to opinions or preferences, in which case the scale was as follows:
a. I strongly agree.
b. I sort of agree.
c. I do not agree or disagree.
d. I sort of disagree.
e. I strongly disagree.

To preserve the students' voices and to illustrate the varieties of opinions about the general topics of practices and preferences for using braille and technology for class work, representative quotes from the interviews were selected to serve as survey item prompts. In most cases, a matched pair of statements was presented, each an authentic statement from a student interview but presenting opposing viewpoints. For example, one statement included was, "Any of my math books are going to be paper braille." It was followed by a statement which read, "I find it easier to use my computer and listen to math." These were 
added to show the range of viewpoints among students, but also as a way of checking internally whether the students saw the statements as opposed and would rank them as such.

After the directions page, a second set of questions was presented which focused on general practices for reading and completing schoolwork with braille or with technology, study and work habits, how they learned to use technology, and what tasks they perform. In this set, specific questions were added about the types of tools they used for reading (e.g., paper braille, electronic braille devices, computers with speech), specific questions about the slate and stylus, who taught them to use technology, and multiliteracy practices, specifically the use of PowerPoint for presentations, blogs, and email. These questions were based on the themes identified in the interviews (see Chapter 4 for details).

The third set of questions focused on the students' opinions and preferences for getting their work done and the tools they used, as well as their feelings about accessibility, and the role of TVIs in teaching technology. These questions were based on interview comments that were positive and negative about braille, positive and negative about the use of AT, the ease with which they found certain tools to use for specific tasks and access to information, and what TVIs should know about technology.

\subsubsection{The Pilot}

The survey was piloted for both content and accessibility. The researcher's previous experience with the Survey Monkey site in designing surveys to be completed by blind users led to the survey design relying primarily on open-ended questions and multiple choice radio buttons where only one choice could be selected. Past experience with this specific site has indicated that other question styles are not as easy to use with speech access software. Two blind adults experienced in the use of both braille and technology reviewed the survey online and were asked to comment as to how clear the questions were, that is, 
whether they understood what was being asked, and whether the question wording matched the Likert scale. They were also asked how user friendly the site was for users of assistive technology, and how generally accessible the question types were. Two of the college students who had participated in the interviews also reviewed the online site and gave comments about its accessibility and the amount of time they needed to complete the survey. Other reviewers who piloted the survey included a college professor skilled in the use of surveys, and two doctoral students who were unfamiliar with the subject area but who could provide a perspective on how clearly the given responses on the Likert scale fit the specific questions, and whether the meaning of the questions was clear, that is, if it was clear what was being asked.

As a result of the pilot, several changes were made to the survey to clarify specific items. More explanation as to the format of the instrument was also added so participants could better know what to expect as they moved through the survey. Additional items were incorporated into the pilot survey that could shed more light on particular practices and opinions. The final survey included 12 demographic questions, and then 28 questions related to practices and 28 questions related to preferences/opinions. The final survey is presented in Appendix F.

\subsubsection{Survey Dissemination}

The survey was disseminated in several ways. For students who were considered minors (16 or 17 year olds) the survey was available via first class mail in paper braille or as an electronic document in Microsoft Word that was emailed to the participants or their parents.

The braille survey was designed so as to preclude a bias against students who have lower proficiency in the use of technology, and was accompanied by an answer sheet for the Likert items and a stamped 
and addressed return envelope. Students had the choice of marking their responses on the answer sheet or on the survey itself. They could also type up their responses to both the open-ended questions and/or the Likert questions and return their survey answers in print or via email.

The Word version was designed so that students could type in short answer responses or place an $X$ before their choice on the Likert scale items; then the completed survey could be emailed back to the researcher. Students who were adult participants (18-22 years old) could request either the braille or Word version of the survey, but could also choose to complete the survey online on a commercial site (Survey Monkey ${ }^{\mathrm{TM}}$ ). In any format, students could also add comments or clarifications for any item; comments could be added in braille on a separate page or provided electronically depending on the students' preference.

Originally, the braille and Word versions of the survey were the only formats planned to be disseminated. It became clear, however, that a more streamlined approach would be needed to encourage as many students as possible to participate. Therefore the protocol was revised and approved by the university's IRB to add the option on offering the survey preceded by the consent form to eligible students who were 18-22 years old. Students in this age group could also take the survey in braille or as an electronic document. The students who were minors, 16 or 17 years old, were still required to do the consent form and survey either on paper in braille or print, or electronically.

The responses were coded numerically and entered into SPSS (Groves, Fowler, Couper, Lepkowski, Singer, \& Tourangeau, 2004). The results were analyzed descriptively with response frequencies and percentages reported. Additional analyses were conducted to investigate potential relationships between variables, and differences between certain groups. For example, certain questions were analyzed by school setting, that is, whether students attended their neighborhood high school or whether they attended a specialized school for the blind. Differences were also examined between the experiences of 
students who were still in high school and those who were in higher education. Chapter 5 presents the results of the survey data.

\subsection{RECRUITMENT AND SELECTION OF PARTICIPANTS}

Students between the ages of 16 and 22 who were enrolled in an academic school program, either high school or college, used braille as their primary medium, and who also used assistive technology were invited to participate in both phases of the study. Consent forms were available electronically so they could be emailed to anyone who asked for one; they were also available in braille and in print to be mailed to interested students, families, and teachers.

For the purposes of this study, assistive technology was defined as any type of hardware or software that allowed access to computers and electronic information, including screen reading software, a refreshable braille display attached to a computer, accessible PDAs with or without a refreshable braille display; for example, it could have a QWERTY keyboard and synthesized speech instead of a braille display, and other portable access devices currently used by people who are blind for reading and writing. Since there are many different types of these items and because one purpose of this study is to see the types of devices students use, selection criteria was not based on a required type of assistive technology device or how many different devices the students had. The students should have, however, considered braille as their primary reading medium, as opposed to print, and use at least one AT device to complete classroom reading and writing tasks. In addition, the students must have been in an academic instructional program participating in general classroom activities, functioning no more than one grade level below their same age peers, if in high school, or be enrolled in classes at a community college, college, or university, if graduated from high school. These criteria were put in place to force 
some homogeneity on a widely divergent population in a multiple case sample (Miles \& Huberman, 1994).

Because of the low incidence of students with visual impairments, a nonprobability sampling procedure was used. A convenience sample of students was recruited through teachers of students with visual impairments (TVIs) known to this researcher, and through existing electronic mailing lists for teachers and for blind consumers. The researcher is a member of several electronic mail lists through professional organizations, such as the Association for Education and Rehabilitation of the Blind and Visually Impaired (AER), as well as the Braille Research Consortium hosted by the National Federation of the Blind (NFB), a national consumer organization of blind people, including parents of children who are blind. NFB maintains national and state electronic mailing lists of students who are blind that sends messages to students who subscribe to the list. An announcement was disseminated through these channels about the study to ask for volunteers to participate, first in the interviews and then later in the survey. The recruitment flyer was also disseminated to the student electronic mailing list of the American Council of the Blind, another national consumer group. The flyer was published in electronic newsletters disseminated by the American Printing House for the Blind, a technology company called Flying Blind, the Braille Institute of America, the Carroll Center for the Blind, and the New York State Resource Center for the Visually Impaired as well as other state-wide email lists that went to TVIs in that state, such as the teacher email lists for the states of Georgia, North Carolina, Colorado, New York, Massachusetts, and possibly others of which the researcher is not aware. A message was also sent to rehabilitation centers in the state of Pennsylvania. Staff from at least seven specialized schools for the blind contacted the researcher for information about the study. To recruit students younger than 18 years old, the flyer sent to TVIs asked the teachers to pass along information about the study to the parents of 
eligible students, so that the parents could contact the researcher directly to acquire a consent form to give permission for their child to participate.

A database of students who were interested in participating was developed using FileMaker $\operatorname{Pro}^{\mathrm{TM}}$ which included fields such as assigned identification numbers, whether informed consent was yet received, and for students under 18, whether parental permission had been received, contact information, which was usually an email address or phone number for the student or parent or TVI, the student's age, and the student's location (usually their state). The database also served as an initial screening tool to ensure that the volunteer participants were braille readers, technology users, enrolled in school, and were between the ages of 16 and 22. The students were asked from the beginning if they wished to only participate in the interviews or the survey, and this was indicated in the database as well; if they wished to only participate in the survey, their preferred format, online, braille, or Word file, was noted. As the database was searchable, a script, which is an automatic series of commands, was developed so that eligible students would be easier to find. As the study progressed, scripts were also created to quickly identify which consent forms had not been returned, which surveys were still outstanding, and general notes about communication with students, parents, and teachers who contacted the researcher. This database was a valuable tool for the researcher to keep track of the process and progress of the study and its participants.

For the interviews in the first phase conducted during the fall of 2009, the researcher examined basic demographic information from responses entered into the database. From this pool, the researcher attempted to interview an equal number of males and females, as well as students evenly distributed between the ages of 16 and 22, and from a wide geographic spread, including urban, suburban, and rural areas from several different states. Students who were not interviewed were asked if they wished to participate in the survey, and when the survey was developed, those students were asked again for their 
willingness to volunteer to take it. Students were continually added to the database as they contacted the researcher throughout the study's time period; students who were added in the spring of 2010 were informed that the interviews had been completed but they could participate in the survey. In this way, the database of potential and actual participants was built over a period of seven months, from October 6, 2009 through April 19, 2010.

The survey was distributed to a larger group of students between the ages of 16 and 22 who use braille and assistive technology as a way of investigating how wide-spread the practices and preferences identified in the interviews were representative of students within the larger group. There are a total of 1,128 students who are braille readers in grades 10, 11, and 12 in the U.S. on the APH registration (APH, 2007). It is likely that a similar number of braille readers between the ages of 18 and 22 have graduated high school in the previous three or four years. Of students whose primary disability is visual impairments, approximately 78\% attend postsecondary school (Newman, Wagner, Cameto, Knockey, 2009), adding an estimated 880 students to the pool of potential survey takers $(1,128 \times .78)$. In round numbers, this means there are an estimated 2,000 braille readers between the ages of 16 and 22 who are enrolled in school. Newman et al. (2009) state that $45 \%$ of students with visual impairments who are out of high school report using the computer daily; if that applies specifically to students who use braille, the potential number of students who could be eligible, that is, a student between the ages of 16 and 22 who reads braille and uses technology, to participate in the survey could be approximately 900 . Due to the difficulty in reaching this geographically wide-spread, heterogeneous group, a return of 200 surveys, a return of $22 \%$ of the potential number of eligible participants, was deemed desirable. A larger number of returned surveys might have been possible, but deemed implausible; even attempting to attract 200 eligible students who might be interested in participating was an ambitious goal. So as an added 
incentive to attract participants, students were informed that if they returned the survey their names would be added to a raffle for an accessible MP3 player. 


\subsection{RESULTS}

Both phases of the study sought to answer the research questions:

1. How do young adults (ages 16-22) who are braille readers use braille, audio, and electronic materials and tools for educational purposes?

2. How do young adults who are blind learn new literacy practices using assistive technology?

3. What are the attitudes of young adults towards hard-copy (paper) braille, and toward access technology?

The interviews allowed for exploratory work while the survey examined selected themes to discover how widespread those practices and preferences might be. This chapter examines the results of the focused interviews, identifying the main themes and subthemes that emerged as a result of open coding, constant comparison of responses and a more refined coding of responses to specific questions.

\subsection{PHASE I: FOCUSED INTERVIEWS}

The interviews were conducted between November 20 and December 9, 2009. Because a large pool of participants had not yet been gathered to choose from, students were selected to participate in the interviews based on a convenience sample of students from whom consent forms had been received. Each student was interviewed using the same protocol. The interviews ranged from 39 minutes to 66 minutes long and were recorded both by a digital recorder and on the researcher's computer and 
transcripts were created for coding. One interview recording was lost by both the digital recorder and the computer program used to record it; fortunately, extensive notes had been taken during the interview so these data were not lost.

\subsubsection{Basic Descriptive Data of Participants}

In November 2009, from an existing pool of approximately 35 students (14 of whom came from the same specialized school for the blind), potential student interviewees were selected in an attempt to reflect as much diversity as possible as far as sex, age, location (state and whether urban, suburban, or

rural), and type of school (that is, whether they attended a specialized school for the blind or their neighborhood public school). The final list of 12 interviewees is presented here in Table 1. 
Table 1: Interview Participants

\begin{tabular}{ccccccc}
\hline ID\# & Sex & Age & State & Area & School & Type \\
\hline I-01 & M & 20 & NY & urban & college & public \\
I-02 & F & 19 & NY & urban & high school & specialized \\
I-03 & M & 18 & NY & rural & high school & public \\
I-04 & F & 19 & NY & rural & college & public \\
I-05 & F & 18 & IN & urban & high school & specialized \\
I-06 & M & 16 & IN & urban & high school & specialized \\
I-07 & M & 17 & MD & suburban & high school & public \\
I-08 & F & 19 & NC & suburban & college & public \\
I-09 & F & 20 & CA & rural & college & public \\
I-10 & M & 19 & WV & rural & college & public \\
I-11 & F & 17 & UT & suburban & high school & public \\
I-12 & M & 18 & PA & urban & high school & specialized \\
\hline
\end{tabular}

\subsubsection{Learning to Read and Write Braille}

All of the students reported that they had learned to read and write braille from a teacher of students with visual impairments (TVI). Eight of the students interviewed had learned braille from preschool or kindergarten; essentially, these students had always used braille, although one had used print as well for math. One student reported that while she had always used braille, her school district was not able to provide sufficient instruction, perhaps just once or twice a week, for her so she felt that she didn't really 
"learn" braille until 4th grade when she finally had a TVI who could provide her the intensity of instruction she needed daily to read and write on grade level. One student had lost vision suddenly in 3rd grade and had been a print reader up to that time; two other students had started with print but had had progressive vision loss so learned braille starting in upper elementary/early middle school grades. One student, a senior in high school, had started braille instruction at the age of 9 and considered herself a proficient but slow braille reader who primarily used speech access and enlarged print to do most of her school work, although she took class notes in braille as she could write braille faster than she could read it, and faster than she could write print. One student had always used paper braille with difficulty; it was discovered that radiation treatments he had received as a young child had damaged the nerve endings in his fingers, so he preferred to read on thermoform paper (a plastic substance that creates sharper dots) or with a refreshable braille display. The responses to this one question, "How long have you read braille?" illustrate the heterogeneity of this population of students, the wide variations of experiences among braille readers, and captures the complexities of defining a primary reading medium for many students.

The interview asked students to think back to what they remembered about learning to read braille, including any favorite books they might recall. The question was asked in this way as a prompt to assist students in thinking back a number of years and connecting with a positive emotional experience. Half of the students interviewed reported they loved books when they first learned to read and could remember favorite books they had read as a child. Many could remember the names of specific books and series they liked when they were in early elementary school. Example responses from those students include:

• "Yeah, I read a lot. . . . I was always reading something."

- "I entered into the Braille Readers are Leaders contest. . . . As a $4^{\text {th }}$ grade kid I read eleven hundred pages." 
- "I liked reading the Arthur books. I remember those as some of the first ones I always wanted to be brailled."

- " . . . we read books like 'Squanto.' We tried to get books that the rest of the curriculum was doing in school."

Most of these students had learned braille from early childhood, but one had started braille instruction in $3^{\text {rd }}$ grade.

Three of the students who had learned braille from the beginning of their schooling reported feeling reluctant to read braille, as evident in the following comments:

• "To be fair I didn't do a lot of reading until later on. As a kid, I didn't like braille. I didn't like to read because it was ... I thought it was slow and it was inefficient. And, you know, it, for all intents and purposes it takes a lot of time and a lot of work to perfect that, and when you're a kid you want to have fun."

- "I knew that it was going to take a long time for me to learn all the signs and contractions that come with braille and I still haven't learned them all and I've been reading since I was 6 years old and I still don't know them all sometimes!"

• "I didn't want to read braille. I wanted to read like everyone else."

Two of the students who learned braille after reading print reported great reluctance to learning braille as demonstrated by statements such as:

- "I was a little resistant to learn braille because I felt like, um, that I could still see and that I could still write ... so, I had a hard time with braille at first."

• "I wasn't very enthusiastic when I first came to school about learning braille. . . . I didn't see any reason to learn braille I mean, . . .because for most of my life after I went blind I used my ears. ... . So I didn't think I needed braille." 
On the other hand, a student who was first given braille instruction in $4^{\text {th }}$ grade but who did not make the switch from print to braille entirely until the year before the interview when she was in $10^{\text {th }}$ grade, was delighted to make the switch, even though she admitted that she found learning braille to be difficult: "I got sick and tired of headaches and I just wanted to switch over to braille where I didn't have as many headaches!"

Once again the comments about learning braille illustrate the variety of experiences for these 12 students, as well as revealing how varying their opinions of themselves as early readers were. Although half of the students reported that they enjoyed learning to read braille, for others the benefits of braille became more obvious later on. For example, one college participant said, "Now, I see the value of it. To me it was very tedious. And, uh, I understand why blind people don't like braille. Because I was the same way for a long time." For that student, discovering the Harry Potter books was an impetus to read braille books. Using this information from the interviews, the survey sought to explore further students' attitudes about learning to read in the "Preferences/Opinions" section by using the quotes "I wasn't very enthusiastic about learning braille" and "Braille is the foundation of a blind person's education" as stems to stimulate responses related to opinions about reading braille.

Almost all of the students had started to learn to write braille at the same time or soon after learning to read it. All but one started with the Perkins Brailler, a mechanical device first introduced in the 1950 s and still in wide use; one student who started braille instruction at age 12 started braille writing using a Braille n' Speak, a portable electronic device in which braille can be input through 6 keys, but which gives only audio output (i.e., it has no braille display). All the students but one reported learning to use the slate and stylus but only one student reported ever using it for functional tasks even while learning it. As far as braille writing, the only other devices that produce braille directly, that is, without the use of computer translation software, are the Jot-a-Dot, a mechanical device that is relatively 
new and not widely used in the United States, and the Mountbatten Brailler, an electronic device that combines braille on paper with speech; none of the students mentioned using either of those tools to write braille.

Four other students reported using the Braille 'n Speak at an early age when they started technology instruction. It's a relatively simple device and uses the same key pattern for input as that found on a Perkins Brailler. Five other students were introduced first to either the BrailleNote or the BrailleLite, portable notetakers that have a refreshable braille display as well as speech output. Other students had their introduction to assistive technology through a computer with screen reading software. Most of the students started technology instruction in elementary school and described using a progression of tools of greater complexity as they got older. For example, they may have started with paper braille books and a Perkins brailler, then were introduced to a portable braille device or a few selected features of this device, and then to a computer. One 16-year old student had not been taught to use any assistive technology until he started attending a specialized school for the blind the year before.

\subsubsection{Current Practices for Reading and Writing}

Several themes emerged from an analysis of the interviews conducted regarding the practices that students who are blind used in conducting school tasks. The themes fall in three categories:

1. the devices or tools they used for reading and writing;

2. the tasks they performed using specific devices and tools; and

3. the way they learned those practices.

Each of these categories will be examined in turn. 


\subsubsection{The devices and tools students used for reading and writing}

All of the students interviewed reported using a multiplicity of tools in the classroom to complete their work, including braille on paper. No student listed fewer than four devices; some listed up to eight tools they used to complete school work. A list of tools mentioned is found in Figure 1.

\begin{tabular}{|lll|}
\hline BrailleNote & BookPort & Cassette tape player \\
Braille Plus & OCR scanner & Books on tape \\
Computer with Jaws & Electronic braille embosser & Books on CD \\
Computer with WindowEyes & Brailliant 24 & Large Print \\
Computer with MAGIC & Cell phone with Mobile Speak & Talking Calculator \\
Victor Reader & Digital recorder & Electronic books from BookShare \\
Victor Wave & GPS system & RFB\&D and WebBraille \\
Victor Stream & Perkins brailler & Franklin Language Master/Talking \\
Victor Vibe & Braille label maker & Dictionarv \\
\hline
\end{tabular}

Figure 1: Tools used by students to complete school work

All 12 of the students reported using a computer with screen access software on it, and most students used some type of portable braille PDA. The tools most frequently mentioned were the BrailleNote, the brand name of a braille PDA ( $n=10)$ and JAWS screen reading software $(n=8)$. One revelation for this researcher was that several students commented that their mobile phone was a device they turned to for assistance with class work, citing features such as the calendar and notes found on many mobile phones. Most of the students reported using electronic books and specific devices designed to access those. Eight students stated they got their books from BookShare.org, and four students cited RFB\&D (Recordings for the Blind and Dyslexic) as the source for their books; two students disclosed using not only those two services 
but also Web Braille from the National Library Service for the Blind and Physically Handicapped (NLS).

There seemed to be a difference between high school and college students as far as some practices were concerned, and reading braille on paper is one example. All of the high school students in specialized schools who are primary braille readers $(n=4)$ reported having most of their textbooks in braille, although they also had some electronic books as well. (One student who was a dual braille-print reader had her books on cassette tapes.) The two high school students who were in their neighborhood schools used a combination of braille and electronic books, but reported they were moving away from hard copy braille to increase their use of electronic texts. However, all of the college students $(n=5)$ stated that they use very little paper braille now; most of their textbooks and other instructional materials are electronic. Some of the college students reported having paper braille for charts and tables if someone had produced it for them (most often the disability office on campus) or if they had made their own for the purposes of studying. Another area in which there seemed to be a difference between the age groups is in the use of an OCR (optical character recognition) scanner. Four of the five college students reported using a scanner with OCR while only one of the high school students did. These differences would be explored further in the survey.

Interestingly, while many students talked about the use of electronic texts for literature, history, social studies, and doing research on the Internet, the subjects in which the students overwhelmingly used braille materials, or wished to, was for mathematics, science, and foreign language. Even the college students who reported using little paper braille preferred, if at all possible, to have those subjects in braille. Two college students reported holding off from taking 
courses in foreign language or math until they could figure out how to get the books in braille. Comments from these students included the following:

• "My math books were always in braille. My Spanish book was always in braille too. And any diagrams, for, like, science classes those were always raised up and put into a raised format for me."

- "Any of my math books are going to be braille. Because you don't want to do math on the Victor, it would just be entirely--you don't want someone to read it to you. I'm one of those visual people who has to have something in front of me."

• "I still did a lot of my math on the braille writer."

- "I'm doing some pretty complicated stuff in math, so, um, so it would be interesting how that would happen [using the computer] . . . . I can't imagine it. It's hard enough to just do it in braille!"

- "Most of my classes except for math I like to read ... electronically just because it's easier."

- " .. . with science where you have all the diagrams it's really necessary to have braille for that."

- " I'm bad enough [in math] as it is <laughs> If I couldn't like read the tactiles and have it in the proper format in columns I think that would make it about 50 times more difficult."

- "If it's a really difficult assignment like Spanish you kind of have to know the words and really be able to interpret the words so that's something more, you know, I like to have the braille." 
- "It was definitely useful because Spanish braille is different. It was better to have it that way, in braille."

- "I really think foreign languages, I think people should fight for them to be in braille."

• "Whenever I do foreign languages then it's essential to have paper braille."

• "A computerized voice doing French is not very good!"

As can be expected for this heterogeneous group, there were exceptions to the preference for math in paper braille, as evidenced by these comments from two college students:

- "I find it easier to use my computer and listen to [math]. It sounds odd but I also use a reader for math."

- "When I took my college algebra class it really would have been nice to have that in braille uh, but for some reason with statistics I haven't really felt the need. I don't know maybe there's less graphs maybe in statistics, or they're more predictable like the bell curve and the different distributions. Definitely with college algebra it would have been nice. I had a reader and she was really good about tracing out the graphs for me and stuff. But that was definitely another situation where some of the numbers if you had really weird signs because the book had been scanned--it's really, really inconvenient."

Because of this difference of opinions and to gather more data about this practice, questions that asked specifically about braille use with foreign language and math or science materials were added to the survey.

It was also intriguing, although not unusual in this researcher's experience, to hear a student express the need for math in hard copy braille in visual terms: "I'm one of those visual people 
who has to have something in front of me." Other students used similar language; one student interviewed talked about the need for algebra to be in paper braille because it "is so visual," and yet another stated, "I think that math is a visual subject and . . . I don't think we're at a point where we can do math fully on the computer."

In fact, the language students used as they talked about their practices was notable in its complexity. For example, it became clear to this researcher almost too late in the interview process that when students said they "read braille" it did not necessarily mean "braille on paper" but could be braille on a refreshable display as well; when students said "read" they may be talking about reading braille (on paper or electronically) or using speech to access the text. "Books" could be both physical books and books they accessed electronically. The researcher learned to probe more carefully while interviewing the students to get a clearer picture of what practices were actually being used.

\subsubsection{Tasks performed by students using braille and technology}

In addition to the practices mentioned above, using braille and technology for reading textbooks and editing papers, students mentioned a number of other school tasks and complex practices for completing those. Those tasks included getting online to do research, and creating essays and written projects for class assignments. Students were also asked to describe their experiences with multiliteracy activities, such as creating presentations, participation in interactive writing tasks, such as Wikis, or using Google Docs, creating and using blogs for classroom tasks, and using the Internet. Several students mentioned communicating through email with instructors and submitting homework and class assignments via email, so this was also explored in the interviews and then later in the survey. 
Almost all of the students used the Internet for doing research for school tasks; only one student had not yet gone online as he had just started using the computer that year. This particular student had transferred from his neighborhood high school to a specialized school for the blind where he was receiving instruction in the use of AT for the first time. Prior to changing schools, he had only used the Perkins Brailler.

The students as a whole reported producing very little paper braille except for personal uses, such as labeling and studying. This was particularly true of the college students who reported creating little braille on paper. Three of the high school students still produced math in braille on the Perkins Brailler. Four students reported creating braille labels for personal items either with a braille labeler or with the Perkins. Three college students reported using an electronic embosser rather than the Perkins if they had to produce braille although they generally didn't have to do so. One college student still wrote letters to blind friends in braille and was a pen-pal to a younger braille-reading student. Another college student used braille notes when making speeches in class. Two college students used paper braille for editing papers that would eventually be turned into print for their instructors who don't read braille, as they felt it made any errors easier to find, but most students edited their work with a refreshable braille display. Not surprisingly, the students primarily produced print on paper for school tasks. Their writing practices tended to be complex.

The questions related to writing were primarily asked to explore how the students learned to create print documents since the majority of their teachers (other than their TVI) would not know how to read braille. So it was interesting to hear that two students still created braille documents on paper to proofread from. One student stated: 
If you actually braille out an essay or something it's a lot easier to edit when you can actually look at your spelling, your grammar, your punctuation and spacing and everything in braille, that is really helpful. That will really help you. And if you gave any sort of speech or notes or any kind of presentation that's also very, very helpful. And foreign language, any kind of foreign language in braille, it would have to be in grade 1 , just for easy editing and everything like that.

However, most students used their computers or devices with refreshable braille displays to write papers to turn in to their teachers. Whether they used the braille PDA or the computer seemed to depend on their personal preference, level of expertise with the device, and how much formatting the paper needed. For example, a high school student who is relatively new to the use of technology explained how he did his writing assignments, comparing his braille PDA to writing on the Perkins Brailler:

I do it on my BrailleNote ... I put it on a memory stick and [my teachers] print it off. You don't have to worry about, you know, going down any lines, you don't have to worry about getting a new piece of paper $\ldots$. you can get it done faster. It'll take less time. [And it's] a lot easier to fix. Won't have any eraser marks or anything.

The high school students tended to be less concerned or perhaps less aware of how their papers looked as far as specific formatting, such as headings, and special styles that are available in word processing software. Another high school student who used her braille PDA to create papers described turning in papers to sighted teachers more in terms of the technical aspects of 
producing the paper as evidenced by this exchange between the researcher (identified as "R") and a student ("S"):

R14: OK. So you said that for the BrailleNote you take notes with it and you also write your papers?

S14: Yeah. If I don't feel like using a computer I will just make a document on my BrailleNote and I'll just write my paper on that which honestly for me is a lot faster than the computer.

R15: Huh! Why is that?

S15: I don't know--I just have--I guess it's because I've spent years writing on the braille writer and the BrailleNote is kind of like a braille writer as far as writing goes. You just use 6 dots and everything like that. So it's a lot faster for me using--so used to having written braille for all these years. So I can do it on the BrailleNote really fast.

R16: So how do you then turn that into a--like a, uh, paper, like a research paper or something like that? How do you--what do you do after you put it in the BrailleNote?

S16: If you want it to be in print, you have to attach a USB cable to it. And it has an option for you to print it, and you just click that, and then you just put a printer on that, and the printer will print out your paper.

R17: So how do you make sure that it's formatted correctly?

S17: Usually it is formatted correctly actually. Sometimes there are mistakes that happen in there especially when it comes to numbers. But most of the time it's formatted correctly. 
Another high school student reported needing assistance to create papers that were formatted correctly, as illustrated by the following exchange:

R107: OK. How about in the past? Have you--like last year, or whatever. How did you turn in papers?

S107: Oh I did. I handed it in in print.

R108: OK. So did you do those on the BrailleNote or on the computer?

S108: Uh, BrailleNote.

R109: BrailleNote, OK. How did you learn how to, like, format the file so it would print out nicely? I mean, did somebody teach you that or ...?

S109: What do you mean? I don't understand what you mean.

R110: Oh, for things like, when you hand in papers like it has a centered heading on it or things indent or[

S110: ]Oh, you're talking about like that.

R111: Yeah, that kind of formatting. For a print file.

S111:. I've never had to--well, the only time I've had to do centering of information like headings and titles is when I do presentations and projects. Stuff like that. $<$ R: Mm-hmm> But just like a daily assignment? No, I don't head or I don't do any of that stuff.

R112: OK. So how did you do it for presentations and things?

S112: Um . . . what would I do? Like PowerPoint? Are you talking about PowerPoint or?

R113: Yeah, that would be--well, I was talking first about papers that you hand in. 
S113: Oh, OK. Um, I would have my ... I'd print it out first so I'd have it with stuff pretty much on top of each other, no--no spatial arrangement or anything. No special arrangement or anything. And then I'd have someone sighted go in and tell me where to put the spaces in and stuff like that.

R114: OK. So somebody would help you then format it so it looks nice and you can then turn it in?

S114: Yeah.

The college students, on the other hand, showed a more sophisticated level of understanding about formatting their print papers, and reported having more demanding instructors who expected their papers to conform to certain standards. As one student put it:

Yeah, uh, well, the thing about that is that a lot of professors are very different in how they want their papers to be formatted. Also they tend to be like, 'OK, there's an example on the board; look at it.' And so usually I email them and ask, 'Can you send me a model of how you want it to look?' And, usually they do and I do my best to follow it. And sometimes I'm OK with it and sometimes I fail at it. And then I always ... first send a paper to a professor or TA. I'm like, 'OK, I tried to format it and I did my best and if there's a problem let me know and I'll fix it' or whatever. And usually they're really good about it as long as I mention that and that I've done my best. And usually like it's fine, but sometimes they're like 'Oh, you need to indent this' blah blah blah and this doesn't look right and sometimes they want me to fix it and sometimes it's like, 'I'm letting you know because some professor down the road might get mad at you and you should know how to learn this.' So it's 
definitely not my favorite thing and I'm always learning about it. But usually they're pretty cool with it.

Since that particular student preferred to use her BrailleNote to create documents, she went on to explain more about her writing process in this exchange:

S37: I'll usually translate them from braille to dot doc and then put them on the computer and format from that end. Because the BrailleNote will format but it usually doesn't come out great.

R38: Right. So who taught you to do that?

S38: Ummm ... I feel like I probably just sat down sometime in high school and messed with the formatting menu and probably just had someone sitting by and telling me when things worked right. I mean, I don't think I had anyone sit down and like 'I'm going to teach you how to format' because I'm still really bad at it and I have to yell at one of my housemates to come and look at it $<$ both laugh $>$ and make sure it looks OK because I never believe that it does so it's definitely not something I'm good at, and I probably should just have someone sit down and teach me how to do it.

Another college student had had explicit instruction in how to format papers, but reported also needing some assistance from time to time from someone who could see the screen:

S61: ]Oh, for writing formal papers and stuff, I use the computer.

R62: OK, and why is that?

S62: I feel like there's more options for formatting and I can, uh, can get someone, someone to look at it. I don't know what it is about Office 2007 but sometimes random things will happen. I turned in a paper the other week and 
the teacher said that everything that was in quotes was in italics, and I had not done that. So .... Just like I can have someone look to see if any little finicky things are going on and I feel that there's just more formatting options so I can make the paper specific to what the professor wants.

R63: OK. Yeah, that was sort of my question--do you ever have trouble with back translation from the BrailleNote into print?

S63: I haven't so far. $<$ R: OK $>$ I know there's a problem if Xxxx

R64: I'm sorry, say that again?

S64: I know it can happen if you don't, if you don't save separately or if you don't go through steps for changing it over, yeah it will definitely screw up but I haven't had that happen. But then again things that I'm going to turn in I don't usually start them on the BrailleNote, I usually do them on the computer so . . . <R: OK> I haven't had any real problems.

R65: OK. Who actually taught you all those formatting things in Word?

S65: Uh, when I was probably in $6^{\text {th }}$ grade I started, I started taking computer classes, just JAWS, basically, with a lady. She ... yeah, she worked for the Division of Services for the Blind. I would go to her once a week and we worked on different applications.

Yet another college student learned to format similarly, by exploring the menus on the computer, but also recalled having received some instruction in formatting:

R54: OK. So when you're doing things for school and you have to turn in a paper, for example, like a research paper, how do you generally do that? 
S54: I usually type up the paper on my laptop or I type it up on the BrailleNote and save it either on to a flash card or a thumb drive, put it in the laptop and print it out. The print copy for the teacher. $<$ R: Mm-hmm $>$ And I turn it in that way, so ...

R55: Um, who taught you how to do all the like formatting stuff for the papers that you print out? ... Was that something that a TVI showed you or you had to learn on your own, or .. ?

S55: Um, the formatting of it $\ldots$ ?

R56: You know, like titles--centered titles and indents for paragraphs and all that kind of thing?

S56: Um, some of that stuff I've kind of figured out on my own. And some of it the TVI showed me. . $<$ R: OK $>$ in school. A lot of it, the TVI showed me. You know, how to do formatting, how to do double spacing ... um, how to do ... Still on JAWS sometimes I'll go into the Virtual Viewer or the Help menu if I don't know something.

R57: OK. Was that hard to do? I've had some other students say that was hard to learn. Did you find that hard to learn or not too bad?

S57: Um . . .I think it is a little bit hard to learn. Um, it's hard because--especially when you're used to doing it in braille you're used to the format markings. It's a little bit--I think it's just a matter of learning the commands. Just a matter of getting the steps down. 
In addition to submitting work on paper, all of the college students mentioned emailing assignments to their teachers as did one high school student, and two of the high school students mentioned putting work on a flash drive to give to their teachers to print out for them.

When asked about multiliteracy activities, these students had few experiences to report. Only one student reported having to create a blog for a school assignment; four additional students stated they have created a blog or online journal for social networking, but not for school. One student described how a friend and she had created a podcast for fun, but not as a school assignment. None of the students had created a Wiki or used GoogleDocs to share a document online with peers, although one student said she had created a Wiki page with a friend as a social activity outside of school. None of the Web 2.0 activities generally cited in recent literature had been part of these students' school experiences.

The one technology experience that was mentioned by most students was creating a multimedia presentation either with a group or as an individual project. Ten of the students stated they had used PowerPoint or been involved in a group project that used PowerPoint. Of those 10 students, eight stated they did not use PowerPoint independently and either just supplied the information to the group while someone else designed the slides, or, if assigned as an individual project, asked a sighted person for help. The following quotes are fairly consistent among the students as far as their experiences using PowerPoint, their difficulties with it, and how they managed the task. The challenges mentioned were the same whether the students were in high school or in college:

- " . . that's just because having been blind since birth you miss out on a lot of things that, uh, that are relevant to most people, you know the aesthetic appearance of PowerPoint presentations and ... A lot of that stuff seems kind 
of ... seems almost arbitrary. There's xxxx type present your PowerPoint, how you format, you know ... a lot of the animation doesn't really mean a whole lot to us as blind individuals. So it's going to be tough. You're going to have to rely on other people's judgment as far as multimedia presentations."

- "I didn't do the PowerPoint independently. I usually had to have some help with doing the PowerPoint 'cause you know it's hard to make sure everything is lined up."

- "I think we've had assignments where we've had to have PowerPoints but I've always gotten paired up with somebody who can do it better than me. Because PowerPoint when you get it and try to do PowerPoint with WindowEyes or JAWS is too hard."

• "I don't like PowerPoint because I find myself having to <laughs> rely--I tend to rely on more, rely on other people rather than do it independently. . . I mean, I'll do the research part. I'll research all the information, get all my information, but when it comes to doing the PowerPoint if it's for someone else's assignment, you have to pick the slides and my teacher wants picture on it and it's a whole different story. And then it sounds like, whatever . . chaos. So I end up doing ... none of it. It becomes kind of frustrating."

- "JAWS has gotten a lot better with PowerPoint. It depends on the situation. If we're doing like a group project, usually the other people in the group tend to do it so they can make it more artsy. I mean I'll like contribute a lot of the information but as far as putting it together $\ldots$. it can be done, I can do 
PowerPoints with JAWS. I know it has gotten better because you used to not be able to."

- "Usually, if I’m, if I have it's with a group so I'll just write my part of it out and they'll do the PowerPoint part of it. I think I had to do a solo one once and I was like, 'Well, I don't really know how to create a PowerP'-- OK, OK, I'm fairly good with technology but when it gets to the presenting stuff and formatting it, I'm always like 'It's going to look horrible and I won't know, and no one's going to say anything' so I think I just send the text and the pictures to my TA and she just stuck them onto basic slides. Because I have no idea--I don't even think I owned PowerPoint back then. <laughs> That was like last year. So I try to do as much as I can independently but if I'm going to present it to the class I don't want it to look dumb or like boring. So I probably just asked her to put them on slides."

- "This year I had to. And, um, I worked with a group there so I was able to --I had all the text that I wanted in the PowerPoint and then, uh, one of the other group members actually helped me put it in the actual PowerPoint slide. And then when we presented I actually brailled out all my slides and then I could tell what slide I was supposed to be on."

Two of the students used remaining vision to complete the task; two students said they had never had to use PowerPoint to do a presentation for class.

It seems notable that PowerPoint was singled out as a common experience for these students but that other and more truly interactive multiliteracy tasks were not common. Whether these particular students just happened to attend schools where multiliteracy activities were not 
part of the curriculum, or whether these students simply had been given alternate assignments, is not clear. It is also interesting to note the number of students who felt they needed help from someone sighted to make the presentations visually appealing. Again, the college students seemed most concerned about this, stating they didn't want their presentations to look "dumb" or "horrible" and would let their "artsy" peers design the slides. Also intriguing was the comment that if the blind student created a PowerPoint that was not visually appealing, "no one will say anything." These students appeared to prefer having help from a trusted friend who was not visually impaired rather than risk creating an inferior project that might still be accepted by instructors or peers.

Questions related to the use of PowerPoint, blogs, and email communication with an instructor were included on the survey to gain additional information about these practices.

\subsubsection{How students learn to use technology for school tasks}

Among the questions about what tools the students use for which tasks, the interviewer also probed to discover how the students learned to use these tools and what resources they used for learning more.

As previously stated, all of the students reported learning to read and write braille from their TVI. However, only one student mentioned learning to use technology primarily from a TVI, although some of them were introduced to devices that way. Seven of the students stated they learned to use technology, at least partly, if not primarily on their own. Several students singled out the BrailleNote as a particularly easy device to learn on one's own because of its helpful and well-designed built-in user guide and Help file. Other students mentioned simply 
"poking around" in menus and exploring the various capabilities of AT devices and specialized software to discover the capabilities available.

Of great surprise to this researcher was that eight of the 12 students reported learning to use technology from a center-based program outside of the school setting or from staff at a specialized school for the blind even if the student didn't attend such a school. Several students reported attending centers or camps led by the National Federation of the Blind, while others attended a program at a rehabilitation center for blind adults, or a special summer program at a technology center. Two students mentioned attending training sessions sponsored by the manufacturers of specific devices. While the NLTS2 data indicated that students learned AT skills outside of school (Levine, Marder, \& Wagner, 2008) this researcher did not expect so many of the interviewees to have had this experience.

The third important subtheme to emerge was the role of friends in supporting the learning of specific technology devices. A third of the students named having blind friends who also use technology as a prime source of information and assistance. The following exchange illustrates how one college student described how important her friends were to her regarding technology:

S53: I'll try to figure it out on my own, but I have a lot of blind xxx friends who I can call up and ask.

R54: <laughs> Did you say "blind geeky friends"?

S54: <laughs> Yes! It's always good to have some of those you know! I hate, I don't know if you're like this, but I just really hate computers. I hate that they mess up at the wrong times. And I just, it's always just easier for me to pass off my problems to someone else who knows how to fix them. $<$ both laugh $>$ I tend to be all like, creative and figure out a way to do it. $<$ both laugh $>$ I'm not 
a computer person. I love figuring things out for myself, but just not computers. I don't know.

Another college student reported a similar experience getting help from a friend:

- "I learned almost everything about the BrailleNote by myself because they have a great user guide built in and I used to just read that for fun. $<$ both laugh $>$ So that I learned almost completely independently. But everything about the PC I definitely learned from [friend's name] who is the other blind student at my school and we were pretty much--he moved here when we were in $3^{\text {rd }}$ grade and so we went through all the grades together and had a bunch of classes together so. It was really helpful because I could just ask him, like, any--he's a total, complete nerd, he goes to Stanford now $<$ R: laughs $>$ And like he knows everything about all kinds of technology and so I would just ask him all these annoying questions and ... As we got older I got better at just like figuring things out on my own but when I first started, particularly like with the Internet I was afraid that I was constantly going to get a virus and so I would just ask him how to do everything. And he taught himself everything so he was--I don't know how he does it but he definitely taught me all of the PC. And he had a BrailleNote also so if I got in a jam with that he totally knew how to fix that too."

A high school student at a specialized school who learned primarily from the AT specialist on staff, also commented on how important it was to have peers to talk to about technology:

- "I have a friend who, when she came here she hated technology but now it's like all she uses. So I'll ask her questions. I have friends that know their 
technology better than me so I'll just ask them what the key command is for something or how to find something on the BrailleNote or something like that."

All three of these subthemes were selected as survey items to gather more data on how students learned to use technology, whether on their own, from a TVI or other adult, or from peers who were blind and also used technology.

\subsubsection{Preferences and Opinions About Braille and Technology}

While the students were discussing their practices as far as how they used braille books on paper or how they used electronic books with speech or refreshable braille, they also shared their opinions about the devices. In fact, it is difficult to truly separate the practices from the preferences in one sense as the practices often derived from the students' strong preferences of how they chose to get their work completed. Once again, there seemed to be three themes that evolved from the interviews. The themes fell in three categories:

1. preferences and positions about their use of braille and of individual technology tools;

2. how they chose to use those tools for specific tasks and to access information;

3. the role of teachers in learning to use technology.

Each of these categories will be examined in turn.

\subsubsection{Opinions about selecting a particular device}

All 12 of the students had strong and very specific preferences for how they used both braille and technology and could articulate their reasons quite clearly. As stated earlier, the students tended 
to use a variety of methods and tools to accomplish school tasks. Their preferences did not seem related to their primary reading medium or how long they had read braille. For example, of the seven students who had always been braille readers, three preferred speech access and four preferred paper or refreshable braille. Of the five students interviewed who had learned braille after being print readers, one still preferred print or speech over braille; the four remaining students were evenly split between their preference for braille or for speech access.

An interesting subtheme in this area related to the use of proprietary vs. mainstream products. The students were certainly aware that their assistive technology was more expensive than similar products that could be used visually, that is, without speech or refreshable braille. In addition, mainstream products were cheaper and easier to fix than their specialized technology. For those reasons, some students preferred to use "off the shelf" devices, like these two students:

• "I'm a huge supporter of mainstream software, you know. Even, even now, um, in terms of, like I said, I don't feel like these braille notetakers really have their place any more in the market. For all intents and purposes they really haven't for quite a number of years, especially now with the new netbook computers that are coming out that are incredibly revolutionary."

- "Notetakers are good but I personally recommend laptops over a notetaker just because they, you don't have to worry about . . .they're a lot cheaper I guess and they're a lot more accessible--like if something goes wrong you can have someone look at your computer and you can't really do that with your notetaker."

Since most specialized technology devices must be sent to the manufacturer when they malfunction, even students who preferred proprietary products mentioned that a disadvantage of 
using specialized devices was the difficulty of being without the devices when they are sent off for repair or maintenance. Despite the expense and occasional inconvenience, however, most of the students interviewed did prefer to use specialized devices. One student had a netbook but kept gravitating back to the BrailleNote because of her preference for a braille display. Among specialized devices, the BrailleNote was often singled out as a preferred tool because of its ease of use and how useful its Help file was so students could learn to use it without much assistance. As mentioned above, 10 of the students mentioned using that specific device and praised it highly; its competitors were not as well liked.

Another device that had widespread unanimity of opinion, although of a different kind, was the slate and stylus. Ten students stated that while they learned to use the slate and stylus, they do not actually use it and cannot foresee that they would ever use it. Only one student stated having a practical use for the slate, reporting that she brings it with her when she travels to copy down people's phone numbers. One student never learned to use it at all. In addition to its disfavor as a braille writing tool of choice, several students had quite strong opinions when asked about their experiences writing with the slate and initially learning to use it:

- "That was about in the third grade when I learned how to use that. And, uh, I hope I don't have to use that again! < both laugh> I don't like it because it's a lot slower. And I would always get frustrated with it, so . . . I've not used it ever since then."

• "I've never really done well with the slate and stylus."

• "I've never actually had any practical use for [the slate \& stylus] ... if I need to jot down a note I wouldn't normally use a slate and stylus. I could record it with my Victor Reader or I can, um, if I really had to I could do it in the notes 
folder, the notes program on my phone and type it in faster than I could ever use my slate and stylus."

- "I was introduced to [the slate and stylus] in kindergarten and I was just never really forced to do it. And so I never did. I hated it when I was little. I didn't understand the purpose of it and just didn't want to do it."

- "I hate [the slate and stylus]. Um, I started that this year. . . . It's very hard, I mean I thought braille was hard at first to learn but this thing is just, just too hard. You know, it's pretty hard. ... You have to like write from right to left in certain little cell places and stuff. You know?"

• "I HATE it."

The vehemence with which some of the students responded to questions about the slate was surprising. This researcher found it interesting that even among students who did not use the slate and did not plan to ever use it themselves, several still had an almost grudging respect for this inexpensive manual device, as evidenced by these comments:

• "I'm terrible at [slate \& stylus]. I can hardly do it at all. . . . it's interesting, I just never really had a reason to learn it since I had a notetaker and it wasn't really something that I needed to learn."

• "I guess if you work with them all the time it could be pretty useful."

- "I still own the devices but I don't use them anymore. But you'll never see me reject the importance of [the slate and stylus]. I think it's great. If, uh, technology should fail you ... It's really the closest thing to having a pen and paper with you. You know, sighted people, you know as long as they have a pen or something they can write on anything. Write on a Burger King napkin . 
. . You know, anything. Not everybody is going to spend money on a digital recorder or not everybody's going to carry around a notetaker and you're not going to turn on a laptop to type somebody's phone number down."

Because of the intensity of the responses about this humble device, several questions about the use of the slate and stylus were included in the survey.

\subsubsection{Opinions about specific tasks and access to information}

Because the students used a variety of devices and methods to complete their school work, they were articulate about how they chose to do specific tasks. They were metacognitive in their approaches for completing work, expressing awareness of the advantages and disadvantages for different tools and methods. The college students in particular, perhaps because of their longer experience in school, had strong opinions to share about the pros and cons of using paper braille, electronic braille, speech access, and other methods, such as the use of readers, to complete school tasks.

All 12 of the students interviewed would advise other blind students to learn to use technology. In general, they felt that technology made doing school work easier. For example, eight of the students specifically stated that an advantage of technology is having access to information, particularly on the Internet, and the ability to do research online for papers and other assignments.

Nine of the students stated that a main advantage of using technology is that it is faster

than using braille. Even the students who stated that they loved braille and preferred to use it if possible acknowledged that in some cases using technology, particularly speech access, allowed 
them to complete school tasks faster. The following quotes illustrate the students' opinions about using technology to complete work more efficiently:

• "I mean I use [technology] for everything pretty much. And I don’t know where I'd be without it. I'm super spoiled. And I love it--it makes everything so much easier. ... I use it all day long."

- "I like using the computer for things that are easy like just straight reading, like just text. If it's straight reading I prefer to read it electronically because it's just, it's an easier way to access it. It's faster, I think, too. It's faster and it's not . . . and it doesn't take up room when you don't need the hard copy braille. If it's an easy class like English or History then it's just, then you can just download it into your laptop or your BrailleNote."

- "I mean, the amount of high volume material that I have to read in college is really not, it's not efficient to use braille unfortunately."

• "I think reading braille is a lot slower than using speech software which you can crank the speed up very, very, very fast. And I do. You can just breeze through. I mean, even in terms of not just not academic things. Even in terms of, just, like, if you're sending somebody a text message ... You don't need to capture every single word."

All of the students but one specifically stated that a major disadvantage of braille books is that they are big, bulky, hard to carry around, and that they take up too much room. In their opinion, the convenience and portability of carrying one device or possibly two rather than hauling voluminous braille volumes was a definite advantage to using access technology. In addition to speed and the smaller size of the devices, using AT tools had other advantages as 
well, including the convenience of having all their work in one place, and being able to use special features in technology devices such as the "find" feature that can help students search for particular sections of the text.

• "I probably got mostly everything in paper braille up until my freshman year of high school and then we started making the switch to electronics.... So I got a lot of books electronically but a lot of the worksheets stayed in paper braille until I would say my junior or senior year when pretty much everything was electronic by then--except for, like, generally teachers didn't like to email tests, so they were still brailled in paper braille. But I remember I used to have to have a roller back pack because I couldn't like carry all my stuff without like breaking my back. < both laugh> And then in my senior year there was like nothing in my backpack because it was all on my BrailleNote or my computer. So it was kind of interesting how that changed."

- "When you use the technology it's going to make things easier, you're going to be able to find things quicker. Like, when you're using the BrailleNote and the laptop, you can find--like if I don't know where the teacher is in class, all I have to do is raise my hand and say 'can you give me the first few words of that paragraph?' and I can search for it and get there really quick."

- "Well, technology is useful for ... you can skip quickly the page, you can skip, you can skip quickly to the specific passage of text if you have an electronic copy of a book or something. Especially if you have a DAISY copy of a book. And if it's marked up properly. . . . You get a much wider experience with technology than you do with braille. Like for example, technology allows you 
to go browse the Internet, receive and send email, you know, all that good stuff. And obviously, paper braille does not allow you to do any of that stuff."

- "A part of me still really misses reading the hard copy books and dragging them around but it's just not practical."

Other students acknowledged that electronic information was the wave of the future. Several students mentioned the fast pace of today's world and felt that soon information on paper will basically disappear. Related to that, some students expressed the opinion that their own personal use for paper braille would be limited in the future particularly in school or on the job. The following quotes exemplify how students see the future unfold as far as paper braille:

• "I think that everyone is just using their computer for everything now."

- "I mean, it seems like everything's going to electronic now and paper's like nonexistent any more."

- "I think braille is very useful; it's, you know, before technology came around it's how blind people competed in the job market. But now that we're going to this technology revolution you're not going to be using braille a lot when you get a job."

- "I would tell [other students] to definitely, um, if they're braille users and they love braille over listening to books and things I would tell them to at least try [technology] because it is an advantage over braille. Because, just of the simple fact that when you go to college you're not going to be able to really access all your books in braille."

- "Well [teachers] definitely have to teach [students]--you know, when they're younger, as early as possible get them to learn braille. Braille is very powerful 
and you know and that's how they're going to survive for, you know, for quite a few years. But once they get into high school and getting closer to college, or if they're not going to college but going to technical school you need to start taking the braille away from them and, you know, and forcing them to use a Stream or a Wave or things like that. You know, start using ... scanners and stuff like that."

- "Well, . . y you find things quicker, you've got the Internet, the speed in which you can find things is just ridiculously fast. We're going in this society, you know, globally we're going to a digital stage now and everything's going to be electronic. There's going to be one day, you know, where there's going to be very little paper used. You know as a world we're being more, I think that as students we're almost forced to be using--because that's what we're going you know. When I you know, 10-15 years from now when I, 5-10 years from now when I'm an adult and have a job, that's what I'm going to be using. Will be using the Internet, will be using email , am going to be using things like xxx, Blackberries, uh, stuff like that."

• "You know it's a double-edged sword really. I, I, I think for half my life in which I had braille textbooks . . . and the other half I'm like, 'Thank God I don't have braille textbooks!' It's just <laughing> really inefficient and unfortunately you know, we live in a society that's perpetually in a rush. And there's not enough hours in a day."

The use of technology has its own disadvantages, however. Three quarters of the students said a disadvantage of technology is that it can crash or just cease working properly, often at the 
most inopportune times. Almost every student had a story to tell of technology going awry. As one student put it simply, "Things break. Things die. Technology sometimes doesn't really work. Technology has good days and bad days."

Because of the pros and cons of both paper braille and technology, the ability to make choices for how to do school tasks was important to these students. The use of specific tools was a personal choice for these students based on their preferences and prior experiences with both braille and technology. For example, two high school students expressed their preference for having speech access rather than reading the books in braille. One student said, "The books I listen to have big words and stuff in them and like I can understand it better if I listen to it." Another liked speech access because, "it allows me to focus on the story more and in the case of books from NLS, um, they're human narrated and you get, like, emotional feedback. Happy, sad, you know, all those kinds of things." On the other hand, another student identified being able to apply her own prosody into what she reads as a reason she prefers braille over speech: "I'd rather be reading than listening. I don't really like to listen to synthetic speech. It annoys me. I mean, I will for the computer but if it's for a story then I like to read it because I can just like express the voices in my head. Because the speech kind of ruins that, it's like . . awkward." It's clear that these students had specific and strong preferences for completing their work, and that a method that works well for one student may not be appropriate or preferred for another.

As stated earlier in this chapter, students expressed a strong preference for paper braille for mathematics, science, and foreign language; in addition to those subjects, about half of the students mentioned that they also prefer braille (either on paper or with a refreshable display) for certain reading tasks because speech access makes them "zone out" or they have a harder time paying attention. 
• "Just, sometimes I get tired of listening. . . . I can't go for huge long periods of time of just listening to my textbooks and taking notes and studying from the computer. Because after a while the voice just becomes like noise."

- "If I just had to read something and just read it and not have to answer any questions about it, I'd prefer it electronically. But if I had to read it and answer questions about it I would want to read it in braille because I feel like I could pay more attention. ... Because my mind has to focus on the words that are on the page and what I'm actually reading. Whereas if I'm listening to it my mind kind of zones out sometimes."

- "If the book is on the laptop I do listen to it. And if there's something that I want to read in braille I just put it in the BrailleNote and read it so. I kind of base it on the assignment, on how--you know, if the assignment is really easy a lot of times I'll just listen to it. If it's a really difficult assignment like Spanish you kind of have to know the words and really be able to interpret the words so that's something more, you know, I like to have the braille."

• "I love reading and writing it and that's how I work best. I find that when I try and write something if I sit down and try to write it on the computer it's practically impossible because I just really think and write better when I can actually read what I'm doing with the refreshable display and type using the braille key board."

Unfortunately for the college students, wanting to have a college textbook in braille can be very expensive. Several students reported trying to get a particular textbook in braille by 
working through their university's disability office and having a difficult time. Two students shared similar experiences in trying to get braille books for college classes:

• "Like I remember I was trying to get one of my books for a class embossed in hard copy braille so I could follow along while we read it in class while I was taking notes. Because it was getting annoying to switch from my notes to the book to, like, file after file--it was just getting kind of tedious. And I was looking around to see if I could get it embossed and it was so expensive. I remember when I looked it was like, I forget, like, 50 cents per page and if we're talking about like a book that's about 400 pages in print, that's like ridiculous amounts of money for braille <laughs> And I was like, 'Forget it! I'll just suffer in silence--I'm not going to pay this money!"'

• " . . if you're looking at buying your own braille books if the school doesn't provide them for you, they're really, really expensive--braille books. The transcribers, they charge a lot. I think one of my science books before we found it already produced they, a transcriber was going to charge like $\$ 8,000$ to braille it, a biology book. That was kind of inaccessible to people, especially in college."

Despite the admitted disadvantages of bulkiness and expense, most of the students still felt that braille reading and writing were important skills to have and would continue to be important in the future. For example, five of the students mentioned that reading braille was important for learning correct spelling and grammar, such as punctuation, sentence structure, and creating paragraphs, elements that are not obvious with speech access alone. In fact, three students stated unequivocally that listening alone is not literacy. While most of the students 
interviewed recognized the importance of technology in their lives, they definitely felt that braille had a place as well. The following quotes illustrate that duality of opinion about the role of braille within the context of an online society:

- "I would say that [technology is] a wonderful tool and I would encourage them to learn it. Even more than I have because I definitely, I hate computers. I have a lot of respect for people who make like web sites and stuff but they should never forget about braille. Because, you know, to me you wouldn't, you would call people crazy if they refused to write things down with a pen and paper anymore. That would just be crazy. But I feel that people like don't think they need braille since they learn to use technology--and they do."

• " . . . especially in your early elementary years it's almost necessary for you to learn braille so you can have that, uh, reading skill that you can actually like-um, what would it be called--read it and not just listen to something being read."

- "So I feel like braille is good for people to learn how to read. Like actually read instead of listening. . . . Because if you listen to book half the time you wouldn't know how to spell, like, properly because you're not really reading the words."

- "If you're listening to a book you're not actually reading it. So you're not actually processing it in your ... I've noticed as I've gone to more technology-based reading and writing my spelling has just--oh, it's just shot. I'm terrible at spelling now than I used to be when I used to read braille because whenever 
you hear a word you don't hear the spelling or you don't have to spell it out in your head and figure out what it means."

- "I mean, kids, sighted kids will listen to audio books but not to the extent that a blind student will when given the chance and the materials. I mean, audio's great but braille's also important. Especially when they're young and learning how to spell and learning the fundamental writing skills. So I think it's great when TVIs really push braille and are trying to get it implemented at home also so basically wherever the student turns there's going to be the opportunity to practice braille."

- "With braille I can read where sighted people can't read . . . I can read in the car and in the dark."

- "Don't totally depend on your technology because you never know when you might have to get it fixed or something. Make sure your braille reading skills are good. . . . Read it all the time. Because if you don't read braille all the time then your skills aren't going to be as good. So keep your braille reading skills sharp."

• "I feel like ... I think maybe this is true because I've started [braille reading] from the beginning but I can comprehend more, you know, compared to listening. I can comprehend more and it's --you know, I feel more equal with the world around me because it's my pencil and paper. I don't have to have, you know, a big smart computer to do it. It's like a machine that's manual, it's not ... you know, I feel like it's our way to be equal." 
Several questions on the survey asked students to comment on the role of braille and technology in their lives, and how they choose which tool to use in specific situations.

\subsubsection{Opinions about the role of TVIs}

Students were asked if they had any advice they wanted to share with TVIs and people studying to become TVIs about braille and technology. As could be expected from this articulate group of young people, they had solid opinions about the importance of braille instruction as well as about technology. As illustrated above, the students definitely felt that braille reading and writing skills continued to be important, particularly for young children. Similarly, they had strong opinions about the role of the TVI in AT instruction as well.

- "I think that it's important that the student has a say [in choosing technology] even if they're really young because it's better to get them started on a device that's beneficial to them right away so they know how to use it by the time they need it for more complex tasks and school work."

- "See I wasn't taught how to do all this stuff until my $10^{\text {th }}$ grade year. Late $9^{\text {th }}$, early $10^{\text {th }}$. Which might have been, probably was--it was a little late. I don't regret, I mean I don't regret--I don't think that I learned late. But I just think you can always start early. The earlier the better but I mean. I think it's up to the students, up to the parents and teachers is to get really ready to get the braille taken away from them."

- "Start with as simple a device as you can. And then work your way up. Also you should assess your student's, your students' skill and cognitive abilities. 
Because the more com--the higher up you go as far as blindness equipment, the more complicated it will get. ... So you don't want something that's too complicated for any one particular person. So do your evals first."

- "I think the more technology that the teachers know the more they're going to be able to help their students. And the more the student is going to learn the skills that they need. Um, to be able to go to college and get a job and ...."

The students were asked specifically if they felt that TVIs should know a little about a great number of technology devices, or if they should know a lot about the most popular devices. The students were evenly split in their opinions as far as what and how much teachers should know about AT. Two students said their advice to teachers was simply, "learn as much as you can."

One college student had this advice for teachers:

I think it's just important to be in tune with what the student needs and how they learn best as you would be with any other student. . . . It's a lot about timing and being able to plan ahead and help in the sense that you're on top of your game and able to get them the material as they need it in the format that they can access the best.

A student at a specialized school also had some words of advice to teachers of high school students about teaching both braille and technology:

I would say like listen to what the students are saying. Like they're telling you that maybe they learn better this way. I think they should listen to that, like, see how it works instead of like telling them what's better for them. That's not going to work. Like, 'cause in the end, kids are just going to learn what they 
want anyway. And that's going to slow down the learning process. Like, if you're doing this one way and they're going to do what they want the other way, they're never really going to learn one way completely. So I just feel like teachers should listen and um to what the kids want and yeah, try to help them that way.

The schematic on the next page (Figure 2) illustrates the themes that developed from these coded interviews and how they interact with one another. These themes and subthemes were the focus of the survey that was conducted in spring of 2010. 


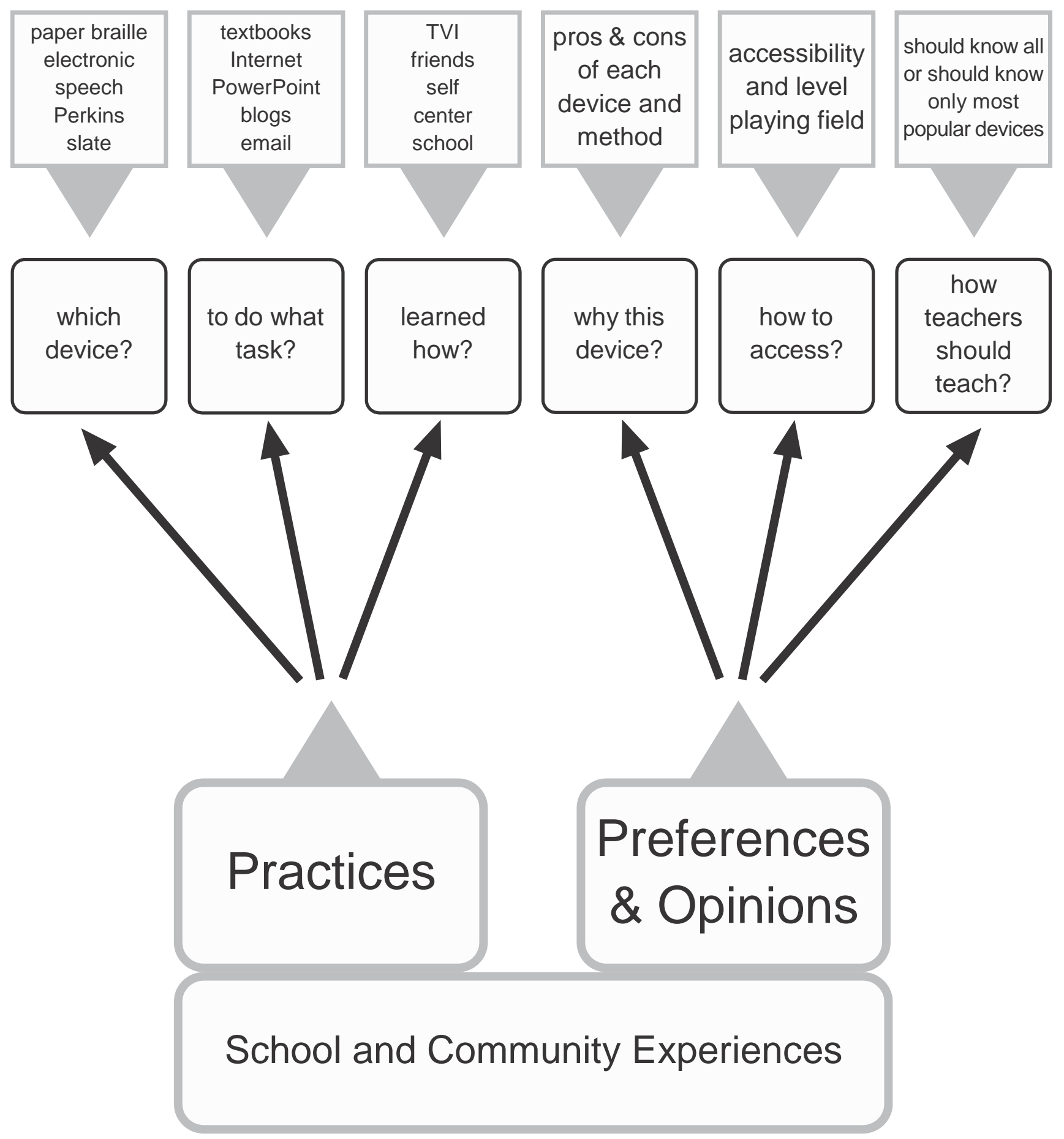

Figure 2: Themes from interviews 


\subsection{PHASE 2: SURVEY RESULTS}

Items representing the most significant coding themes identified in the interviews were included in the survey. Specific quotes from the interviewees were selected and converted into survey questions to be rated by other students. In this way, data from the first phase could be triangulated and hypotheses drawn from the interviews could be tested for validity.

Once again, the focus of the survey was to shed light on these basic research questions:

1. How do young adults (ages 16-22) who are braille readers use braille, audio, and electronic materials and tools for educational purposes?

2. How do young adults who are blind learn new literacy practices using assistive technology?

3. What are the attitudes of young adults towards hard-copy (paper) braille, and toward access technology?

This chapter provides a descriptive analysis of the survey results, including demographics, frequencies of responses to specific questions, and correlations to investigate any possible relationship between categories of student responders (for example, age or grade of the student) and specific responses. 


\subsection{PROCEDURES AND RESPONSE RATE}

The survey was prepared, piloted, and then sent for approval by the University of Pittsburgh's IRB. Approval was granted on February 11, 2010. Students from whom consent forms had already been received (from adult participants and from minors who had parental consent as well as individual) were contacted via email to let them know the survey was ready. This also gave the researcher the opportunity to verify which format they preferred: braille or Word file, which was sent electronically as an attachment. In addition, students who were known to be 18 and older were notified of the option to take the survey online. The survey was immediately disseminated to students via email for students who preferred Word, and the link was sent to students over 18 who wished to take the survey online. The braille version of the survey was produced by a local transcribing group from a Duxbury braille translation file created by the researcher and then mailed to students who had requested that format. The teacher at one specialized school for the blind requested the researcher email the Duxbury file so she could emboss copies for her students to save time and mailing expense.

A call for participants was again conducted via email and by posting the flyer on the same electronic mail lists that had been used in the fall, as well as other lists and newsletters and through word of mouth with TVIs known to this researcher. Students who contacted the researcher after seeing this second call for participation were informed of their survey format options and the appropriate format was sent to them. Teachers and parents who had heard of the study also contacted the researcher, generally by email but occasionally by phone, to request information about the study on behalf of a student who was interested in participating. 
The total number of students, teachers, or parents who contacted the researcher during the entire recruitment period was 127 . Of these, 17 were not eligible to participate, most often because their ages fell outside the eligibility requirement, but also because they were not currently enrolled in school. Of those 110 eligible students, 95 students completed a consent form, either on paper or online. There were 13 eligible students or teachers who had eligible students who sent a message about their interest in participating but who did not send in a consent form and did not respond to further invitations. In all, 85 surveys were disseminated by the researcher via braille, a Microsoft Word attachment to an email, or by being sent the link to the online survey, with additional braille copies distributed by the teacher at the specialized school mentioned earlier.

There were 79 surveys returned. One had been completed online by a student who said she was eligible but who fell outside the age range requirement; that survey was discarded and not included in the analysis. In addition, one survey was sent in by a student for whom the consent form had not been received; this student was at the specialized school from which a large number of students participated and the TVI had forgotten that this student's consent form had not been signed by a parent. While numerous attempts were made to have the parent sign the form, by the end of the recruitment period the required parental consent was not received so this survey was also discarded and not included in the analysis. Several students did not complete the survey in the original format they requested, but asked for a different format after receiving the survey. Three students requested both braille and the Word file; two returned the Word file and one did not ultimately participate in the study. The total number of surveys included in the analysis, then, was 77. Table 2 illustrates the break down by format of surveys sent and received. 
Table 2: Survey Response Rate per Media Type

\begin{tabular}{|c|c|c|c|c|}
\hline Survey Formats & $\begin{array}{l}\text { Format first } \\
\text { requested }\end{array}$ & $\begin{array}{l}\text { Surveys returned in } \\
\text { original format }\end{array}$ & $\begin{array}{l}\text { Surveys } \\
\text { returned in } \\
\text { different format }\end{array}$ & $\begin{array}{l}\text { Valid surveys } \\
\text { analyzed }\end{array}$ \\
\hline $\begin{array}{l}\text { Electronic(Word) } \\
\text { only }\end{array}$ & 32 & 22 & & 33 \\
\hline Braille only & 11 & 12 & $\begin{array}{r}3 \text { returned as } \\
\text { Word } \\
1 \text { done online }\end{array}$ & 10 \\
\hline Online (sent link) & 41 & 37 & $\begin{array}{r}2 \text { returned as } \\
\text { Word }\end{array}$ & 34 \\
\hline Braille \& Word & 3 & $\begin{array}{r}0 \text { in braille } \\
2 \text { returned as Word }\end{array}$ & & 0 \\
\hline Total & 87 & 73 & 6 & 77 \\
\hline
\end{tabular}

\subsubsection{Demographic information}

The average age of the students who responded was 18.49 years, with most responses from students who were 18 years old. There were 47 males (61\%) and 30 females (39\%). Table 3 illustrates the break down in ages of the students who participated.

Table 3: Age of participants

\begin{tabular}{crr}
\hline \hline Age & Frequency & Percent \\
\hline 16 & 9 & $11.7 \%$ \\
17 & 11 & $14.3 \%$ \\
18 & 20 & $26.0 \%$ \\
19 & 15 & $19.5 \%$ \\
20 & 16 & $20.8 \%$ \\
21 & 4 & $5.2 \%$ \\
22 & 2 & $2.6 \%$ \\
\hline \hline
\end{tabular}


The majority of the respondents (33.8\%) attended high school at a public or private school that was not a specialized school for students who are blind. The next largest group was currently attending a specialized school (31.2\%), while $28.6 \%$ of the students attended a college or university program. One student attended classes at a community college, and three were enrolled in other programs, such as the Hadley School for the Blind (an international distance learning program), or an NFB training center. Table 4 illustrates the type of school attended by the students.

Table 4: Type of schools attended by students

\begin{tabular}{rcr}
\hline \hline $\begin{array}{r}\text { Type of School } \\
\text { Public high } \\
\text { school }\end{array}$ & Frequency & Percent \\
\hline $\begin{array}{r}\text { High school } \\
\text { residential }\end{array}$ & 26 & $33.8 \%$ \\
$\begin{array}{r}\text { College/university } \\
\text { Community } \\
\text { college }\end{array}$ & 24 & $31.2 \%$ \\
$\begin{array}{r}\text { Other program } \\
\text { Total }\end{array}$ & 1 & $28.6 \%$ \\
Missing & 3 & $1.3 \%$ \\
Total & 76 & $3.9 \%$ \\
\hline \hline
\end{tabular}

The students who participated ranged in grade from high school freshman through college junior; there was also one student at the graduate level, and two others in ungraded 
programs. The highest percentage of participants (41.6\%) was high school seniors. Table 5 shows the numbers and percentages of participants by grade level.

Table 5: Grade Levels

\begin{tabular}{lll}
\hline \hline \multicolumn{1}{c}{ Grade } & Frequency & Percent \\
\hline $\begin{array}{l}\text { Level } \\
\text { High school }\end{array}$ & 1 & $1.3 \%$ \\
$\begin{array}{c}\text { High school } \\
\text { sophomore } \\
\text { High school }\end{array}$ & 10 & $13.0 \%$ \\
junior & 11 & $14.3 \%$ \\
$\begin{array}{l}\text { High school } \\
\text { senior } \\
\text { College } \\
\text { freshman } \\
\text { College } \\
\text { sophomore }\end{array}$ & 32 & $41.6 \%$ \\
College junior & 5 & $6.5 \%$ \\
Ungraded/other & 9 & $11.7 \%$ \\
Total & 5 & $6.5 \%$ \\
\hline \hline
\end{tabular}

Students were also asked if they had attended a specialized school for the blind at any point in their education, and if so, how long they attended. Forty-two students (54.5\%) stated they had attended a school for the blind at some point, while 35 students (45.5\%) had not. Of those who had attended a specialized school, the largest percentage (25\%) had attended from 1 to 5 years. Table 6 provides a closer look at the break down of amount of time in a specialized school. 
Table 6: Time in a Specialized School

\begin{tabular}{lcc}
\hline \hline \multicolumn{1}{c}{$\begin{array}{c}\text { Time in } \\
\text { specialized } \\
\text { school }\end{array}$} & Frequency & Percent \\
\hline $\begin{array}{l}\text { None } \\
\text { Less than a year } \\
\text { or summer } \\
\text { program only }\end{array}$ & 35 & $45.5 \%$ \\
$1-5$ years & 6 & $7.8 \%$ \\
$6-10$ years & 18 & $23.4 \%$ \\
$11+$ years & 10 & $13.0 \%$ \\
5 & 6 & $7.8 \%$ \\
Missing & 1 & $1.3 \%$ \\
Total & 1 & $1.3 \%$ \\
\hline \hline
\end{tabular}

As stated in the analysis of the interviews, defining a primary reading medium for many students is complex. Even though the survey required the students to choose one medium, a number of students balked at putting a "primarily read" format and used the category "other" to further describe their reading media. Students were asked to respond to the question: "In a typical week, I primarily read" by selecting one choice. The majority of students (32.5\%) reported using primarily braille electronically, with auditory and paper braille close behind (24.7\% and $23.4 \%$ respectively). The online version of the survey was designed to only allow one choice, although there was space for comments. Students who completed the braille or Word versions of the survey often took advantage of the fact that they could actually select more than 
one choice, and did so. Table 7 shows the responses of students including a new category of "Other" reflecting the percentage of students (16.9\%) who reported using a combination of methods equally rather than just one primary method.

Table 7: Primary Reading Medium

\begin{tabular}{lcc}
\hline \hline Reading Medium & Frequency & Percent \\
\hline Braille on paper & 18 & $23.4 \%$ \\
$\begin{array}{l}\text { Braille } \\
\text { electronically }\end{array}$ & 25 & $32.5 \%$ \\
Auditorily & 19 & $24.7 \%$ \\
Print & 2 & $2.6 \%$ \\
Other & & \\
(combination of & & $16.9 \%$ \\
methods) & 13 & \\
Total & 77 & \\
\hline \hline
\end{tabular}

Students were asked to list all of the technology they used on a regular basis to complete school work. The range in the number of devices that students reported using was from 2 devices to 13 devices, with the average number of devices used at about 5 (actual average 4.7). The mode responses were 4 devices $(n=20)$ and 5 devices $(n=20)$. The most frequently named technology tool by brand name was JAWS ( $\mathrm{n}=57$ ), a screen reading program which students used with either a laptop or desktop computer; another brand name, WindowEyes, or simply "screen reading software" (unspecified) was also mentioned by seven students for a total of 64 students (83\%) who used screen reading software. The second most mentioned device by name was the BrailleNote ( $\mathrm{n}=47$ ), while an additional 13 students listed the PacMate notetaker or simply 
"notetaker" (unspecified) by eight students, for a total of 68 students (88\%) who used some type of braille PDA. Some version of the Victor Reader (e.g., Vibe, Stream) was mentioned by 34 students (44\%). The Perkins Brailler was referred to by 29 students (38\%). A scanner and/or scanning software was mentioned by 15 students (19\%). Other devices were listed as well in varying number matching the list of devices mentioned in the interviews shown in Figure 1 in Chapter 4. Only five students mentioned the slate and stylus among the tools they used (6\%); two mentioned using an iPod, and only one student used a Macintosh computer with VoiceOver screen access. It is important to note that these responses were self-reported by students and may not include all the devices used. For example, it's possible that more students used the Perkins Brailler but did not consider it "technology" or simply forgot to mention it. In addition, these numbers and percentages are not exclusive but simply indicate how many times a particular type of technology was mentioned by students in the open-ended question.

In response to the question of which one or two devices were used most often, a computer (laptop or desktop) with screen reading software was mentioned 58 times and a braille notetaker/PDA was mentioned 38 times. Other items mentioned were the Perkins Brailler $(n=5)$, Victor Reader ( $\mathrm{n}=5)$, Braille+ $(\mathrm{n}=3)$, talking scientific calculator $(\mathrm{n}=2)$, ZoomText screen enlargement $(\mathrm{n}=2)$, and cellular phone $(\mathrm{n}=1)$.

Students were asked to estimate when they began to use technology, particularly for school work. This was an open-ended question, and students responded by giving the age or the grade they recall starting to use technology for class. The responses were grouped together by range of ages or grades mentioned and coded from 1 to 5 , with 5 being the earliest set of ages (prior to $1^{\text {st }}$ grade or age 6 ) and 1 representing students who started in high school. The largest 
percentage of students (39\%) started to use technology in upper elementary grades, approximately ages 9-11 years old. Table 8 illustrates the range of responses to this question.

Table 8: Age students began to use technology for schoolwork

\begin{tabular}{rrr}
\hline \hline Age & Frequency & Percent \\
\hline $\begin{array}{r}\text { Prior to } 1^{\text {st }} \text { grade } \\
\text { younger than 6 yrs. } \\
\text { old) }\end{array}$ & 3 & \\
$1-3$ grade (approx. & & $4.0 \%$ \\
$6-8$ yrs) & 18 & $23 \%$ \\
$4-6$ grade (approx. & 30 & $39 \%$ \\
$9-11$ yrs. old) & 12 & $16 \%$ \\
$7-8$ grade (approx. & & \\
$12-13$ yrs. old) & 14 & $18 \%$ \\
$9-12$ grade (approx & 77 & 100.0 \\
$14-18$ yrs. old) & & \\
Total & & \\
\hline \hline
\end{tabular}

\subsection{STUDENT PRACTICES FOR USING BRAILLE AND TECHNOLOGY}

The first set of questions on the survey was organized primarily to help answer the first research question: How do young adults (ages 16-22) who are braille readers use braille, audio, and electronic materials and tools for educational purposes? These survey items will be discussed by coding scheme, specifically by type of device or procedure. 


\subsubsection{Use of paper and electronic braille}

A subset of these questions relate specifically to the use of paper or electronic braille. The results of Questions 1, 3, 10,11, 13, and 14 are presented here to show the frequencies with which these students indicated they use braille in some form for school work. The mode in each table is shown in bold type to clearly show the most frequent answer.

Table 9: Question 1: I use a portable braille notetaker to do most of my schoolwork

\begin{tabular}{|c|c|c|}
\hline Response & Frequency & Percent \\
\hline This is very unlike me & 11 & $14.3 \%$ \\
\hline This is somewhat unlike me & 6 & $7.8 \%$ \\
\hline $\begin{array}{l}\text { This is neither like me nor } \\
\text { unlike me }\end{array}$ & 5 & $6.5 \%$ \\
\hline This is sort of like me & 15 & $19.5 \%$ \\
\hline This is very much like me & 38 & $49.4 \%$ \\
\hline Missing & 2 & $2.6 \%$ \\
\hline Total & 77 & $100 \%$ \\
\hline
\end{tabular}


Table 10: Question 3: All of my textbooks are in paper braille

\begin{tabular}{lcr}
\hline \multicolumn{1}{c}{ Response } & Frequency & Percent \\
\hline This is very unlike me & 22 & $28.6 \%$ \\
This is somewhat unlike me & 8 & $10.4 \%$ \\
$\begin{array}{l}\text { This is neither like me nor } \\
\text { unlike me }\end{array}$ & 5 & $6.5 \%$ \\
$\begin{array}{l}\text { This is sort of like me } \\
\text { This is very much like me }\end{array}$ & 15 & $19.5 \%$ \\
Missing & $\mathbf{2 6}$ & 33.8 \\
Total & 1 & $1.3 \%$ \\
\end{tabular}

Table 11: Question 10: When I'm listening my mind kind of zones out sometimes, so when I study I use braille

\begin{tabular}{lcr}
\hline \multicolumn{1}{c}{ Response } & Frequency & Percent \\
\hline $\begin{array}{l}\text { This is very unlike me } \\
\begin{array}{l}\text { This is somewhat unlike } \\
\text { me }\end{array}\end{array}$ & 16 & $20.8 \%$ \\
$\begin{array}{l}\text { This is neither like me nor } \\
\text { unlike me }\end{array}$ & 6 & $7.8 \%$ \\
$\begin{array}{l}\text { This is sort of like me } \\
\text { This is very much like me }\end{array}$ & 21 & $16.9 \%$ \\
& 20 & $27.3 \%$ \\
Missing & 1 & $1.3 \%$ \\
Total & 77 & $100 \%$ \\
\hline \hline
\end{tabular}


Table 12: Question 11: If it's a really difficult assignment I like to have the braille

\begin{tabular}{lcr}
\hline \multicolumn{1}{c}{ Response } & Frequency & Percent \\
\hline This is very unlike me & 13 & $16.9 \%$ \\
This is somewhat unlike me & 4 & $5.2 \%$ \\
$\begin{array}{l}\text { This is neither like me nor } \\
\text { unlike me } \\
\text { This is sort of like me }\end{array}$ & 9 & $11.7 \%$ \\
This is very much like me & 10 & $13.0 \%$ \\
Total & $\mathbf{4 1}$ & $\mathbf{5 3 . 2 \%}$ \\
\hline \hline
\end{tabular}

Table 13: Question 13: I read with the refreshable braille display all day long

\begin{tabular}{lcr}
\hline \multicolumn{1}{c}{ Response } & Frequency & Percent \\
\hline This is very unlike me & $\mathbf{2 9}$ & $\mathbf{3 7 . 7 \%}$ \\
$\begin{array}{l}\text { This is somewhat unlike } \\
\text { me }\end{array}$ & 10 & $13.0 \%$ \\
$\begin{array}{l}\text { This is neither like me nor } \\
\text { unlike me } \\
\text { This is sort of like me }\end{array}$ & 8 & $10.4 \%$ \\
$\begin{array}{l}\text { This is very much like me } \\
\text { Total }\end{array}$ & 18 & $23.4 \%$ \\
\hline \hline
\end{tabular}


Table 14: Question 14: I don't like to read long books on a 32-cell braille display

\begin{tabular}{lcr}
\hline \hline \multicolumn{1}{c}{ Response } & Frequency & Percent \\
\hline This is very unlike me & 19 & $24.7 \%$ \\
$\begin{array}{l}\text { This is somewhat unlike } \\
\text { me }\end{array}$ & 4 & $5.2 \%$ \\
$\begin{array}{l}\text { This is neither like me nor } \\
\text { unlike me } \\
\text { This is sort of like me }\end{array}$ & 17 & $22.1 \%$ \\
$\begin{array}{l}\text { This is very much like } \\
\text { me } \\
\text { Total }\end{array}$ & 11 & $14.3 \%$ \\
\hline \hline
\end{tabular}

Given the number of times that students mentioned using a braille PDA and singled it out as one of the devices most often used earlier in this survey, it is not surprising that $49.4 \%$ of students responded in Question 1 that they use a braille notetaker to do most of their schoolwork. Question 3, which is about the use of paper braille, will be discussed again later in this chapter as it needs further analysis, specifically to examine the use of paper braille in relation to other variables such as age and grade. Students seemed to feel that having braille is useful for difficult tasks that require close attention to detail (Question 10 and 11), but perhaps not with a refreshable braille display (Questions 13 and 14). These results support the hypotheses made on the basis of the interview data. 


\subsubsection{Use of speech access and other electronic methods}

The next subset of questions refers to the use of speech access and electronic materials in general. These were represented in the survey by Questions 2, 4, 5, 9, 12, and 15. Again the most frequent response has been bolded in the tables that follow.

Table 15: Question 2: I use a computer with speech to do most of my work

\begin{tabular}{lcr}
\hline \multicolumn{1}{c}{ Response } & Frequency & Percent \\
\hline This is very unlike me & 4 & $5.2 \%$ \\
This is somewhat unlike & 6 & $7.8 \%$ \\
me & & \\
$\begin{array}{l}\text { This is neither like me nor } \\
\text { unlike me }\end{array}$ & 4 & $5.2 \%$ \\
This is sort of like me & 22 & $28.6 \%$ \\
This is very much like me & $\mathbf{4 0}$ & $\mathbf{5 1 . 9 \%}$ \\
Missing & 1 & $1.3 \%$ \\
Total & 77 & $100 \%$ \\
\hline \hline
\end{tabular}


Table 16: Question 4: I have DAISY files of all my textbooks

\begin{tabular}{lcr}
\hline \multicolumn{1}{c}{ Response } & Frequency & Percent \\
\hline This is very unlike me & $\mathbf{4 1}$ & $\mathbf{5 3 . 2 \%}$ \\
$\begin{array}{l}\text { This is somewhat unlike } \\
\text { me }\end{array}$ & 8 & $10.4 \%$ \\
$\begin{array}{l}\text { This is neither like me nor } \\
\text { unlike me } \\
\text { This is sort of like me }\end{array}$ & 3 & $3.9 \%$ \\
$\begin{array}{l}\text { This is very much like me } \\
\text { Missing }\end{array}$ & 7 & $15 \%$ \\
Total & 3 & $9.1 \%$ \\
\hline \hline
\end{tabular}

Table 17: Question 5: I'm finding that I'm reading fewer and fewer books tactually; I don't really use paper braille anymore

\begin{tabular}{lrr}
\hline \multicolumn{1}{c}{ Response } & Frequency & Percent \\
\hline This is very unlike me & 21 & $27.3 \%$ \\
$\begin{array}{l}\text { This is somewhat unlike } \\
\text { me }\end{array}$ & 11 & $14.3 \%$ \\
$\begin{array}{l}\text { This is neither like me nor } \\
\text { unlike me } \\
\text { This is sort of like me }\end{array}$ & 5 & $6.5 \%$ \\
$\begin{array}{l}\text { This is very much like me } \\
\text { Missing }\end{array}$ & $\mathbf{2 2}$ & $\mathbf{2 8 . 6 \%}$ \\
Total & 17 & $22.1 \%$ \\
\hline \hline
\end{tabular}


Table 18: Question 9: If I want to read something long it's going to be time consuming, so I'll just listen to it

\begin{tabular}{lcr}
\hline \multicolumn{1}{c}{ Response } & Frequency & Percent \\
\hline This is very unlike me & 7 & $9.1 \%$ \\
This is somewhat unlike me & 7 & $9.1 \%$ \\
$\begin{array}{l}\text { This is neither like me nor } \\
\text { unlike me } \\
\text { This is sort of like me }\end{array}$ & 6 & $7.8 \%$ \\
$\begin{array}{l}\text { This is very much like me } \\
\text { Total }\end{array}$ & 17 & $22.1 \%$ \\
\hline \hline
\end{tabular}

Table 19: Question 12: I found that using speech was a lot faster than trying to read the braille with the display

\begin{tabular}{lcr}
\hline \multicolumn{1}{c}{ Response } & Frequency & Percent \\
\hline This is very unlike me & 7 & $9.1 \%$ \\
$\begin{array}{l}\text { This is somewhat unlike } \\
\text { me }\end{array}$ & 5 & $6.5 \%$ \\
$\begin{array}{l}\text { This is neither like me nor } \\
\text { unlike me } \\
\text { This is sort of like me }\end{array}$ & 12 & $15.6 \%$ \\
$\begin{array}{l}\text { This is very much like me } \\
\text { Total }\end{array}$ & 18 & $23.4 \%$ \\
\hline \hline
\end{tabular}


Table 20: Question 15: I base what device to use on the particular assignment

\begin{tabular}{lcr}
\hline \multicolumn{1}{c}{ Response } & Frequency & Percent \\
\hline This is very unlike me & 4 & $5.2 \%$ \\
This is somewhat unlike & 2 & $2.6 \%$ \\
me & & \\
This is neither like me nor \\
unlike me \\
This is sort of like me & 3 & $3.9 \%$ \\
$\begin{array}{l}\text { This is very much like me } \\
\text { Missing }\end{array}$ & 13 & $16.9 \%$ \\
Total & 54 & $\mathbf{7 0 . 1 \%}$ \\
\hline \hline
\end{tabular}

Similar to the responses to Question 1, given the frequency with which screen reading software was mentioned by students as the device often used to do school work, it makes sense that a high percentage (51.9\%) would agree strongly with the statement in Question 2. Students who were interviewed stated that they would use speech access because it was faster, particularly for assignments that simply required reading, as opposed to studying for a test. The results of questions 9 and 12 appear to verify this theme from the interviews as $74 \%$ of the students said it was "very much" or "sort of" like them to use speech for long documents or to save time. The theme of choice-making that was discussed in chapter 4 was verified by the strong response to 
question 15 in which $87 \%$ of students said it was "very much" or "sort of" like them to choose a device or tool based on the assignment they have to accomplish.

\subsubsection{Mathematics and foreign language materials}

Two special cases need their own analysis as indicated in the interviews: use of paper braille for mathematics and for studying foreign language. Questions 6, 7, and 8 deal with these subjects specifically and the tables of results are shown here.

Table 21: Question 6: Any of my math books are going to be paper braille

\begin{tabular}{lcr}
\hline \hline \multicolumn{1}{c}{ Response } & Frequency & Percent \\
\hline This is very unlike me & 14 & $18.2 \%$ \\
$\begin{array}{l}\text { This is neither like me nor } \\
\text { unlike me } \\
\text { This is sort of like me }\end{array}$ & 5 & $6.5 \%$ \\
This is very much like me & 4 & $5.2 \%$ \\
Total & 54 & $\mathbf{7 0 . 1 \%}$ \\
\hline \hline
\end{tabular}


Table 22: Question 7: I find it easier to use my computer and listen to math

\begin{tabular}{lrr}
\hline \hline \multicolumn{1}{c}{ Response } & Frequency & Percent \\
\hline This is very unlike me & 54 & $\mathbf{7 0 . 1 \%}$ \\
$\begin{array}{l}\text { This is somewhat unlike } \\
\text { me }\end{array}$ & 5 & $6.5 \%$ \\
$\begin{array}{l}\text { This is neither like me nor } \\
\text { unlike me } \\
\text { This is sort of like me }\end{array}$ & 10 & $13.0 \%$ \\
$\begin{array}{l}\text { This is very much like me } \\
\text { Total }\end{array}$ & 6 & $7.8 \%$ \\
\hline \hline
\end{tabular}

Table 23: Question 8: Whenever I do foreign languages then it's essential to have paper braille

\begin{tabular}{lrr}
\hline \multicolumn{1}{c}{ Response } & Frequency & Percent \\
\hline This is very unlike me & 12 & $15.6 \%$ \\
$\begin{array}{l}\text { This is somewhat unlike } \\
\text { me }\end{array}$ & 5 & $6.5 \%$ \\
$\begin{array}{l}\text { This is neither like me nor } \\
\text { unlike me } \\
\text { This is sort of like me }\end{array}$ & 11 & $14.3 \%$ \\
$\begin{array}{l}\text { This is very much like } \\
\text { me }\end{array}$ & 13 & $16.9 \%$ \\
Missing & 35 & $\mathbf{4 5 . 5 \%}$ \\
Total & 1 & $1.3 \%$ \\
\hline \hline
\end{tabular}


These results also give credence to the interview finding that students strongly prefer to have certain materials, specifically mathematics, in paper braille as opposed to electronic sources (refreshable braille or speech access). Fully three-quarters of respondents stated that using paper braille for math was "very much" or "sort of" like them. While the numbers were not as large for foreign language books to be in braille as for mathematics and science materials, $62.4 \%$ of students still said that using paper was "very much" or "sort of" their practice. Several students mentioned in the optional Comments area of the survey that they were not currently taking a foreign language class, which may account for the number of students who were neutral on this item or said it did not describe them.

\subsubsection{Use of the Slate and stylus}

Because of the strong reaction toward the use of the slate and stylus in the interviews as recounted in Chapter 4, two items specifically about the slate and stylus, Questions 16 and 17, were added to the survey. These results are shown in Tables 24 and 25. 
Table 24: Question 16: I've never had any practical use for the slate and stylus

\begin{tabular}{lrr}
\hline \hline \multicolumn{1}{c}{ Response } & Frequency & Percent \\
\hline This is very unlike me & 13 & $16.9 \%$ \\
$\begin{array}{l}\text { This is somewhat unlike } \\
\text { me }\end{array}$ & 6 & $7.8 \%$ \\
$\begin{array}{l}\text { This is neither like me nor } \\
\text { unlike me } \\
\text { This is sort of like me }\end{array}$ & 4 & $5.2 \%$ \\
$\begin{array}{l}\text { This is very much like } \\
\text { me }\end{array}$ & 14 & $18.2 \%$ \\
Missing & 39 & $\mathbf{5 0 . 6 \%}$ \\
Total & 1 & $1.3 \%$ \\
\hline \hline
\end{tabular}

Table 25: Question 17: I use the slate and stylus for short tasks like taking down people's phone numbers

\begin{tabular}{lrr}
\hline \multicolumn{1}{c}{ Response } & Frequency & Percent \\
\hline This is very unlike me & $\mathbf{4 8}$ & $\mathbf{6 2 . 3 \%}$ \\
$\begin{array}{l}\text { This is somewhat unlike } \\
\text { me }\end{array}$ & 6 & $7.8 \%$ \\
$\begin{array}{l}\text { This is neither like me nor } \\
\text { unlike me } \\
\text { This is sort of like me }\end{array}$ & 4 & $5.2 \%$ \\
$\begin{array}{l}\text { This is very much like me } \\
\text { Total }\end{array}$ & 9 & $11.7 \%$ \\
\hline \hline
\end{tabular}


The results of these two questions lend support to the findings of the interviews that the slate and stylus are not widely used tools. Two-thirds of the students responded that it was "very much" or "sort of" like them to not use the slate, and a similar number said that it was "very unlike" or "somewhat unlike" them to use the slate even for short tasks. Opinions and attitudes about the slate and stylus were asked in the Preferences section of the survey and will be discussed later in this chapter.

\subsubsection{Engaging in Specific multiliteracy tasks}

As stated earlier, the only tasks mentioned in the interviews that could be considered multiliteracy activities were the use of PowerPoint, blogs and email. Questions probing these specific practices were added to the survey, and the results of Questions 26, 27, 28, and 29 are below.

Table 26: Question 25: I usually had to have some help from a sighted person when using PowerPoint

\begin{tabular}{lcr}
\hline \multicolumn{1}{c}{ Response } & Frequency & Percent \\
\hline This is very unlike me & 9 & $11.7 \%$ \\
$\begin{array}{l}\text { This is somewhat unlike } \\
\text { me }\end{array}$ & 11 & $14.3 \%$ \\
$\begin{array}{l}\text { This is neither like me nor } \\
\text { unlike me } \\
\text { This is sort of like me }\end{array}$ & 16 & $20.8 \%$ \\
$\begin{array}{l}\text { This is very much like } \\
\text { me } \\
\text { Total }\end{array}$ & 12 & $15.6 \%$ \\
\hline \hline
\end{tabular}


Table 27: Question 26: I managed to do PowerPoint by myself with no problem

\begin{tabular}{lrr}
\hline \hline \multicolumn{1}{c}{ Response } & Frequency & Percent \\
\hline This is very unlike me & 34 & $\mathbf{4 4 . 2 \%}$ \\
$\begin{array}{l}\text { This is somewhat unlike } \\
\text { me }\end{array}$ & 6 & $7.8 \%$ \\
$\begin{array}{l}\text { This is neither like me nor } \\
\text { unlike me } \\
\text { This is sort of like me }\end{array}$ & 14 & $18.2 \%$ \\
$\begin{array}{l}\text { This is very much like me } \\
\text { Missing }\end{array}$ & 17 & $22.1 \%$ \\
Total & 1 & $6.5 \%$ \\
\hline \hline
\end{tabular}

Table 28: Question 27: I do have my own blog

\begin{tabular}{lcr}
\hline \multicolumn{1}{c}{ Response } & Frequency & Percent \\
\hline This is very unlike me & $\mathbf{4 6}$ & $\mathbf{5 9 . 7 \%}$ \\
$\begin{array}{l}\text { This is somewhat unlike } \\
\text { me }\end{array}$ & 2 & $2.6 \%$ \\
$\begin{array}{l}\text { This is neither like me nor } \\
\text { unlike me } \\
\text { This is sort of like me }\end{array}$ & 4 & $5.2 \%$ \\
$\begin{array}{l}\text { This is very much like me } \\
\text { Total }\end{array}$ & 10 & $13.0 \%$ \\
\hline \hline
\end{tabular}


Table 29: Question 28: My teachers email me my assignments

\begin{tabular}{|c|c|c|}
\hline Response & Frequency & Percent \\
\hline This is very unlike me & 9 & $11.7 \%$ \\
\hline $\begin{array}{l}\text { This is somewhat unlike } \\
\text { me }\end{array}$ & 6 & $7.8 \%$ \\
\hline $\begin{array}{l}\text { This is neither like me nor } \\
\text { unlike me }\end{array}$ & 7 & $9.1 \%$ \\
\hline This is sort of like me & 27 & $35.1 \%$ \\
\hline $\begin{array}{l}\text { This is very much like } \\
\text { me }\end{array}$ & 28 & $36.4 \%$ \\
\hline Total & 77 & $100 \%$ \\
\hline
\end{tabular}

The independent use of PowerPoint appears to be problematic for the majority of students who responded to this question with more than half indicating that they require some sort of assistance to use this software. This finding supports similar responses from the students who were interviewed. One student wrote in the optional Comments area at the end of the Practices section that while he needed visual assistance to prepare the PowerPoint slides, he was able to give the presentation itself independently, a distinction he felt was important to note.

Only a third of the students reported having their own blog, but it should be remembered that students were asked to consider the questions in the context of school tasks. It may be that additional students have a personal blog or participate in social networking.

A large majority of students (71.5\%) responded positively by saying "very much" or "sort of" like them to the question of whether they have teachers email their assignments. This was a larger percentage of students than those interviewed. 


\subsection{HOW DO STUDENTS LEARN THESE PRACTICES?}

To answer the second research question, "How do young adults who are blind learn new literacy practices using assistive technology?" items from the interviews were added to both the Practices and the Preferences sections of the survey. Questions 18, 19, 20, 21, 22, 23, and 24 in the Practices set deal specifically with how students learned to use technology. Questions 53, 54, 55, and 56 from the Preferences section involve the role of TVIs in learning to use technology. These items are shown in the tables below in two sets: the first set dealt with the issues of from whom and where they learned to use technology; the second set probed their opinions on the role of the TVI in technology instruction based on their own experiences.

\subsubsection{How they learned}

The following seven tables present the responses to the questions that probe the students' experiences in learning technology as far as the important people involved and the settings in which they learned. 
Table 30: Question 18: I learned the bulk of the technology I use all by myself

\begin{tabular}{lcr}
\hline \hline \multicolumn{1}{c}{ Response } & Frequency & Percent \\
\hline This is very unlike me & 19 & $24.7 \%$ \\
$\begin{array}{l}\text { This is somewhat unlike } \\
\text { me }\end{array}$ & 11 & $14.3 \%$ \\
$\begin{array}{l}\text { This is neither like me nor } \\
\text { unlike me } \\
\text { This is sort of like me }\end{array}$ & 5 & $6.5 \%$ \\
$\begin{array}{l}\text { This is very much like me } \\
\text { Total }\end{array}$ & $\mathbf{2 4}$ & $\mathbf{3 1 . 2 \%}$ \\
\hline \hline
\end{tabular}

Table 31: Question 19: The technology specialist from the school for the blind taught me technology

\begin{tabular}{|c|c|c|}
\hline Response & Frequency & Percent \\
\hline This is very unlike me & 31 & $40.3 \%$ \\
\hline $\begin{array}{l}\text { This is somewhat unlike } \\
\text { me }\end{array}$ & 7 & $9.1 \%$ \\
\hline $\begin{array}{l}\text { This is neither like me nor } \\
\text { unlike me }\end{array}$ & 6 & $7.8 \%$ \\
\hline This is sort of like me & 14 & $18.2 \%$ \\
\hline This is very much like me & 19 & $24.7 \%$ \\
\hline Total & 77 & $100 \%$ \\
\hline
\end{tabular}


Table 32: Question 20: My TVI got me started on technology

\begin{tabular}{lcr}
\hline \hline \multicolumn{1}{c}{ Response } & Frequency & Percent \\
\hline This is very unlike me & 12 & $15.6 \%$ \\
$\begin{array}{l}\text { This is somewhat unlike } \\
\text { me }\end{array}$ & 1 & $1.3 \%$ \\
$\begin{array}{l}\text { This is nei like me nor } \\
\text { unlike me }\end{array}$ & 5 & $6.5 \%$ \\
$\begin{array}{l}\text { This is sort of like me } \\
\text { This is very much like } \\
\text { me } \\
\text { Total }\end{array}$ & 17 & $22.1 \%$ \\
\hline \hline
\end{tabular}

Table 33: Question 21: I didn't learn technology in school, I went to a center

\begin{tabular}{lcr}
\hline \hline \multicolumn{1}{c}{ Response } & Frequency & Percent \\
\hline This is very unlike me & 56 & $\mathbf{7 2 . 7 \%}$ \\
This is somewhat unlike me & 8 & $10.4 \%$ \\
$\begin{array}{l}\text { This is neither like me nor } \\
\text { unlike me } \\
\text { This is sort of like me }\end{array}$ & 5 & $6.5 \%$ \\
Missing & 6 & $7.8 \%$ \\
Total & 2 & $2.6 \%$ \\
\hline \hline
\end{tabular}


Table 34: Question 22: I have friends who know their technology better than me so I'll just ask them how to do something

\begin{tabular}{lrr}
\hline \hline \multicolumn{1}{c}{ Response } & Frequency & Percent \\
\hline This is very unlike me & $\mathbf{2 3}$ & $\mathbf{2 9 . 9 \%}$ \\
$\begin{array}{l}\text { This is somewhat unlike } \\
\text { me } \\
\text { This is neither like me nor } \\
\text { unlike me } \\
\text { This is sort of like me }\end{array}$ & 8 & $10.4 \%$ \\
$\begin{array}{l}\text { This is very much like me } \\
\text { Total }\end{array}$ & 18 & $10.4 \%$ \\
\hline \hline
\end{tabular}

Table 35: Question 23: My TVI taught me everything I know about technology

\begin{tabular}{lcr}
\hline \multicolumn{1}{c}{ Response } & Frequency & Percent \\
\hline This is very unlike me & 37 & $\mathbf{4 8 . 1 \%}$ \\
$\begin{array}{l}\text { This is somewhat unlike } \\
\text { me }\end{array}$ & 11 & $14.3 \%$ \\
$\begin{array}{l}\text { This is neither like me nor } \\
\text { unlike me } \\
\text { This is sort of like me }\end{array}$ & 10 & $13.0 \%$ \\
$\begin{array}{l}\text { This is very much like me } \\
\text { Missing }\end{array}$ & 14 & $18.2 \%$ \\
Total & 3 & $3.9 \%$ \\
\hline \hline
\end{tabular}


Table 36: Question 24: I don't really have any blind friends to ask about technology

\begin{tabular}{lrr}
\hline \multicolumn{1}{c}{ Response } & Frequency & Percent \\
\hline This is very unlike me & 53 & $\mathbf{6 8 . 8 \%}$ \\
$\begin{array}{l}\text { This is somewhat unlike } \\
\text { me }\end{array}$ & 6 & $7.8 \%$ \\
$\begin{array}{l}\text { This is neither like me nor } \\
\text { unlike me } \\
\text { This is sort of like me }\end{array}$ & 6 & $7.8 \%$ \\
$\begin{array}{l}\text { This is very much like me } \\
\text { Missing }\end{array}$ & 4 & $5.2 \%$ \\
Total & 1 & $9.1 \%$ \\
\hline \hline
\end{tabular}

Fully half of the students indicated that learning technology by themselves was either "very much" or "sort of" like them, with the mode in the "sort of" category. Both in the interviews and in the optional Comments area of the survey, students stated that some devices, such as the BrailleNote, were easy to learn on their own but other technology needed more instruction.

The TVI was responsible for introducing the respondents to technology in over half of the cases (actually, over three-quarters if the categories "very much" or "sort of" are added together). However, it was unlikely that the TVI was the sole instructor as a much smaller percentage of students indicated that the TVI taught them everything they knew, and the majority (48.1\%) stated it was "very unlike" them. The role of the TVI is examined again in the next set of questions. 
A surprising finding to this researcher was how few students indicated that they had gone to a center-based program to learn technology skills. While the majority of students who were interviewed stated that they had attended a special program outside of school to learn technology skills, only $7.8 \%$ of survey takers said that it was "very much" like them, and $72.7 \%$ responded that going to a center was "very unlike" them. It's possible that students who took the survey did not understand the reference to "center" in the question, or it's possible that the number of students interviewed who learned outside school was just an anomaly. This is one area in which the interview findings were not supported by the survey results.

The role that friends play in learning technology was less clear in the survey than in the interviews. While two-thirds of the students strongly disagreed with the statement that they had no blind friends to ask about technology, the responses to Question 22, "I have friends who know their technology better than me so I'll just ask them how to do something," were widely dispersed. In fact, the most frequent answer was "this is very unlike me" (29.9\%) although "this is very much like me" was close behind at $26 \%$. It's possible that the wording of the question, which presupposes that a friend is "better" at technology than the respondent, led to a lower response-perhaps the friend is "equally skilled" or "as interested" in technology. Of course, it is also possible that for this group of respondents, the role of friends in learning technology was not as critical as it was for the students who were interviewed.

\subsubsection{Role of TVI}

As stated above, Questions 53, 54, 55, 56 (in Set 2, Preferences, these questions were numbered 25, 26, 27, and 28) dealt specifically with the role of the TVI in learning technology. These items 
were taken primarily from the part of the interviews where students were asked to give advice to future TVIs. Tables 37, 38, 39 and 40 below illustrate the range of responses to these questions.

Table 37: Question 53: TVIs should do their research before buying any sort of assistive technology for a student because a kid doesn't really know all the options available

\begin{tabular}{lrr}
\hline \hline \multicolumn{1}{c}{ Response } & Frequency & Percent \\
\hline I strongly disagree & 4 & $5.2 \%$ \\
I sort of disagree & 8 & $10.4 \%$ \\
I do not agree or disagree & 9 & $11.7 \%$ \\
I sort of agree & 12 & $15.6 \%$ \\
I strongly agree & $\mathbf{4 4}$ & $\mathbf{5 7 . 1 \%}$ \\
Total & 77 & $100 \%$ \\
\hline \hline
\end{tabular}

Table 38: Question 54: I think that it's important that the students have a say in the technology bought for them even if they're really young

\begin{tabular}{lrr}
\hline \hline \multicolumn{1}{r}{ Response } & Frequency & Percent \\
\hline I strongly disagree & 2 & $2.6 \%$ \\
I sort of disagree & 5 & $6.5 \%$ \\
I do not agree or & 8 & $10.4 \%$ \\
disagree & 29 & $37.7 \%$ \\
I sort of agree & $\mathbf{3 3}$ & $\mathbf{4 2 . 9 \%}$ \\
I strongly agree & 77 & $100 \%$ \\
Total & \\
\hline \hline
\end{tabular}


Table 39: Question 55: TVIs should only know about the most popular devices so they can teach their students how to use them

\begin{tabular}{lrr}
\hline \hline \multicolumn{1}{c}{ Response } & Frequency & Percent \\
\hline I strongly disagree & $\mathbf{3 1}$ & $\mathbf{4 0 . 3 \%}$ \\
I sort of disagree & 21 & $27.3 \%$ \\
I do not agree or & 5 & $6.5 \%$ \\
disagree & 14 & $18.2 \%$ \\
I sort of agree & 5 & $6.5 \%$ \\
I strongly agree & 1 & $1.3 \%$ \\
Missing & 77 & $100 \%$ \\
Total &
\end{tabular}

Table 40: Question 56: I think that TVIs should know about every technology device that's out there and keep up with it

\begin{tabular}{lcr}
\hline \hline \multicolumn{1}{c}{ Response } & $\begin{array}{c}\text { Frequenc } \\
\text { y }\end{array}$ & Perce \\
\hline I strongly disagree & 2 & $2.6 \%$ \\
I sort of disagree & 4 & $5.2 \%$ \\
I do not agree or & & $5.2 \%$ \\
disagree & 4 & $20.8 \%$ \\
I sort of agree & 16 & $\mathbf{6 6 . 2 \%}$ \\
I strongly agree & $\mathbf{5 1}$ & $100 \%$ \\
Total & 77 & \\
\hline \hline
\end{tabular}

While the researcher saw questions 53 and 54 as opposed to one another since the first question assumes that students don't know much about technology, and yet the second question insists that students still have a say in the technology selected for them, the respondents did not appear to see these items as diametrically opposed. They responded favorably to both statements, with 57.1\% saying that they agreed strongly with the statement that TVIs should do their 
research before purchasing products, and $42.9 \%$ agreeing strongly that students should have a say in what is bought.

While students who were interviewed were evenly split on the question of what TVIs should know about technology, the responses to the survey were much clearer. $87 \%$ of students agreed "strongly" or "sort of" that TVIs should know about a wide variety of technology devices and what new devices are offered. About two-thirds of the students did not feel that for TVIs, simply knowing the most popular devices was enough. For instance, one student added the following comment to the survey:

A TVI should never be responsible for a student's proficiency in assistive technology. Students should learn that, although a TVI can provide needed products and basic foundational training, most specific uses for said technology can only be self-taught. As students get older, they need to learn how to advocate for the technology they need-if that skill is not acquired at an early age, good luck negotiating with a rehab counselor or college DRC. A TVI can assist and recommend, but the primary roll [sic] of a TVI is to facilitate, not to educate.

\subsection{PREFERENCES RELATED TO BRAILLE AND TECHNOLOGY}

The third research question was, "What are the attitudes of youth towards hard-copy braille, and access technology?" To answer this question, quotes from the interviews that expressed opinions about braille and electronic devices were selected as survey items. The 
responses to these items are presented below in sets regarding preferences for paper and refreshable braille, speech access, the slate and stylus, the use of proprietary and specialized devices, and the role of technology in access to information.

\subsubsection{Preferences for braille}

A number of questions probed students' attitudes about using braille. Most of the questions did not differentiate between reading braille on paper and reading electronically with a refreshable braille display, as the interviews indicated that in most instances the students themselves didn't differentiate between the two. Questions 29, 30, 31, 32, 33, 34, 36, 49 probed the issue of braille usage for school work in several ways. (In the survey, these questions were in Set 2 and numbered as 1, 2, 3, 4, 5, 6, 8, and 21.) Tables 41 through 48 below illustrate the responses to these eight questions.

Table 41: Question 29: I wasn't very enthusiastic about learning braille

\begin{tabular}{lrr}
\hline \hline \multicolumn{1}{c}{ Response } & Frequency & \multicolumn{1}{c}{ Percent } \\
\hline I strongly disagree & 33 & $\mathbf{4 2 . 9 \%}$ \\
I sort of disagree & 14 & $18.2 \%$ \\
I do not agree or disagree & 8 & $10.4 \%$ \\
I sort of agree & 13 & $16.9 \%$ \\
I strongly agree & 8 & $10.4 \%$ \\
Missing & 1 & $1.3 \%$ \\
Total & 77 & $100 \%$ \\
\hline \hline
\end{tabular}


Table 42: Question 30: I love reading and writing braille and that's how I work best

\begin{tabular}{lrr}
\hline \hline \multicolumn{1}{c}{ Response } & Frequency & Percent \\
\hline I strongly disagree & 6 & $7.8 \%$ \\
I sort of disagree & 8 & $10.4 \%$ \\
I do not agree or disagree & 15 & $19.5 \%$ \\
I sort of agree & 17 & $22.1 \%$ \\
I strongly agree & $\mathbf{3 1}$ & $\mathbf{4 0 . 3 \%}$ \\
Total & 77 & $100 \%$ \\
\hline \hline
\end{tabular}

Table 43: Question 31: I try to use braille as little as I can

\begin{tabular}{lrr}
\hline \hline \multicolumn{1}{c}{ Response } & Frequency & Percent \\
\hline I strongly disagree & $\mathbf{4 2}$ & $\mathbf{5 4 . 5 \%}$ \\
I sort of disagree & 12 & $15.6 \%$ \\
I do not agree or disagree & 9 & $11.7 \%$ \\
I sort of agree & 7 & $9.1 \%$ \\
I strongly agree & 7 & $9.1 \%$ \\
Total & 77 & $100 \%$ \\
\hline \hline
\end{tabular}

Table 44: Question 32: Braille is the foundation of a blind person's education

\begin{tabular}{lrr}
\hline \hline \multicolumn{1}{c}{ Response } & Frequency & \multicolumn{1}{c}{ Percent } \\
\hline I strongly disagree & 2 & $2.6 \%$ \\
I do not agree or disagree & 6 & $7.8 \%$ \\
I sort of agree & 8 & $10.4 \%$ \\
I strongly agree & $\mathbf{6 0}$ & $\mathbf{7 7 . 9 \%}$ \\
Missing & 1 & $1.3 \%$ \\
Total & 77 & $100 \%$ \\
\hline \hline
\end{tabular}


Table 45: Question 33: I didn't like to read braille because I thought it was slow and inefficient

\begin{tabular}{lrr}
\hline \hline \multicolumn{1}{c}{ Response } & Frequency & Percent \\
\hline I strongly disagree & $\mathbf{3 7}$ & $\mathbf{4 8 . 1 \%}$ \\
I sort of disagree & 8 & $10.4 \%$ \\
I do not agree or disagree & 11 & $14.3 \%$ \\
I sort of agree & 13 & $16.9 \%$ \\
I strongly agree & 8 & $10.4 \%$ \\
Total & 77 & $100 \%$ \\
\hline \hline
\end{tabular}

Table 46: Question 34: I find that when I'm reading braille I process and comprehend things better than when I'm listening

\begin{tabular}{lrr}
\hline \hline \multicolumn{1}{c}{ Response } & Frequency & Percent \\
\hline I strongly disagree & 13 & $16.9 \%$ \\
I sort of disagree & 11 & $14.3 \%$ \\
I do not agree or disagree & 10 & $13.0 \%$ \\
I sort of agree & 17 & $22.1 \%$ \\
I strongly agree & $\mathbf{2 5}$ & $\mathbf{3 2 . 5 \%}$ \\
Missing & 1 & $1.3 \%$ \\
Total & 77 & $100 \%$ \\
\hline \hline
\end{tabular}


Table 47: Question 36: I think reading braille is a lot slower than using speech software

\begin{tabular}{lrr}
\hline \hline \multicolumn{1}{c}{ Response } & Frequency & Percent \\
\hline I strongly disagree & 11 & $14.3 \%$ \\
I sort of disagree & 7 & $9.1 \%$ \\
I do not agree or disagree & 12 & $15.6 \%$ \\
I sort of agree & 16 & $20.8 \%$ \\
I strongly agree & $\mathbf{3 1}$ & $\mathbf{4 0 . 3 \%}$ \\
Total & 77 & $100 \%$ \\
\hline \hline
\end{tabular}

Table 48: Question 49: It's important to read braille because it teaches you how to spell and punctuate

\begin{tabular}{lrr}
\hline \hline \multicolumn{1}{c}{ Response } & Frequency & \multicolumn{1}{c}{ Percent } \\
\hline I strongly disagree & 2 & $2.6 \%$ \\
I sort of disagree & 2 & $2.6 \%$ \\
I do not agree or disagree & 3 & $3.9 \%$ \\
I sort of agree & 11 & $14.3 \%$ \\
I strongly agree & $\mathbf{5 7}$ & $\mathbf{7 4 . 0 \%}$ \\
Missing & 2 & $2.6 \%$ \\
Total & 77 & $100 \%$ \\
\hline \hline
\end{tabular}

Close to $80 \%$ of the students agreed strongly with the statement: "Braille is the foundation of a blind person's education." When combined with the students who selected the answer "I sort of agree" that percentage reaches $88.3 \%$. Clearly these students valued the role of braille literacy in their lives. The same percentage "strongly" or "sort of" agreed that braille teaches spelling and punctuation (question 49) and that these were important skills.

But while the large majority of students saw the benefits of braille literacy, their views were nuanced. Only $40.3 \%$ of students strongly agreed (and an additional $22.1 \%$ sort of agreed) with the statement: "I love reading and writing braille and that's how I work best." This item was 
specifically worded in that way to capture not only affection for braille, but also preference for braille as a learning medium. An almost identical percentage agreed with the statement: "I think reading braille is a lot slower than using speech software," indicating that these participants also recognize the disadvantages of using braille identified by the students who were interviewed.

The optional Comments area of the Preferences section of the survey allowed students to provide additional context for their ratings of the survey items. Many of the comments mirror those from the interviewed students in Phase I of this study. For example, one student wrote:

I think that Braille is an important skill to have and to know even though I and most other blind students don't use it. I am a legally blind student and it is so much faster for me to read Braille than to read print. However, it is so much faster to read listening to a speech output than reading Braille. However, in my case, I comprehend a lot faster the material if I read it on Braille than if I just hear it. So I decided to marry the two. I take notes on the university with my computer and I read the majority of my books on my computer, however I create outlines and summaries on Braille to help me study.

\subsubsection{Preferences regarding speech and other technology}

A number of items on the survey directly related to the use of speech access for school work, whether through the use of screen reading software on the computer or with book reader devices such as the Victor. Based on comments in the interviews, Questions 35, 37, 38, 39, 40, 41, and 42 were added to the survey (numbered as Questions 7, 9, 10, 11, 12, 13, and 14 in Set 2). Within this set are three questions specifically about the use of PowerPoint; since students used 
speech access to use this program, they are included in the discussion about speech access rather than pulled out separately.

Table 49: Question 35: Speech allows me to focus on the story more

\begin{tabular}{lrr}
\hline \hline \multicolumn{1}{c}{ Response } & Frequency & Percent \\
\hline I strongly disagree & 9 & $11.7 \%$ \\
I sort of disagree & 10 & $13.0 \%$ \\
I do not agree or disagree & 14 & $18.2 \%$ \\
I sort of agree & 16 & $20.8 \%$ \\
I strongly agree & $\mathbf{2 8}$ & $\mathbf{3 6 . 4 \%}$ \\
Total & 77 & $100 \%$ \\
\hline \hline
\end{tabular}

Table 50: Question 37: I don't really like to listen to synthetic speech

\begin{tabular}{lrr}
\hline \hline \multicolumn{1}{c}{ Response } & Frequency & Percent \\
\hline I strongly disagree & $\mathbf{2 2}$ & $\mathbf{2 8 . 6 \%}$ \\
I sort of disagree & 17 & $22.1 \%$ \\
I do not agree or disagree & 10 & $13.0 \%$ \\
I sort of agree & 17 & $22.1 \%$ \\
I strongly agree & 11 & $14.3 \%$ \\
Total & 77 & $100 \%$ \\
\hline \hline
\end{tabular}

Table 51: Question 38: I'm a huge supporter of mainstream products rather than devices designed for blind people

\begin{tabular}{lrr}
\hline \hline \multicolumn{1}{c}{ Response } & Frequency & Percent \\
\hline I strongly disagree & 20 & $26.0 \%$ \\
I sort of disagree & 10 & $13.0 \%$ \\
I do not agree or & 32 & $\mathbf{4 1 . 6 \%}$ \\
disagree & 9 & $11.7 \%$ \\
I sort of agree & 6 & $7.8 \%$ \\
I strongly agree & 77 & $100 \%$ \\
Total & \\
\hline \hline
\end{tabular}


Table 52: Question 39: I think these new netbooks are taking the place of braille notetakers

\begin{tabular}{lrr}
\hline \hline \multicolumn{1}{c}{ Response } & Frequency & \multicolumn{1}{c}{ Percent } \\
\hline I strongly disagree & 17 & $22.1 \%$ \\
I sort of disagree & 12 & $15.6 \%$ \\
I do not agree or disagree & $\mathbf{2 8}$ & $\mathbf{3 6 . 4 \%}$ \\
I sort of agree & 9 & $11.7 \%$ \\
I strongly agree & 11 & $14.3 \%$ \\
Total & 77 & $100 \%$ \\
\hline \hline
\end{tabular}

Table 53: Question 40: I don't like PowerPoint because I have to rely on other people to use it

\begin{tabular}{lrr}
\hline \hline \multicolumn{1}{c}{ Response } & Frequency & Percent \\
\hline I strongly disagree & 15 & $19.5 \%$ \\
I sort of disagree & 10 & $13.0 \%$ \\
I do not agree or disagree & 14 & $18.2 \%$ \\
I sort of agree & 15 & $19.5 \%$ \\
I strongly agree & $\mathbf{2 3}$ & $\mathbf{2 9 . 9 \%}$ \\
Total & 77 & $100 \%$ \\
\hline \hline
\end{tabular}

Table 54: Question 41: It's gotten a lot easier to do PowerPoint with speech now than it used to

\begin{tabular}{lrr}
\hline \hline \multicolumn{1}{c}{ Response } & Frequency & Percent \\
\hline I strongly disagree & 15 & $19.5 \%$ \\
I sort of disagree & 8 & $10.4 \%$ \\
I do not agree or disagree & $\mathbf{2 6}$ & $\mathbf{3 3 . 8 \%}$ \\
I sort of agree & 12 & $15.6 \%$ \\
I strongly agree & 16 & $20.8 \%$ \\
Total & 77 & $100 \%$ \\
\hline \hline
\end{tabular}


Table 55: Question 42: PowerPoint with WindowEyes or JAWS is just too hard

\begin{tabular}{lrr}
\hline \multicolumn{1}{c}{ Response } & Frequency & \multicolumn{1}{c}{ Percent } \\
\hline I strongly disagree & 17 & $22.1 \%$ \\
I sort of disagree & 12 & $15.6 \%$ \\
I do not agree or disagree & $\mathbf{2 3}$ & $\mathbf{2 9 . 9 \%}$ \\
I sort of agree & 10 & $13.0 \%$ \\
I strongly agree & 12 & $15.6 \%$ \\
Total & 77 & $100 \%$ \\
\hline \hline
\end{tabular}

Responses to the survey confirmed the findings in the interviews about the role of speech access in students' abilities to complete school work efficiently. More than half of the students also disagreed "strongly" or "sort of" that they dislike the sound of synthetic speech and the same percentage agreed that it helps them focus on their work better.

Most students were neutral about the use of mainstream products rather than specialized devices. As one student put in the comments textbox: "After all, the most important objective is to get something that offers potential for a user-something that allows a student to communicate well with his or her peers, as well as bring potential and open up a way of independence." Another student noted, after giving an example of the technology devices most useful in his experience: "All I am trying to point out is that it is important to look at all available devices on the market, not just those that are more popular or are used by everyone else." There appeared to be a pragmatic approach to answering this question with an acknowledgement that many devices are available that might be useful. 
The questions that asked about the use of PowerPoint reaffirm findings from the interviews in that roughly half the students agreed to some extent with the statement that they needed assistance using PowerPoint, as opposed to about a third who disagreed. However the questions that asked the students' opinions about whether it had gotten easier or if it was still too difficult to use PowerPoint received responses that were more dispersed with the mode responses in the neutral "do not agree or disagree" category. While one or two students commented that they had not used PowerPoint, it is also possible that students were loathe to say that any particular task was "too hard" or that they didn't know enough about using the application to have an opinion.

\subsubsection{Preferences for the slate and stylus}

Questions that asked specifically about the students' opinions on the slate and stylus were added to the survey as Questions 43 and 44. (In the original survey, they were in Set 2, Preferences, and numbered 15 and 16.) Results are shown in the following tables.

Table 56: Question 43: I don't like the slate because it's much slower

\begin{tabular}{lrr}
\hline \hline \multicolumn{1}{c}{ Response } & Frequency & Percent \\
\hline I strongly disagree & 4 & $5.2 \%$ \\
I sort of disagree & 7 & $9.1 \%$ \\
I do not agree or disagree & 12 & $15.6 \%$ \\
I sort of agree & 15 & $19.5 \%$ \\
I strongly agree & $\mathbf{3 8}$ & $\mathbf{4 9 . 4 \%}$ \\
Missing & 1 & $1.3 \%$ \\
Total & 77 & $100 \%$ \\
\hline \hline
\end{tabular}


Table 57: Question 44: I'll never reject the importance of the slate and stylus

\begin{tabular}{lrr}
\hline \hline \multicolumn{1}{c}{ Response } & Frequency & Percent \\
\hline I strongly disagree & $\mathbf{1 9}$ & $\mathbf{2 4 . 7 \%}$ \\
I sort of disagree & 9 & $11.7 \%$ \\
I do not agree or disagree & 15 & $19.5 \%$ \\
I sort of agree & 17 & $22.1 \%$ \\
I strongly agree & 15 & $19.5 \%$ \\
Missing & 2 & $2.6 \%$ \\
Total & 77 & $100 \%$ \\
\hline \hline
\end{tabular}

Close to $70 \%$ of the students agreed to some extent that they felt writing with the slate and stylus was too slow, which could explain why so few reported using the device in the Practices set of survey questions.

It is interesting to note, however, that while so few students reported using the slate and stylus and the majority find it slow to use, there was not an overwhelming disregard for the device. The mode of responses was to strongly disagree with the statement: "I'll never reject the importance of the slate and stylus", suggesting that almost a quarter of the students (24.7\%) could do just that, that is, reject its importance. However, while 36.4\% of the students "strongly" or "sort of" disagreed with the statement, there were more who agreed with it: $41.6 \%$, either “strongly” or "sort of" agreed. The responses to this particular question were more dispersed than this researcher expected, possibly indicating a more ambivalent attitude about the device. While responding to question 43 as "strongly agree", one student also added the comment: "Although it may have practical applications and everyone should be taught how to use it." 


\subsubsection{Preferences for mathematics}

Two questions were added to the survey to capture specific attitudes about the role of braille and technology for mathematics instruction and materials. The results of Questions 45 and 46 are shown in Tables 58 and 59 below: (In the survey, these items were numbered in Set 2, Preferences, as Questions 17 and 18.)

Table 58: Question 45: I can't imagine how I would do math on the computer

\begin{tabular}{lrr}
\hline \hline \multicolumn{1}{c}{ Response } & Frequency & Percent \\
\hline I strongly disagree & 10 & $13.0 \%$ \\
I sort of disagree & 10 & $13.0 \%$ \\
I do not agree or disagree & 8 & $10.4 \%$ \\
I sort of agree & 13 & $16.9 \%$ \\
I strongly agree & 35 & $\mathbf{4 5 . 5 \%}$ \\
Missing & 1 & $1.3 \%$ \\
Total & 77 & $100 \%$ \\
\hline \hline
\end{tabular}

Table 59: Question 46: For my math class I haven't felt the need for braille--speech is fine

\begin{tabular}{lrr}
\hline \hline \multicolumn{1}{c}{ Response } & Frequency & Percent \\
\hline I strongly disagree & $\mathbf{5 6}$ & $\mathbf{7 2 . 7 \%}$ \\
I sort of disagree & 6 & $7.8 \%$ \\
I do not agree or disagree & 7 & $9.1 \%$ \\
I sort of agree & 6 & $7.8 \%$ \\
I strongly agree & 1 & $1.3 \%$ \\
Missing & 1 & $1.3 \%$ \\
Total & 77 & $100 \%$ \\
\hline \hline
\end{tabular}


These results indicate an accordance with the interview findings about the importance of having math materials in paper braille for most of these students. One student wrote in the Comments area:

Braille is escential [sic] for my education, especially in advanced classes. Take, for instance, math. Relying on computers to graph quadratic equations, conic sections and the like seems impossible to me, and that's not even including trig which is almost all graphical and, therefore, tactual for blind students.

Another student noted:

As to math in Braille, I'll most likely have to do my college physics homework twice: once in Braille and once to a computer or transcriber until I get used to the idea. Right now, Braille (whether paper or electronic) is the only way for me to know or think that I've solved a problem correctly. I even have trouble using a talking calculator (I love the one built into my notetaker) because I can feel if I made a mistake entering a calculation. Audio does not give me that.

However, another student pointed out the benefits of technology, even for mathematics:

It is important to know that one text book for a sighted student equals many volumes when translated in to braille. For instance, my sophomore year, I had a total of 52 volumes of the Algebra math book while other students who were sighted had the same Algebra book in one text book. Therefore, having the braille-note and or other technologies allows us blind students to load our text books electronically and carry with us where ever we go without heavy weight. 


\subsubsection{Accessing information in general}

The last set of questions in this section investigated students' attitudes towards technology in general, and in particular, its role in access to information. Questions 47, 48, 50 51, and 52 (numbered as 19, 20, 22, 23 and 24 in Set 2 of the original survey) explored the issues as shown in tables 60 thorough 64 below.

Table 60: Question 47: A part of me still really misses reading the hard copy braille books but it's just not practical

\begin{tabular}{lrr}
\hline \hline \multicolumn{1}{c}{ Response } & Frequency & Percent \\
\hline I strongly disagree & 15 & $19.5 \%$ \\
I sort of disagree & 10 & $13.0 \%$ \\
I do not agree or & $\mathbf{1 9}$ & $\mathbf{2 4 . 7 \%}$ \\
disagree & 18 & $23.4 \%$ \\
I sort of agree & 14 & $18.2 \%$ \\
I strongly agree & 1 & $1.3 \%$ \\
Missing & 77 & $100 \%$ \\
Total
\end{tabular}

Table 61: Question 48: I'm not a computer person even though I use it all the time

\begin{tabular}{lrr}
\hline \hline \multicolumn{1}{c}{ Response } & Frequency & \multicolumn{1}{c}{ Percent } \\
\hline I strongly disagree & 32 & $\mathbf{4 1 . 6 \%}$ \\
I sort of disagree & 11 & $14.3 \%$ \\
I do not agree or disagree & 7 & $9.1 \%$ \\
I sort of agree & 11 & $14.3 \%$ \\
I strongly agree & 16 & $20.8 \%$ \\
Total & 77 & $100 \%$ \\
\hline \hline
\end{tabular}


Table 62: Question 50: If I can read the menu online I don't care if I have a braille menu or not

\begin{tabular}{lrr}
\hline \hline \multicolumn{1}{c}{ Response } & Frequency & Percent \\
\hline I strongly disagree & 17 & $22.1 \%$ \\
I sort of disagree & 11 & $14.3 \%$ \\
I do not agree or & $\mathbf{2 2}$ & $\mathbf{2 8 . 6 \%}$ \\
disagree & 17 & $22.1 \%$ \\
I sort of agree & 10 & $13.0 \%$ \\
I strongly agree & 77 & $100 \%$ \\
Total &
\end{tabular}

Table 63: Question 51: When you use technology it's going to make things easier

\begin{tabular}{lrr}
\hline \hline \multicolumn{1}{c}{ Response } & Frequency & \multicolumn{1}{c}{ Percent } \\
\hline I strongly disagree & 2 & $2.6 \%$ \\
I sort of disagree & 7 & $9.1 \%$ \\
I do not agree or disagree & 7 & $9.1 \%$ \\
I sort of agree & 21 & $27.3 \%$ \\
I strongly agree & $\mathbf{4 0}$ & $\mathbf{5 1 . 9 \%}$ \\
Total & 77 & $100 \%$ \\
\hline \hline
\end{tabular}

Table 64: Question 52: Once students get into high school and as they get closer to college you need to start taking the braille away from them and forcing them to use speech

\begin{tabular}{lrr}
\hline \hline \multicolumn{1}{c}{ Response } & Frequency & Percent \\
\hline I strongly disagree & $\mathbf{3 8}$ & $\mathbf{4 9 . 4 \%}$ \\
I sort of disagree & 15 & $19.5 \%$ \\
I do not agree or disagree & 7 & $9.1 \%$ \\
I sort of agree & 12 & $15.6 \%$ \\
I strongly agree & 4 & $5.2 \%$ \\
Missing & 1 & $1.3 \%$ \\
Total & 77 & $100 \%$ \\
\hline \hline
\end{tabular}


To this researcher, this set of results illustrates the changing nature of reading in these students' lives. While the overwhelming majority (89.2\%) agree to some level that technology makes things easier, there was a much more dispersed response to the question that it's "just not practical" to use braille books. The response to the question about access to information, as conceptualized by the statement, "If I can read the menu online I don't care if I have a braille menu or not" also showed a wide variety of responses, with the mode $(\mathrm{n}=22)$ taking a neutral position.

As demonstrated in the interviews and survey results, students appear to like having choices about what they use for school tasks, whether it's paper braille for mathematics or foreign language study, refreshable braille for some tasks, or audio books and information for other tasks, these students seem to embrace technology and identify themselves as technology users. Half of the students disagreed to some extent with the statement that they would not consider themselves "a computer person".

Perhaps the strongest reaction to any question in the Preferences section of the survey was received in regard to question 52: "Once students get into high school and as they get closer to college you need to start taking the braille away from them and forcing them to use speech." This statement was chosen for the survey because of the challenging way in which it was worded, so as to encourage a strong response. Almost half of the students strongly disagreed with the statement (49.4\%) with an additional 19.5\% "sort of" disagreeing. In addition, several students wrote comments specifically about this item:

- As for the question of taking Braille away from high school students to prepare them, I object to the notion in principle, not in substance. Though it would force blind students to prepare for their college career in which Braille books 
are rare, it would deprive them the chance of learning on their own how to adapt to new situations; a lesson infinitely more important than teaching them to do without Braille prematurely.

- I do not think that when students get into high school and college that Braille should be taken away from them, rather they need a balance of Braille and other assistive technology. Braille is a crucial skill, but sometimes, for me at lease, it is simply easier to use a screen reader; it also depends on what the assignment is and what it involves.

- Braille is great. A blind person should always know how to use it, and it should never ever be taken from them.

- Concerning the removal of Braille from the classroom as students progress: I think the student should decide. If one is a strong Braille reader, encourage that. I didn't really want to learn Braille as a little kid, but once I did, I flourished, reading several steps above grade level for my entire academic career. While I acknowledge that Braille may be less apparent in college, I intend to keep it around.

- I feel students should be taught how to do Braille and use the technology they are given. Computers have put us on a more even playing field with out sighted counter parts, as long as we learn to utilize them properly. Teach the student and let them choose what is best for them, and only then do you get a truly well balanced person capable of decision making.

- Let people learn in the way that is best for them. 


\subsection{RELATIONSHIPS BETWEEN VARIABLES}

To investigate any significant relationships between variables on the survey, the statistical procedure of Spearman's correlation was used. Spearman's rho is recommended for testing correlations of variables in nonparametric distributions that use ordinal scales (Gravetter \& Wallnau, 2007). Several significant findings were noted by examining these data using SPSS.

The first relationship analyzed was whether there was a correlation between the students' grade level and their use of paper braille as asked in question 3: "All my textbooks are in paper braille." The responses to the question were coded as $1=$ "this is very unlike me", 2 = "this is somewhat unlike me", 3 = this is neither like me nor unlike me", 4 = "this is sort of like me", and 5 = "this is very like me." Results shown in Table 65, indicate a significant result that is negative and moderate in strength. This suggests that the higher the grade level, the less likely the student is to use paper braille.

Table 65: Spearman's correlation between grade level and use of braille

\begin{tabular}{lll}
\hline \hline & & USEBRL \\
\hline GRADE & Correlation Coefficient & $-.423\left(^{* *}\right)$ \\
& Sig. (2-tailed) & .000 \\
& $\mathrm{~N}$ & 75 \\
\hline \hline
\end{tabular}

**Correlation is significant at the 0.01 level (2-tailed).

The relationship between the student's age and use of braille was also examined. This, too, was found to be significant, negative, and of medium strength suggesting a similar 
relationship as with grade level: the older the student, the less likely he or she is to use paper braille. This relationship is shown in Table 66 below.

Table 66: Spearman's correlation between age and use of braille

\begin{tabular}{lll}
\hline \hline & & USEBRL \\
\hline \multirow{2}{*}{ AGE } & Correlation Coefficient & $-.437\left(^{* *}\right)$ \\
& Sig. (2-tailed) & .000 \\
$\mathrm{~N}$ & 76 \\
\hline \hline
\end{tabular}

** Correlation is significant at the 0.01 level (2-tailed).

Another variable found to have a significant correlation with the use of braille was the length of time students had read braille. This correlation was positive, but not as strong, as shown in Table 67 below. This suggests a weak but significant relationship where the longer the student has used braille, the more likely to read paper braille.

Table 67: Spearman's correlation between time reading braille and usage

\begin{tabular}{lll}
\hline \hline & & USEBRL \\
\hline BRLTIME & Correlation Coefficient & $.307(* *)$ \\
& Sig. (2-tailed) & .007 \\
& $\mathrm{~N}$ & 76 \\
\hline \hline
\end{tabular}

**Correlation is significant at the 0.01 level (2-tailed).

One last significant correlation with the use of braille was the number of years the student spent in a specialized school for the blind. This test yielded a weak but positive correlation, 
shown in Table 68 below, implying that the more years students have spent at a specialized school the more likely they are to use paper braille. It should be noted that this correlation is significant at a lower level, .05, indicating a 95\% confidence level rather than the 99\% confidence level shown in the other correlations.

Table 68: Spearman's correlation between time at specialized school and braille usage

\begin{tabular}{lll}
\hline \hline & & \\
\hline BLINDSCH & Correlation Coefficient & $.269\left(^{*}\right)$ \\
& Sig. (2-tailed) & .019 \\
& $\mathrm{~N}$ & 76 \\
\hline \hline
\end{tabular}

* Correlation is significant at the 0.05 level (2-tailed).

Two other sets of variables showed significant relationships. A positive correlation existed between the variable BRLNPRAC, that is, strength of agreement with the statement, "A part of me still really misses reading hard copy braille book but it's just not practical" and the age of the student answering that item. In other words, the older the student, the more likely the student was to agree with the statement. The correlation was weak, but was significant at the .01 level, indicating a higher level of confidence that this was not a Type I error, that is, saying there is a relationship when there is not one. Table 69 below illustrates this correlation.

Table 69: Spearman's correlation between age and practicality of braille

\begin{tabular}{lll}
\hline \hline & & AGE \\
\hline BRLNPRAC & Correlation Coefficient & $.295\left(^{* *}\right)$ \\
& Sig. (2-tailed) & .010 \\
& $\mathrm{~N}$ & 76 \\
\hline \hline
\end{tabular}

** Correlation is significant at the 0.01 level (2-tailed). 
The last significant correlation was between the variables ENTHUS and how long the students had known braille. ENTHUS was the code used for Question 29: "I wasn't very enthusiastic about learning braille." The Spearman's test statistic, shown below in Table 70, was negative, moderate, and significant, suggesting that the longer the students had known braille, the less likely they were to agree with that statement. Or, put another way, students who had learned braille later (i.e., known it for the least amount of time) were more likely to agree that they were not enthusiastic about learning braille.

Table 70: Spearman's correlation between enthusiasm and years knowing braille

\begin{tabular}{clr}
\hline \hline & & BRLTIME \\
\hline ENTHUS & Correlation & $-.330\left(^{* *}\right)$ \\
& Coefficient & .004 \\
& Sig. (2-tailed) & 76 \\
& $\mathrm{~N}$ & Correlation is significant at the 0.01 level (2-tailed).
\end{tabular}

Other correlations run by the researcher did not yield significant statistics. For example, there was no significant correlation between the use of email with teachers and either grade level or age of the student, suggesting that this practice is not related to one age group or grade level over another. There was no correlation between time spent at a specialized school and choice of primary reading medium, nor between number of years reading braille and primary reading medium. Of interest to this researcher was the lack of correlation between the variable NOBRL, that is, agreement with Question 5 about not using paper braille anymore, and either grade or age. 


\subsection{VALIDITY}

Correlation data is often used to test reliability and validity and to verify theory (Gravetter and Wallnau, 2007). While care was taken to select a test statistic that best fit the type of variables (Spearman's rho for interval scale variables), caution must be taken when looking at these data and the results. This study is not presented as a definitive set of variables relating to braille and technology use among youth, but as a beginning, exploratory study investigating possible important factors.

The most important limitation is the small sample size. As Gravetter \& Wallnau warn, "As the sample size gets smaller, the magnitude of the correlation needed for significance gets larger. . . . Therefore, a small sample requires a very large correlation before you can be confident that there is a real (nonzero) relationship in the population" (p. 525). None of the correlation statistics were large. On the other hand, most of them were significant at the .01 level, which gives a 99\% confidence level that a Type I error was avoided. The fact that some significant correlations were reported is helpful in discussing the results of this study.

It must also be noted that the main purpose of the survey was to triangulate the data gleaned from the interviews and support hypotheses and theory built from the interview responses. For the most part, the survey results did support the main themes identified in Phase I of this study. Even beyond the correlation statistics, the frequency measures and modes matched those suggested by interview responses. In this way, the survey succeeded in many ways and proved to be a reliable measure of several factors related to braille and technology use, such as the decreasing usage of paper braille as students get older and advance in school, the tendency of 
students to match their methods to the task they need to accomplish, the general lack of use of the slate and stylus, and the widespread positive regard with which braille is held.

Undoubtedly, there are many other factors related to this complex subject and a great deal more research is needed. This will be discussed at greater length in Chapter 6. 


\subsection{DISCUSSION}

The purpose of this study was to investigate the current practices and preferences of students between the ages of 16 and 22 who were blind, read braille, and used assistive technology. A search of the literature indicated very few studies had been conducted in the area of technology use for students who are blind, and none that looked specifically at the use of both braille and technology for completing school work among high school and college students.

It was also important to this researcher that the methods used in the study preserved the students' voices. For that reason, this exploratory study combined interview and survey methods to paint a broad picture of contemporary practices and opinions from the student's point of view. The structured qualitative approach used in the interviews to look for patterns and emerging themes was then compared to the quantitative responses from the survey analysis.

The resulting picture leads to several topics worthy of further discussion and exploration. In this chapter, a summary of the themes and patterns that emerged from the interviews and strengthened by the survey responses will be considered in a broader context with implications for teacher preparation as well as directions for future research. 


\subsection{THE CHANGING NATURE OF READING}

What is reading and literacy in the $21^{\text {st }}$ century? While entire books have been written exclusively around this question, it is beneficial to think of the larger context in which reading and writing play in the school lives of students who are blind or visually impaired.

As discussed in Chapter 2, the definition of reading and what it means to be literate has changed greatly in the last century, but the wide-spread use of technology, particularly in schools, in the last 20 years has propelled an even great change (Leu, 2000). For students who are blind or visually impaired, the changes that technology has brought to education have been consequential. This researcher started as a TVI in 1982, in addition to large print and braille books the technology available to students at that time was limited primarily to the Perkins Brailler, slate and stylus, and the typewriter,. While books on tape were obtainable, the number of titles was relatively limited. Starting in the mid-1980s, however, with devices such as the VersaBraille ${ }^{\mathrm{TM}}$ and the Braille 'n Speak ${ }^{\mathrm{TM}}$, technology for people who were blind started to evolve at a more rapid rate, with more features and vastly improved performance than that found in those early devices.

As a result, the concept of "reading" has changed a great deal for students who are blind. As mentioned in Chapter 4, it became clear to this researcher that when students said they read "braille" it could mean paper braille or braille on a refreshable display. To most students, braille was braille and unless they were asked specifically, or if the context of their answer made it clear, it was nebulous when they referred to "braille" in which format it might appear. In addition, when students described how they "read," they might be referring to reading braille on paper, on a refreshable display, or using speech to access the text on a computer or other device 
such as an audio book reader. Although students acknowledged the importance of braille, the larger concept of "reading" appears to have expanded from simply words on paper, paralleling the expansion of "reading" in the world of their sighted peers discussed in Chapter 2.

There are potentially large implications of these changes in how braille reading is perceived. One implication is related to the propensity of a tool to become "transparent" to people who are skilled in its use. In other words, as people become more proficient in a tool, its usage becomes unremarkable. As Tyner reflects, "It is interesting that in a millennium of alphabetic print use, 'pen literacy' has never vied for its place as a multiliteracy category, perhaps because of its commonplace presence in the classroom" (1998, p. 78). Perhaps in time, the use of the specific tool will no longer be required when talking about the reading that students who are blind engage in for class work.

Another implication is the blurring of the lines between the concepts of "reading" and "access", and between "book" and "information." Peter Osborne, chair of the United Kingdom Association for Accessible Formats, and head of the Library and Production Services for the Royal National Institute for Blind People, remarked at a recent BANA meeting: "Braille used to be about books and magazines; now it's about access to information" (P. Osborne, personal communication, April 10, 2010).

The students in this study appear to recognize and value the greater access to information they have compared to students who read braille in previous generations. While they continue to value the literacy opportunities that braille affords, particularly for specific subjects such as mathematics, they also appreciate the virtually unlimited access to information that technology allows. As one college student who was interviewed put it: 
You know it's about reading for access versus reading for comprehension. It's very-I think those are two very different things, and uh, I mean, sometimes that's why I don't get picky over what format I receive my stuff in. As long as it's easy access--that's really what you want for most things, you know. I mean, I go and read menus from restaurants online. I don't really care if somebody gives me a braille menu or not. I'm happy with the access.

\subsection{THE IMPORTANCE OF CHOICE IN STUDENTS' LIVES}

Another large theme that emerged from these data is the importance of choice-making. Students were quite opinionated about their likes and dislikes, their preferences, and how they get specific tasks accomplished. As reported in Chapter 5, 87\% of students said it was "very much" or "sort of" like them to choose a device or tool based on the assignment they have to accomplish. The multiplicity of devices used, generally four or five different types, suggests that students in this age range prefer to use more than one device or method for accessing information and completing school work.

It was equally clear that different students employed different methods for similar tasks. While some students preferred to use refreshable braille all day, others did not. Although some preferred to use speech access primarily, others felt lost without a braille display. The difference

in preferences between students illustrates why a one-size-fits-all approach (that is, assuming 
that students will need only speech access, or only paper braille, or only refreshable braille) would be considered detrimental to their own efficiency by these students.

However, a distinction appeared when discussing the acquisition of reading and writing skills as opposed to the use of literacy skills once they have become proficient readers. When speaking of younger children learning to read and when giving advice to future TVIs, the message from these participants was unmistakable: teach children to use braille. Students overwhelmingly stated that braille is the foundation of literacy even when they used very little braille on paper themselves, particularly as college students. Once students know braille, it seems, they may then choose methods and devices that work best for the individual. Knowledge of braille increases the choices available to students, including the choice to use other methods such as speech access.

This seemingly dichotomous scenario also fits into the larger theme of choice, as making choices includes students who are dual readers or who learned braille later in school but who then choose to use print in addition to braille and speech. For instance, the high school student interviewed who used print, braille and speech felt that braille slowed her down, even though she was a proficient braille reader and a proponent of students with visual impairments learning to use braille. But she also felt that her teachers judged her as "being in denial" when she chose to use large print instead of braille; she spoke passionately about the need for teachers to listen to students when they expressed their preferences about how they worked best. This dichotomy appeared in the other direction as well: students who wished to use braille but were not encouraged to do so, such as the high school student who embraced braille because she "got tired of headaches" all the time. Just as there were students who chose not to use braille once it was 
learned, others wished to use it but did not receive encouragement to do so. One student stated in the survey comments:

At [my college], I am specifically discouraged by the DSS office workers from using Braille because they say that it is an outdated and inefficient form of communication. I really hate the fact that my Braille skills are atrophying, but I am focused first on getting my school work done and will try to maintain my Braille skills on my own time. So far, I really have not read more than 10 pages of Braille since I graduated high school.

Other students reported wishing to learn braille earlier in their education but felt they were denied that choice. One college student reported that it was a fight to receive braille instruction in elementary school, and wrote the following comment on the survey:

In my case, the State of [name of state] refused to give me Braille instruction until the third grade, and this necessarily caused a prolonged period during which I read below grade level. I only mention this because, contrary to the tenner [sic] of the questions here, it is not always the student that refuses Braille instruction.

Another student had a similar story, reporting in part:

I started reading braille at age 18 . I probably should have been taught braille (or at least introduced to it) a year or two earlier. I enjoy reading something in braille. My speed is not great, so I use speech for most school assignments. . . . I wish I had been introduced to braille when I was younger so that I could have built up my reading speed more. 
One implication of these themes of the blurring of reading and access and the importance of choice is that it has become more important than ever to provide students with as many tools as possible. To allow students to take advantage of the many choices available to efficiently and adequately complete school tasks means that they must be proficient in multiple methods and tools for learning. Learning to read and write braille continues to be important, but just knowing braille on paper is not enough anymore. If this is true, then someone has to teach these important skills. Results of this study indicate that students felt that this is an important role for the TVI, if only to introduce a wide variety of devices that could be useful to them in school. It is important, then, to look at the issue of teacher preparation and preservice instruction in the context of AT and braille.

\subsection{TEACHER PREPARATION AND INSTRUCTION}

Articles about the impact of technology for people who are visually impaired have been published in professional literature since the 1980s. It was clear that the personal technology revolution would have a huge impact on the lives of adults who were blind. Many of the first articles about technology were related to employment, independent travel, and success in higher education (see, for example, the special issue on microcomputers of the Journal of Visual Impairment \& Blindness, 1984). Research and practice articles related to K-12 education came soon after (Koenig, Mack, Shenck, \& Ashcroft, 1985; Mack, Koenig, \& Ashcroft, 1990; Parker, Buckley, Truesdell, Riggio, Collins, \& Boardman, 1990). Assistive technology is one of the 
specific areas mentioned as part of the Expanded Core Curriculum acknowledged by the field of blindness as the essential disability-specific skills needed for students who are blind or visually impaired (Hatlen, 2000).

More than 20 years ago, Mack, Koenig, and Ashcroft (1990) recognized the promise of technology for students who were blind, and concluded their article about access technology during pre-service teacher training by saying:

Teacher preparation programs have the critical obligation to produce graduates who have the necessary knowledge, skills, and motivation to provide a link to microcomputers for their students ... it is imperative that all teacher training programs initiate and continue to provide instruction in this area that is fundamental to the independence of students who are blind or visually impaired (p. 530).

Two decades later, teachers of students with visual impairments still reported feeling unprepared to teach the use of assistive technology devices (Abner \& Lahm, 2002; Corn \& Wall, 2002; Edwards \& Lewis, 1998; Kapperman, Sticken, \& Heinze, 2002). While teachers for the most part report a comfort level with certain technology themselves (Corn \& Wall, 2002), studies indicate that they wish to have additional training in the use of assistive technology. In fact, many of the same barriers identified by Parker et al. (1990), such as a lack of knowledge about AT devices, were still issues more than a decade later. The impediments relate to both preservice teachers and teachers currently working with students who are visually impaired.

At the pre-service level, one roadblock to teacher success could be the lack of standards for what is taught to pre-service teachers of students with visual impairments regarding the use of AT, as illustrated in a recent study by Smith and Kelly (2007). In addition, of the 30 university programs that have preparation programs in visual impairments that responded to their survey, 
only half offer a stand-alone course specifically in assistive technology designed for individuals who are visually impaired. The other programs that responded had either generic AT courses or infused AT throughout specific courses or the entire program. Smith and Kelly (2007) also found that wide variations existed between both what was taught during pre-service instruction and the intensity to which skills were taught. Almost half (47\%) of the technology devices or software reported to be included in the training were only covered at the "awareness" level (defined as "limited knowledge--aware but needs more skills"); 37\% were covered at the "proficient" level (defined as "skilled by needs to expand") and another 17\% at an advanced level ("expert in the use of this assistive technology" p. 431). The researchers conclude that "there is no agreement on what assistive devices are critical for teacher of students with visual impairments to be able to use at the higher technology-awareness levels” (p. 432), and that standards and professional competencies for AT should be developed.

The rapid pace of change in technology dictates the need for frequent training. There is an overall lack of opportunity for in-service training in AT for teachers who work with visually impaired students, and teachers would like to have more training and resources available to them (Abner \& Lahm, 2002; Corn \& Wall, 2002; Murphy, Hatton, \& Erickson, 2008). Professional development opportunities are important for teachers of all types to keep skills up to date, but because of the low incidence of students who are visually impaired, TVIs in some states do not receive enough chances to participate in in-service workshops and trainings specific to their field.

As mentioned in Chapter 2, classroom teachers in general education report having difficulty embracing technology and incorporating its use in schools, so in some ways it is not surprising that TVIs report a similar amount of unreadiness. It is possible that this is a generational issue, 
and that through attrition older teachers who may be less adept or experienced with technology tools will retire, and new teachers who are more tech-savvy will fill the ranks. This will only happen if all university training programs offer robust courses in the use and instruction of assistive technology. In the meantime, students will still need to learn to use AT and someone has to provide that instruction.

In addition to the overall lack of training both at the pre-service and in-service stage, there is an overwhelming lack of research about best practices for AT instruction for students with visual disabilities. A review of the literature indicates that while a number of articles report on overall accessibility of electronic tools and online resources, such as those found in AccessWorld, the online technology journal published by the American Foundation for the Blind, information on how to teach students who are blind to use these tools is limited and much of it is anecdotal. It is clear that teachers need assistance in learning to use AT devices which are designed to be used by people with visual impairments, but just as important, they need information on instructional approaches they can use with their students. While this study does not deal specifically with pedagogical questions, this is an area in need of additional research if indeed TVIs are expected to teach technology skills.

\subsection{CHALLENGES ASSOCIATED WITH THIS STUDY}

As discussed in Chapter 3, based on an estimated number of eligible students the researcher hoped for participation from 200 students, or $22 \%$ of the estimated population. The actual return was 12 interviews and 77 valid surveys ( $n=89)$, a rate of $9 \%$, based on the estimate 
of 900 potentially eligible students in the United States. While a review of the literature indicates that low response rates are typical in our small, heterogeneous, and widely geographically spread field, it was still a disappointment to this researcher particularly because of the great support received from many national organizations. While the flyer to recruit potential participants was first distributed immediately after IRB approval was received on October 1, 2009, it was simply very difficult to find participants for this study; eligible students were still being added to the database six months after the study period began. The incentive of being entered in a drawing did not appear to entice a great many students. One student who contacted me but did not participate told me that more students would probably participate if they received a $\$ 5$ Starbucks coffee card. Future researchers of this demographic should take note that a more tangible incentive might be useful.

As reported, 127 interested parties responded to the flyer that was disseminated over a number of electronic mailing lists and expressed an interest in the study. By the end of the study, the thoughts and opinions of 89 total students were represented, but a great deal of time and effort was needed by the researcher to get these data. Since the study included minors who needed parental consent as well as adult participants who needed only to indicate personal consent, and because the consent forms and survey were available in numerous formats, such as braille, electronic, and print, keeping up with the various needs of participants and potential participants was time consuming. The following observations are added here for the benefit of future researchers who may wish to conduct studies with this demographic group.

Students who were 16 or 17 years old needed consent forms that required a parent or guardian signature, and these forms often needed to be provided more than once before they were returned (if indeed they were). Students were given the option to return the signed consent 
form in one of several ways: via fax to the university, by mail to the university, scanned and emailed back to the researcher, or via email with digital versions of the appropriate signatures on the electronic form. Several students expressed difficulty in supplying a digital copy of their signature to put on the consent forms and asked for assistance in how to do so. While these steps were explained, very often the consent forms were still not returned. Other students expressed difficulty in finding access to a fax machine or to a scanner. The study protocol was revised for students 18-22 years old to add the option of completing the consent form and then the survey online. (In fact, permission was also granted to do the consent form orally with adult participants, but no one requested that option.) For adult participants, the online consent and survey proved to be a great boon to the process of this study, as the researcher could simply send the link to students who were over 18 and wished to participate. It is quite likely that a much smaller number of surveys would have been received if the online consent option had not been available. Several students who had not returned the separate consent form previously sent to them as a Word document participated in the study once they had the option to simply click on a link to complete the entire process (i.e., provide consent and take the survey) online.

Once the minors returned their consent forms, the survey could be sent to them. Some students requested a survey in one format, and then in a second format as well. One student did not have Word on his computer so the survey was sent in Rich Text Format (.rtf). Another student, after being sent the braille version, said he wanted it electronically and then told the researcher he had filled out the survey but couldn't find it on his computer, and was sent yet another. Future researchers should take note that for adult participants using Survey Monkey with multiple choice and text boxes for open-ended questions appeared to be a generally accessible option. Even so, two students reported having difficulty with the online format and 
were then sent Word versions after completing the online consent. One student mistakenly did the online survey twice so the second version was deleted from analysis. The due date for the surveys was pushed back from March 26 until April 19 in an attempt to encourage more students to return completed surveys. These extra weeks proved useful in gaining additional surveys.

The ability to email electronic versions of forms or links to the online survey allowed the researcher to send the forms and surveys in a timely fashion and, in fact, in almost all cases the requested information was emailed the day it was requested. While some students responded immediately to researcher entreaties, that was not the norm. Many students were not diligent about returning the consent forms and surveys even after several reminders. The most frequently used tool in contacting students to provide information and to encourage the return of documents was email. Some students required four more messages before they returned the survey; several required six or seven reminders. The total number of emails from the researcher to potential and actual participants (including messages to parents and teachers) explaining the study, sending consent forms, answering questions, and reminding students to return the surveys or to fill them in online totaled 1,200 email messages during the recruitment period. This does not include the handful of telephone calls. Besides email, the FileMaker Pro ${ }^{\mathrm{TM}}$ database created for this project was this researcher's most valued tool to keep track of participants and their status.

It is interesting to note that while this is a study of braille readers, only one student requested the consent form in braille and all the others requested an electronic version. Very few students requested the survey in braille $(n=3)$, and those who did also requested an electronic version. As reported earlier, one large group of surveys were completed in braille from a specific school for the blind because their teacher had created braille copies with an embosser at the school. Without the efforts of this teacher, very few braille surveys would have been used for this 
study. Some of this teacher's students returned their responses by typing them on the computer and printing them, so even using the braille survey did not always ensure that the responses were in braille. Overall, most students used electronic forms of the survey or used electronic means to reply.

\subsection{LIMITATIONS OF THIS STUDY}

As mentioned in Chapter 5, one obvious limitation of this study is the small number of participants. While every effort was made to assemble as large a number of students as possible, the final tally was much smaller than hoped for.

In addition to the small number of responses, the question of representativeness is important: are the participants in this study a good cross section of young adults who are blind and use both braille and AT? It's difficult to say with any certainty, and even within that group this is a subset of youth who are attending school. Perhaps young adults who are not in school but instead are involved with competitive employment would have different responses than these students. This study asked specifically about school tasks, and it is entirely possible that the experiences of youth who use technology for social networking and communication would have different responses as well.

In examining the demographic information of the participants, there was an overrepresentation of students in specialized schools. One quarter of the students interviewed, and $31 \%$ of students who took the survey, were at a school for the blind. By contrast, according to the American Printing House for the Blind federal quota report (2007), approximately 9\% of 
students who are registered as legally blind attend specialized schools. It is possible that this overrepresentation skewed the results somewhat, and that a larger group of students who attended their neighborhood school would have different experiences and opinions.

Both the interviews and survey included questions that required self-reported information that may be difficult for students to recall. Some questions, such as how old they were when they first learned to use AT, would rely on students' recollections of events that may have happened a number of years before. They may not recall exactly when they learned to first use AT, or which devices they used first, or even how they were taught. There was no triangulation of data from other sources, such as interviews with parents or teachers or a review of the students' records or other school work to check the veracity of the students' recollections.

Despite these acknowledged limitations, the survey results helped generate a picture of how widespread the practices and attitudes expressed in the interview were among other students of the same age; the results for the most part are descriptive and correlational rather than causal. In addition, a convenience sample was used for the survey rather than a random or stratified sample.

While the survey was designed primarily as a way to provide further evidence to the implications found from the interviews, it was not designed to be replicated or used by other researchers. There was no factor analysis or reliability testing done on the survey itself. It was primarily a vehicle for this exploratory study and to suggest further study. As a result, some of the individual items may not have been as clearly written as they could have been, even though the survey was piloted by a number of experienced braille and technology users. One example of a question that might not have yielded useful information was Question 4: "I have DAISY files of all my textbooks." While many students reported the use of a Victor Reader or other book 
reader technology, about $64 \%$ of students responded that that statement was "very unlike" or "somewhat unlike" them. While Victor Readers can access and use many different types of files (that is, not just DAISY files) it is possible that the students didn't understand or misinterpreted this question. This researcher wonders if students are truly not using DAISY files or if they just don't call them that because they're unfamiliar with the term. A better way to phrase the question might have been to refer to "electronic files of all my textbooks" instead.

\subsection{NEED FOR ADDITIONAL RESEARCH}

As is typical of exploratory studies, more intriguing questions were raised than definitive answers were revealed. This study is no exception, and several areas of further research are indicated.

The question remains in the mind of this investigator of how students learn to use AT, whether in school or outside school. In the interviews, most students said they learned outside of school at a center-based program but that was not the case in the surveys. Further research into the provision of AT assessment and instruction is warranted, including the age at which technology instruction generally begins, what tasks are taught first and with what devices, and what approaches and instructional strategies appear most promising.

As mentioned in Chapter 4, a great deal of research is needed about student writing. Specific topics could include the purposes for which students still use braille to write, and how braille users learn to write for others who don't read braille. This latter topic could include information such as how students learn to format print papers, such as adding headings, creating 
paragraphs, etc. In particular, the issue of backtranslation, that is, translating electronic braille into print should be studied in greater detail. In the interviews, this was not identified as a major problem for most of the students but the issue was not probed in depth, nor was it included on the survey. Attitudes about the slate and stylus appeared to be neutral at best. Further research into how widely the slate is taught in schools and the strategies used to teach it might give additional information into its use as a tool. Beyond the tools themselves, however, specific writing practices could be investigated as well as the processes by which students learn to brainstorm, write, revise, edit, and publish their work.

A great deal more needs to be learned about multiliteracy practices, particularly the use of the Internet in the classroom. Most of the students mentioned accessing the Internet to do research for school papers. However, specific practices or methods that students employ for finding and using information on the Internet was not investigated. A deeper look into other multiliteracy activities beyond using PowerPoint for presentations should be explored as well. It was noteworthy to this researcher how few students reported engaging in Web 2.0 activities in school. It could be that for these students having access was having access, not just to the general curriculum but also to the larger world around them.

One interesting finding from the survey was that of the students who attended a specialized school, the greatest percentage of them had been enrolled from one to five years. This is certainly a change from decades ago when students started at a school for the blind in kindergarten and did not leave until they finished high school. Over the years the role of specialized schools in the education of children who are visually impaired has evolved. IDEA supports the full continuum of services for students with disabilities, and an interesting study could examine the continuing role of specialized schools. While placement at a school for the 
blind is considered by some a "more restrictive" environment than placement in a neighborhood public school, often specialized schools offer courses and instruction in skills that are not easily available elsewhere. This survey did not ask students at what point in their education they attended such a school: Did they attend in early grades to build braille and AT skills and then transferred to a public high school? Or did they start in their neighborhood school and then transfer to a specialized school for intensive instruction in AT and other skills? Many other questions could be considered in a study of AT instruction for students at schools for the blind.

Other topics mentioned in passing by students include the use of live readers, tactile graphics, distance learning, motivation to learn technology, and the use of braille for labeling and organizing and all of these topics could be explored further. One student mentioned using technology to produce music braille. The use of special codes such as music and the Computer Braille Code (CBC) also warrants study. While originally the interview protocol included a probe about the use of $\mathrm{CBC}$ with braille PDAs, this question was dropped after the first few interviews as so few students were familiar with it.

Lastly, the important role of university programs for preparing TVIs merits additional research, particularly in the area of AT. Studies could investigate promising methods for educating future teachers about AT devices, as well as pedagogical approaches that TVIs can use to teach the use of technology to their students. Building upon the study conducted by Smith and Kelly (2007), one next step might be the development of standards and competencies in the area of assistive technology for university programs in the field of visual impairments. 


\subsection{CONCLUDING THOUGHTS}

All the students who participated in this study were told that their comments and opinions would be used to inform the field of visual impairments and to assist in the preparation of preservice teachers and to inform current teachers. In conclusion, perhaps it is best to let the students themselves have the last word. These final quotes summarize many of the themes and subthemes that have been discussed in this paper and can be springboards to further study and exploration:

• "I taught myself how to use most of the technology I use by reading the manual or the tutorial. Also, I would be lost without my BrailleNote!"

• "I think braille has its benefits, particularly when you are doing math and foreign language assignments. However, technology is improving and more people are starting to become aware of its even greater benefits."

- "Although I do not use Braille I feel it is important for every blind person to learn it."

- "Speech is great, but it is not reading. When I read braille, it is like reading when I was sighted."

• "Braille is our way of being equal."

In a world where textbooks and other learning media for all students are increasingly available online or electronically, an investigation of the role of paper braille for students who are blind was timely. The multiplicity of viewpoints collected in this study reflect the heterogeneity of students in this age group as well as their varying needs, ability levels, and preferences. If one thing can be generalized about these results, it is that the students themselves 
cannot be generalized. TVIs must recognize each student's unique needs and provide a variety of opportunities and experiences for them. Figure 3 illustrates how the themes discussed in this study lead to better-informed choices, and better chances for success. 


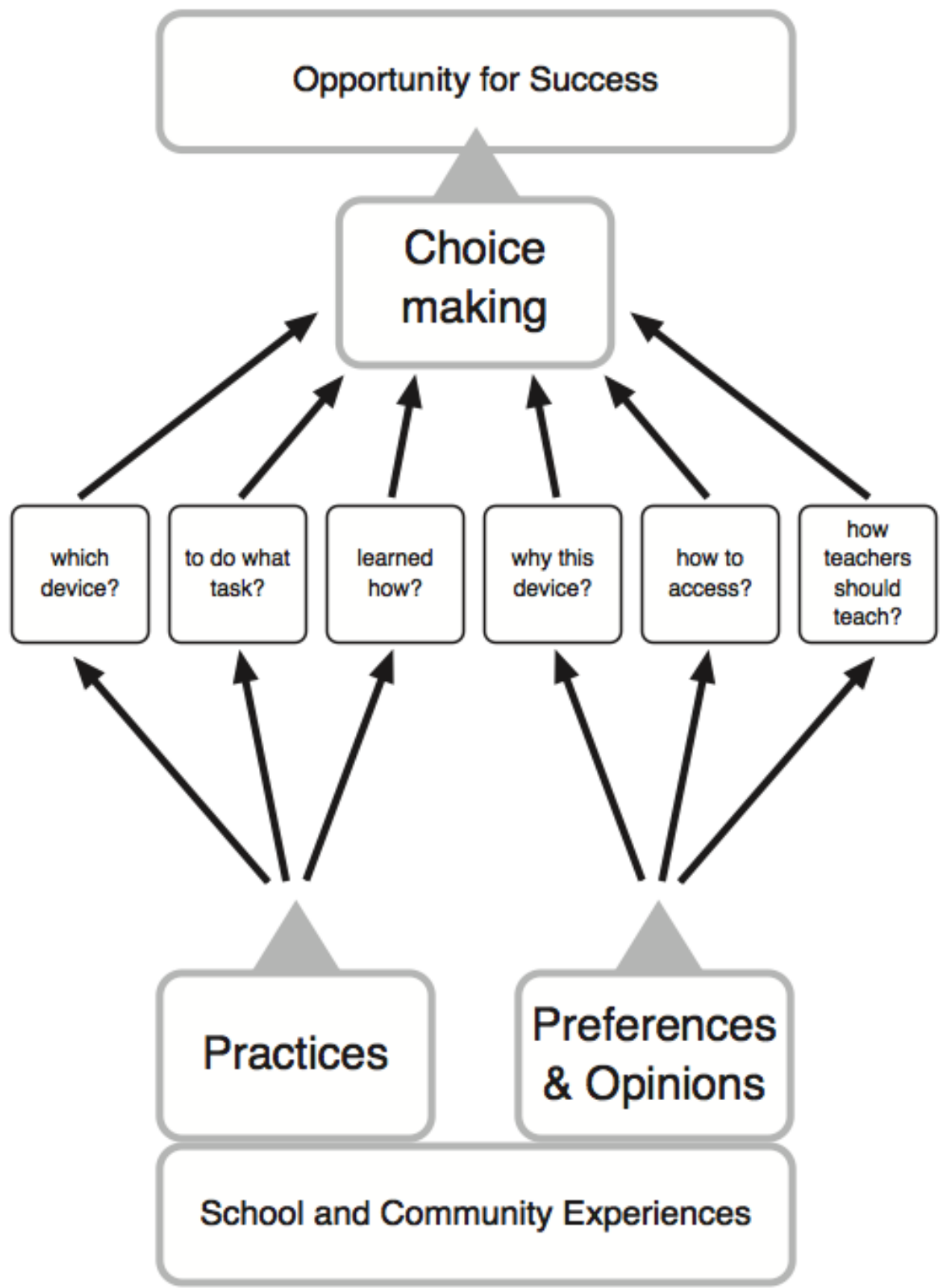

Figure 3: The effect of more choices on future success 
APPENDIX A

PARENTAL CONSENT FORM

University of Pittsburgh

School of Education

Department of Instruction and Learning
5300 Wesley W. Posvar Hall 230 South Bouquet Street

Pittsburgh, PA 15260

412-624-7254

Fax: $412-648-7081$

\title{
PARENTAL INFORMED CONSENT DOCUMENT
}

\section{Consent to Act as a Subject in a Research Study}

Title: Attitudes and Practices Among Students Who Read Braille and Use Assistive Technology

\author{
Principal Investigator: $\quad$ Frances Mary D’Andrea \\ NCLVI Doctoral Fellow
}


5513 WW Posvar Hall

University of Pittsburgh

Pittsburgh, PA 15260

Telephone: 412-624-7830

Source of Support: School of Education Doctoral Fellowship Research Award

\section{Why is this research being done?}

This research project seeks to explore how advances in technology have changed literacy practices for young adults who are blind and who use braille and assistive technology. Specifically, this study will explore how they use both braille and electronic information, and how they learned these literacy practices. The purpose of this research will be to add to our understanding of the current role of both hard-copy (paper) braille and use of electronic access to information by people who are blind from ages 16-22, and their attitudes and perceptions about both braille and technology. This information will inform how we prepare pre-service teachers to instruct young braille readers.

\section{Who is being asked to take part in this research study?}

Your child is being invited to take part in this study. Participation in this study is limited to students who are between the ages of 16-22 years of age, enrolled in school, and who are braille readers and users of assistive technology devices.

\section{What procedures will be performed for research purposes?}


This research project seeks to explore how advances in technology have changed literacy practices for young adults who are blind and who use braille and assistive technology. It will do this in two ways: through interviews and through a survey. Both will ask for your child's opinions, but your child will only be asked to do either the interview or the survey, not both.

The interviews will center around how paper braille is used by your child and for what purposes, and how assistive technology is used by your child and for what purposes. In addition, the interviewer will ask how your child learned these skills, and from whom. Digital audio recording will only include the recording of talk from student participants whose parents have consented for their children to participate in the study. Students will be interviewed on an entirely voluntary basis and will also be asked for their consent. Interviews will be conducted in the students' homes, unless the student and parent indicates a different and preferred site. In that situation, permission will be sought from that site prior to the interview. If face to face interviews are difficult to arrange and schedule, the interviews could instead be conducted via telephone at the expense of the interviewer (Frances Mary D’Andrea).

The survey will also ask how paper braille is used by your child and for what purposes, and how assistive technology is used by your child and for what purposes. The survey will also ask opinions about using braille and electronic devices for class work. The survey will be mailed to your child in braille, but he or she may also choose to do the survey electronically as a Word document if preferred. Your child will need to mark your response either by making a mark on the paper copy or placing an $\mathrm{X}$ before his or her choice on the electronic copy.

\section{Risks and Benefits}


What are the possible risks, side effects, and discomforts of this research study?

There are no risks for your child in participating in this study.

\section{What are the possible benefits from taking part in this study?}

The possible benefit is that by participating in the study, your child will have a chance to reflect on the kinds of literacy practices in which your child participates. This kind of reflection may help your child become more aware and successful in using certain practices for reading, writing, and access to information. However, there is no guarantee that your child will receive such benefits.

\section{Costs and Payments}

Will I be charged for the costs of any procedures performed as part of this research study?

You will not be charged for any of the procedures performed as part of this study.

\section{Will I be paid if I take part of this research study?}

There will be no general compensation for participation in this research study. However, as an incentive for completing the interview or survey, at the end of the study the names of all students who participated will be entered into a raffle for an accessible MP3 player.

\section{Confidentiality}




\section{Who will know about my participation in this research study?}

Your child will not be specifically identified in any publication of research results. If any individual's data are reported, name or initials will not identify the participant. The audio recording and information obtained will only be accessible to the investigator listed on the first page of this document. According to University policy, all research records must be kept for a period of at least five years. Any documentation will be kept in a password-protected computer and in a locked file drawer only accessible to the principal investigator. The University of Pittsburgh Research Conduct and Compliance Office may access identifiable research records for the purposes of monitoring this study. In rare cases, identifiable research records may be released, such as in response to a court order.

\section{Right to Participate or Withdraw from Participation}

\section{Is my participation in this research study voluntary?}

Your child's participation in this study is completely voluntary. Your child does not have to take part in these research studies, and should you or your child change your mind, your child can withdraw from the study at any time. Likewise, your child has the right to answer interview questions voluntarily, and refuse to answer any specific question at any time. Your child's

decision to participate will not affect your or your child's relationship with the University of Pittsburgh. Your child will also be assured that there are no right or wrong answers to the interview or survey questions.

\section{Voluntary Consent/Parental Certification}




\section{(for participants under age 18)}

All of the above information has been explained to me and all of my current questions have been answered. I understand that I am encouraged to ask questions about any aspect of this research study during the course of this study, and that such future questions will be answered by the researcher listed on the first page of this form at the telephone number(s) given. I understand that I may always request that my questions, concerns or complaints be addressed by a listed investigator.

I understand that I may contact the Human Subjects Protection Advocate of the IRB Office, University of Pittsburgh (1-866-212-2668) to discuss problems, concerns, and questions; obtain information; offer input; or discuss situations in the event that the research team is unavailable.

By signing this form, I agree for my child to participate in this research study. A copy of this consent form will be given to me/my child

\section{Printed Name of Child-Subject}

I understand that, as a minor (age less than 18 years), the above-named child is not permitted to participate in this research study without my consent. Therefore, by signing this form, I give my consent for his/her participation in this research study. 
Child Assent (to be used with children who are developmentally able to sign)

This research has been explained to me, and I agree to participate.

Signature of Child-Subject

Date

Printed Name of Child-Subject

\section{CERTIFICATION of INFORMED CONSENT}


I certify that I have explained the nature and purpose of this research study to the abovenamed individual(s), and I have discussed the potential benefits and possible risks of study participation. Any questions the individual(s) have about this study have been answered, and we will always be available to address future questions as they arise. I further certify that no research component of this protocol was begun until after this consent form was signed.

Printed Name of Person Obtaining Consent

Signature of Person Obtaining Consent
Role in Research Study

Date 
APPENDIX B

\title{
PARTICIPATION CONSENT FORM
}

University of Pittsburgh

School of Education

Department of Instruction and Learning
5300 Wesley W. Posvar Hall 230 South Bouquet Street Pittsburgh, PA 15260 412-624-7254

Fax: $412-648-7081$

\section{Consent to Act as a Subject in a Research Study}

Title: Attitudes and Practices Among Students Who Read Braille and Use Assistive Technology

\author{
Principal Investigator: $\quad$ Frances Mary D’Andrea \\ NCLVI Doctoral Fellow \\ 5513 WW Posvar Hall \\ University of Pittsburgh
}


Pittsburgh, PA 15260

Telephone: 412-624-7830

Source of Support: $\quad$ School of Education Doctoral Fellowship Research Award

\section{Why is this research being done?}

This research project seeks to explore how advances in technology have changed literacy practices for young adults who are blind and who use braille and assistive technology. Specifically, this study will explore how they use both braille and electronic information, and how they learned these literacy practices. The purpose of this research will be to add to our understanding of the current role of both hard-copy (paper) braille and use of electronic access to information by people who are blind from ages 16-22, and their attitudes and perceptions about both braille and technology. This information will inform how we prepare pre-service teachers to instruct young braille readers.

\section{Who is being asked to take part in this research study?}

You are invited to take part in this study. Participation in this study is limited to students who are between the ages of 16-22 years of age, enrolled in school, and who are braille readers and users of assistive technology devices.

\section{What procedures will be performed for research purposes?}


This research project seeks to explore how advances in technology have changed literacy practices for young adults who are blind and who use braille and assistive technology. It will do this in two ways: through interviews and through a survey. Both will ask for your opinions, but you will only be asked to do either the interview or the survey, not both.

The interviews will center around how you use paper braille and for what purposes, and how assistive technology is used and for what purposes. In addition, the interviewer will ask how you learned these skills and from whom. These interviews will be digitally audio recorded. Students will be interviewed on an entirely voluntary basis. Interviews will be conducted in the your home upon permission, unless you indicate a different and preferred site. In that situation, permission will be sought from that site prior to the interview. If face to face interviews are difficult to arrange and schedule, the interviews could instead be conducted via telephone at the expense of the interviewer (Frances Mary D’Andrea).

The survey will also ask how you use paper braille and for what purposes, and how assistive technology is used and for what purposes. The survey will also ask opinions about using braille and electronic devices for class work. The survey will be mailed to you in braille, but you may also choose to do the survey electronically as a Word document if you prefer. You will need to mark your response either by making a mark on the paper copy or placing an $\mathrm{X}$ before your choice on the electronic copy.

\section{Risks and Benefits}

\section{What are the possible risks, side effects, and discomforts of this research study?}

There is no risk for your participation in this study. 


\section{What are the possible benefits from taking part in this study?}

The possible benefit is that by participating in the study, you will have a chance to reflect on the kinds of literacy practices that you participate in. This kind of reflection may help you become more aware and successful in using certain practices for reading, writing, and access to information. However, there is no guarantee that you will receive such benefits.

\section{Costs and Payments}

Will I be charged for the costs of any procedures performed as part of this research study?

You will not be charged for any of the procedures performed as part of this study.

\section{Will I be paid if I take part of this research study?}

There will be no general compensation for participation in this research study. However, as an incentive for completing the interview or survey, at the end of the study the names of all students who participate will be entered into a raffle for an accessible MP3 player.

\section{Confidentiality}

\section{Who will know about my participation in this research study?}

You will not be specifically identified in any publication of research results. If any individual's data are reported, name or initials will not identify the participant. The audio 
recording and information obtained will only be accessible to the investigator listed on the first page of this document. According to University policy, all research records must be kept for a period of at least five years. Any documentation will be kept in a password-protected computer and in a locked file drawer only accessible to the principal investigator. The University of Pittsburgh Research Conduct and Compliance Office may access identifiable research records for the purposes of monitoring this study. In rare cases, identifiable research records may be released, such as in response to a court order.

\section{Right to Participate or Withdraw from Participation}

\section{Is my participation in this research study voluntary?}

Your participation in this study is completely voluntary. You do not have to take part in these research studies, and should you change your mind, you can withdraw from the study at any time. Likewise, you have the right to answer interview questions voluntarily, and refuse to answer any specific question at any time. Your decision to participate will not affect your relationship with the University of Pittsburgh. There are no right or wrong answers to the interview or survey questions.

\section{Voluntary Consent}

All of the above has been explained to me and all of my current questions have been answered. I understand that I am encouraged to ask questions about any aspect of this research 
study during the course of this study, and that such future questions will be answered by the researcher listed on the first page of this form.

Any questions I have about my rights as a research participant will be answered by the Human Subject Protection Advocate of the IRB Office, University of Pittsburgh, 1-866-2122668.

I understand that by signing this form I give my consent to participate in this research study.

I agree to participate in this study.

Participant's Signature

Participant's Name (print)

Date 
APPENDIX C

\title{
FLYER FOR STUDENTS: ANNOUNCEMENT OF STUDY
}

\author{
Seeking Students for Research Study
}

Students who are between the ages of 16 and 22 years who are braille readers and users of assistive technology are needed for a study. This study will explore how you use both braille and electronic information for classroom work, and how you learned these literacy practices. The purpose of this research will be to add to our understanding of the current role of both hard-copy (paper) braille and use of electronic access to information by people who are blind from ages 1622, and your attitudes and perceptions about both braille and technology. This information will inform how we prepare pre-service teachers to instruct young braille readers.

If you are interested in participating in this study or getting more information, please contact me via email at fmd22@pitt.edu, by calling 412-521-5797, or by writing to me at:

Frances Mary D'Andrea 
5513 Posvar Hall

University of Pittsburgh

Pittsburgh PA 15260

If you are under 18, you MUST have your parents' or guardians' permission. A consent form will be send to you in braille or electronically after you verify that you are:

1. between the ages of $16-22$

2. a student enrolled in school

3. a braille reader

4. a user of electronic assistive technology devices, hardware, or software.

If you are under 18, your parents will also receive a consent form that must be signed before you can participate.

Let me know if you have any questions. Thank you for your interest!

Frances Mary D'Andrea 
APPENDIX D

\section{FLYER FOR TEACHERS: ANNOUNCEMENT OF STUDY TO BE POSTED ON LISTSERVS}

Seeking Students for Research Study

Students who are between the ages of 16 and 22 years who are braille readers and users of assistive technology are needed for a study. This study will explore how they use both braille and electronic information for classroom work, and how they learned these literacy practices.

To be eligible, students must:

1. between the ages of $16-22$

2. a student enrolled in school

3. a braille reader

4. a user of electronic assistive technology devices, hardware, or software. 
If you know of students who are eligible and may be interested in participating in this study, please share this information with them and ask them to contact me to receive more information on the study and consent forms. If the student is under 18, the student's parents or guardians must contact me and will also receive consent forms. The student or parents/guardians can contact me via email at fmd22@pitt.edu, by calling 412-521-5797, or by writing to me at:

Frances Mary D'Andrea

5513 Posvar Hall

University of Pittsburgh

Pittsburgh PA 15260

Let me know if you have any questions. Thank you for your interest and your help!

Frances Mary D'Andrea

NCLVI Fellow

Doctoral Candidate, University of Pittsburgh 


\section{APPENDIX E}

\section{INTERVIEW PROTOCOL}

Research Question(s): 1. How do young adults who are braille readers use braille, audio, and electronic materials and tools for educational purposes?

2. How do young adults who are blind learn new literacy practices using assistive technology?

3. What are youths' attitudes towards hard-copy (paper) braille, and toward access technology?

Description of Participants/Interviewees: Young adults, between the ages of 16-22 (high school students and undergraduate college students).

Purpose of Interview: “I'm interested in how students your age are using braille and technology to do school work, complete assignments, and other tasks that involve reading and writing. I'll be asking questions about your opinions about using technology devices and about reading braille. There are no right or wrong answers; I just want your opinions. Your opinions as a user of technology and braille will help me understand what teachers need to know in order to teach students who are blind or visually impaired." 
Probes to Keep in Mind:
1. What kinds of access technology do
a. What's your favorite device? Why?
you use? What do you use it for?
How old were you when you learned it?
b. What other technology do you use?
c. Who taught you to use it/them? What do
you remember about learning to use technology?
2. We talked about what you remember about a. Who taught you to read braille? When?
learning technology. Now, what do you b. Where did you learn? Home? School?
remember about learning to read \& write braille? c. What did you use to read and write when you first learned? For example, did you use a Perkins? A slate \& stylus?
d. Do you remember particular books you used when you first began to read?

$\begin{aligned} & \text { 3. How do you use paper braille now? } \\ & \text { do you use it for? }\end{aligned} \quad$ How do you get your braille books?



b. Do you read a lot of braille? For school or at home, too?
c. Do you produce braille for yourself? How?

\begin{tabular}{|l}
$\begin{array}{l}\text { 4. How do you use technology now for } \\
\text { reading and writing? }\end{array}$ \\
$\begin{array}{l}\text { a. For example, do you read electronic books? Do } \\
\text { do you turn in papers, say? }\end{array}$ \\
thing you read for school? How did you read it? \\
b. Do you use it to access electronic information \\
(Internet, etc.)? \\
c. What other things do you use it for? \\
d. Do you know computer braille code? How did \\
you learn it?
\end{tabular}

5. In general, what do you think hard copy (paper) braille is most useful for? Anything you don't like to read in braille? a. What do you like to read in braille only (as opposed to electronically)?

b. Are there advantages to hard copy (paper) braille for both reading and writing? Can you give me an example? c. Are there disadvantages to hard copy braille? 


$\begin{array}{|ll|}\begin{array}{l}\text { 6. What do you think technology is } \\ \text { most useful for? }\end{array} & \text { a. What do you like to read electronically (as } \\ & \text { Anything you don't like to read electronically? } \\ & \text { What do you like to access with speech only? } \\ \text { b. Are there advantages to the use of access } & \text { technology? } \\ \text { c. Are there disadvantages to the use of access } \\ \text { technology? }\end{array}$

\begin{tabular}{|c|c|}
\hline 7. What advice would you have for & a. What do you think people your age who read \\
\hline students who are braille readers about & braille should know about technology? \\
\hline using technology? Do you have advice & b. What do you think teachers should know? What \\
\hline for teachers? & would you tell them if you could? \\
\hline
\end{tabular}




\section{APPENDIX F}

\section{SURVEY: PRACTICES AND PREFERENCES AMONG STUDENTS WHO READ BRAILLE AND USE ASSISTIVE TECHNOLOGY}

Welcome! Thank you for your interest in participating in this study which will examine how high school and college students (ages 16-2) use both hard copy braille and assistive technology (computers, notetakers, etc.) to complete school work.

You have requested this survey as an electronic Word document. There are three sections to this survey. The first section asks about your experiences with braille and assistive technology. The second set of questions will ask about your current practices, and the third set your preferences and opinions. For questions that have multiple choice answers, you may simply put the letter $\mathrm{X}$ in front of your choice. For short answer questions, you may type in your responses after each question. Please remember to save this document (or do as "save as" and rename) to email back to me as an attachment.

This survey is also available in braille. If you'd prefer another format or have any questions, please contact the researcher, Frances Mary D'Andrea, at fmd22@pitt.edu or 412-5215797. 
Thank you again for your participation.

Sincerely,

Frances Mary D'Andrea, Doctoral Candidate

University of Pittsburgh

5513 W.W. Posvar Hall

230 South Bouquet Street

University of Pittsburgh

Pittsburgh, PA 15260 
* Section 1: About YOU.

Your responses to the following questions are needed to provide a fuller picture of all participants in this study. This information is required for tracking purposes so I know who has completed the survey and so that your name can be added to the drawing. These questions are required but will be kept strictly confidential and no individual identifying information will be reported or shared with anyone except the researcher. There are 12 questions in this set.

For multiple choice questions, please put an $\mathrm{X}$ in front of your choice; for other questions, simply type your response in after the question.

\section{Your name:}

2. Your email address:

3. Today's date:

4. Your age:

5. Name of school attending:

6. Year/grade in school:

7. Do you now or have you ever attended a specialized school for the blind? yes no

If yes, for how long did you attend?

8. I learned to read braille (choose one answer):

a. From early childhood or preschool (I have always read braille)

b. In elementary school (I started with print but switched to braille in school)

c. In middle school (I started with print but switched to braille in school) 
d. Along with print throughout school but now I primarily use braille

e. Other (please explain)

9. In a typical week, I primarily read:
a. Braille on paper
b. Braille electronically (with refreshable braille)
c. Auditorily (whether on computer, CD, tapes, etc.)
d. Print
e. Other (please explain)

10. Please list the all technology you use on a regular basis to complete school work. Please list all that you use, both mainstream products as well as devices designed for people who are blind. For example, you might list your braille notetaker, your computer, specialized software, any other portable devices you use, etc.:

11. Of the above list of technology, which do you use most frequently (list one or two)?

12. How old were you when you first started using technology to complete school tasks? 
* Directions for Sections 2 and 3:

The survey questions in the following two sections are based on responses to interviews conducted with high school and college students between the ages of 16-22 who use both braille and assistive technology to complete school work. The students were asked about how they use paper braille, refreshable braille, and other electronic options to do classroom tasks. Each item on this survey contains a statement along with responses that indicate your level of agreement with the statement.

The first set of statements will refer to practices used by students who are blind. For those items, you will rate whether the statement describes practices you use or not. You will choose one of the following rankings:
a. this is very much like me
b. this is sort of like me
c. this is neither like me nor unlike me
d. this is somewhat unlike me
e. this is very unlike me

The second set of statements will refer to preferences for getting class work done, in other words, what you generally like to do or don't like to do, and your opinions about the practices you use. For those items, the scale will be as follows:
a. I strongly agree
b. I sort of agree
c. I do not agree or disagree
d. I sort of disagree
e. I strongly disagree 
You will find a variety of statements in this survey. Some of them may truly describe your own situation, that is, your own practices and preferences as far as how you get your work done. Others will be very different from your own experiences and opinions and you may not agree with the statement. There are no right or wrong answers. Please just select the response that generally describes your opinion and your own experiences with braille and assistive technology by placing an $\mathrm{X}$ in front of the letter that represents your response. 
* Section 2

\section{Set 1: Practices:}

For each of the following statements, you will rate your agreement by selecting one of the following choices:
a. this is very much like me
b. this is sort of like me
c. this is neither like me nor unlike me
d. this is somewhat unlike me
e. this is very unlike me

There are 28 statements in this section. Some will describe you well, some won't be very much like you at all. Remember that the statements refer to your practices for completing school work. Please respond to each statement by indicating how well the statement describes you.

1. I use a portable braille notetaker to do most of my schoolwork.
a. this is very much like me
b. this is sort of like me
c. this is neither like me nor unlike me
d. this is somewhat unlike me
e. this is very unlike me

2. I use a computer with speech to do most of my work.
a. this is very much like me
b. this is sort of like me 

c. this is neither like me nor unlike me
d. this is somewhat unlike me
e. this is very unlike me

3. All of my textbooks are in paper braille.
a. this is very much like me
b. this is sort of like me
c. this is neither like me nor unlike me
d. this is somewhat unlike me
e. this is very unlike me

4. I have DAISY files of all my textbooks.
a. this is very much like me
b. this is sort of like me
c. this is neither like me nor unlike me
d. this is somewhat unlike me
e. this is very unlike me

5. I'm finding that I'm reading fewer and fewer books tactually; I don't really use paper braille anymore.
a. this is very much like me
b. this is sort of like me
c. this is neither like me nor unlike me 

d. this is somewhat unlike me
e. this is very unlike me

6. Any of my math books are going to be paper braille.
a. this is very much like me
b. this is sort of like me
c. this is neither like me nor unlike me
d. this is somewhat unlike me
e. this is very unlike me

7. I find it easier to use my computer and listen to math.
a. this is very much like me
b. this is sort of like me
c. this is neither like me nor unlike me
d. this is somewhat unlike me
e. this is very unlike me

8. Whenever I do foreign languages then it's essential to have paper braille.
a. this is very much like me
b. this is sort of like me
c. this is neither like me nor unlike me
d. this is somewhat unlike me
e. this is very unlike me 
9. If I want to read something long it's going to be time consuming, so I'll just listen to it.
a. this is very much like me
b. this is sort of like me
c. this is neither like me nor unlike me
d. this is somewhat unlike me
e. this is very unlike me

10. When I'm listening my mind kind of zones out sometimes, so when I study I use braille.
a. this is very much like me
b. this is sort of like me
c. this is neither like me nor unlike me
d. this is somewhat unlike me
e. this is very unlike me

11. If it's a really difficult assignment I like to have the braille.
a. this is very much like me
b. this is sort of like me
c. this is neither like me nor unlike me
d. this is somewhat unlike me
e. this is very unlike me 
12. I found that using speech was a lot faster than trying to read the braille with the display.
a. this is very much like me
b. this is sort of like me
c. this is neither like me nor unlike me
d. this is somewhat unlike me
e. this is very unlike me

13. I read with the refreshable braille display all day long.
a. this is very much like me
b. this is sort of like me
c. this is neither like me nor unlike me
d. this is somewhat unlike me
e. this is very unlike me

14. I don't like to read long books on a 32-cell braille display.
a. this is very much like me
b. this is sort of like me
c. this is neither like me nor unlike me
d. this is somewhat unlike me
e. this is very unlike me

15. I base what device to use on the particular assignment. 

a. this is very much like me
b. this is sort of like me
c. this is neither like me nor unlike me
d. this is somewhat unlike me
e. this is very unlike me

16. I've never had any practical use for the slate and stylus.
a. this is very much like me
b. this is sort of like me
c. this is neither like me nor unlike me
d. this is somewhat unlike me
e. this is very unlike me

17. I use the slate and stylus for short tasks like taking down people's phone numbers.
a. this is very much like me
b. this is sort of like me
c. this is neither like me nor unlike me
d. this is somewhat unlike me
e. this is very unlike me

18. I learned the bulk of the technology that I use all by myself.
a. this is very much like me
b. this is sort of like me 

c. this is neither like me nor unlike me
d. this is somewhat unlike me
e. this is very unlike me

19. The technology specialist from the school for the blind taught me technology.
a. this is very much like me
b. this is sort of like me
c. this is neither like me nor unlike me
d. this is somewhat unlike me
e. this is very unlike me

20. My TVI (teacher for the visually impaired) got me started on technology.
a. this is very much like me
b. this is sort of like me
c. this is neither like me nor unlike me
d. this is somewhat unlike me
e. this is very unlike me

21. I didn't learn technology in school, I went to a center.
a. this is very much like me
b. this is sort of like me
c. this is neither like me nor unlike me 
d. this is somewhat unlike me

e. this is very unlike me

22. I have friends who know their technology better than me so I'll just ask them how to do something.
a. this is very much like me
b. this is sort of like me
c. this is neither like me nor unlike me
d. this is somewhat unlike me
e. this is very unlike me

23. My TVI taught me everything I know about technology.
a. this is very much like me
b. this is sort of like me
c. this is neither like me nor unlike me
d. this is somewhat unlike me
e. this is very unlike me

24. I don't really have any blind friends to ask about technology.
a. this is very much like me
b. this is sort of like me
c. this is neither like me nor unlike me
d. this is somewhat unlike me 
e. this is very unlike me

25. I usually had to have some help from a sighted person when using PowerPoint.
a. this is very much like me
b. this is sort of like me
c. this is neither like me nor unlike me
d. this is somewhat unlike me
e. this is very unlike me

26. I managed to do PowerPoint by myself with no problem.
a. this is very much like me
b. this is sort of like me
c. this is neither like me nor unlike me
d. this is somewhat unlike me
e. this is very unlike me

27. I do have my own blog.
a. this is very much like me
b. this is sort of like me
c. this is neither like me nor unlike me
d. this is somewhat unlike me
e. this is very unlike me 
28. My teachers email me my assignments.
a. this is very much like me
b. this is sort of like me
c. this is neither like me nor unlike me
d. this is somewhat unlike me
e. this is very unlike me

If you wish, please add any details you would like to about what devices you use, how you learned them, and how you use them in school. 


\section{*Section 3}

\section{Set 2: Preferences and Opinions:}

For each of the following statements, you will rate your agreement by selecting one of the following choices:
a. I strongly agree
b. I sort of agree
c. I do not agree or disagree
d. I sort of disagree
e. I strongly disagree

There are 28 items in this section. You will find statements that you agree with and some that you do not agree with. Remember that the statements refer to your preferences and opinions for completing school work. There are no right or wrong responses.

1. I wasn't very enthusiastic about learning braille.
a. I strongly agree
b. I sort of agree
c. I do not agree or disagree
d. I sort of disagree
e. I strongly disagree

2. I love reading and writing braille and that's how I work best.
a. I strongly agree
b. I sort of agree 

c. I do not agree or disagree
d. I sort of disagree
e. I strongly disagree

3. I try to use braille as little as I possibly can.
a. I strongly agree
b. I sort of agree
c. I do not agree or disagree
d. I sort of disagree
e. I strongly disagree

4. Braille is the foundation of a blind person's education.
a. I strongly agree
b. I sort of agree
c. I do not agree or disagree
d. I sort of disagree
e. I strongly disagree

5. I didn't like to read braille because I thought it was slow and inefficient.
a. I strongly agree
b. I sort of agree
c. I do not agree or disagree
d. I sort of disagree 
e. I strongly disagree

6. I find that when I'm reading braille I process and comprehend things better than when I'm listening.
a. I strongly agree
b. I sort of agree
c. I do not agree or disagree
d. I sort of disagree
e. I strongly disagree

7. Speech allows me to focus on the story more.
a. I strongly agree
b. I sort of agree
c. I do not agree or disagree
d. I sort of disagree
e. I strongly disagree

8. I think reading braille is a lot slower than using speech software.
a. I strongly agree
b. I sort of agree
c. I do not agree or disagree
d. I sort of disagree
e. I strongly disagree 
9. I don't really like to listen to synthetic speech.
a. I strongly agree
b. I sort of agree
c. I do not agree or disagree
d. I sort of disagree
e. I strongly disagree

10. I'm a huge supporter of mainstream products rather than devices designed for blind people.
a. I strongly agree
b. I sort of agree
c. I do not agree or disagree
d. I sort of disagree
e. I strongly disagree

11. I think these new netbooks are taking the place of braille notetakers.
a. I strongly agree
b. I sort of agree
c. I do not agree or disagree
d. I sort of disagree
e. I strongly disagree 
12. I don't like PowerPoint because I have to rely on other people to use it.
a. I strongly agree
b. I sort of agree
c. I do not agree or disagree
d. I sort of disagree
e. I strongly disagree

13. It's gotten a lot easier to do PowerPoint with speech now than it used to.
a. I strongly agree
b. I sort of agree
c. I do not agree or disagree
d. I sort of disagree
e. I strongly disagree

14 PowerPoint with WindowEyes or JAWS is just too hard.
a. I strongly agree
b. I sort of agree
c. I do not agree or disagree
d. I sort of disagree
e. I strongly disagree

15. I don't like the slate because it's so much slower.
a. I strongly agree 

b. I sort of agree
c. I do not agree or disagree
d. I sort of disagree
e. I strongly disagree

16. I'll never reject the importance of the slate and stylus.
a. I strongly agree
b. I sort of agree
c. I do not agree or disagree
d. I sort of disagree
e. I strongly disagree

17. I can't imagine how I would do math on the computer.
a. I strongly agree
b. I sort of agree
c. I do not agree or disagree
d. I sort of disagree
e. I strongly disagree

18. For my math class I haven't felt the need for braille--speech is fine.
a. I strongly agree
b. I sort of agree
c. I do not agree or disagree 

d. I sort of disagree
e. I strongly disagree

19. A part of me still really misses reading the hard copy braille books but it's just not practical.
a. I strongly agree
b. I sort of agree
c. I do not agree or disagree
d. I sort of disagree
e. I strongly disagree

20. I'm not a computer person even though I use it all the time.
a. I strongly agree
b. I sort of agree
c. I do not agree or disagree
d. I sort of disagree
e. I strongly disagree

21. It's important to read braille because it teaches you how to spell and punctuate.
a. I strongly agree
b. I sort of agree
c. I do not agree or disagree 

d. I sort of disagree
e. I strongly disagree

22. If I can read the menu online I don't care if I have a braille menu or not.
a. I strongly agree
b. I sort of agree
c. I do not agree or disagree
d. I sort of disagree
e. I strongly disagree

23. When you use the technology it's going to make things easier.
a. I strongly agree
b. I sort of agree
c. I do not agree or disagree
d. I sort of disagree
e. I strongly disagree

24. Once students get into high school and as they get closer to college you need to start taking the braille away from them and forcing them to use speech.
a. I strongly agree
b. I sort of agree
c. I do not agree or disagree
d. I sort of disagree 
e. I strongly disagree

25. TVIs should do their research before buying any sort of assistive technology for a student because a kid doesn't really know all the options available.
a. I strongly agree
b. I sort of agree
c. I do not agree or disagree
d. I sort of disagree
e. I strongly disagree

26. I think that it's important that the students have a say in the technology bought for them even if they're really young.
a. I strongly agree
b. I sort of agree
c. I do not agree or disagree
d. I sort of disagree
e. I strongly disagree

27. TVIs should only know about the most popular devices so they can teach their students how to use them.
a. I strongly agree
b. I sort of agree
c. I do not agree or disagree 

d. I sort of disagree
e. I strongly disagree

28. I think that TVIs should know about every technology device that's out there and keep up with it.
a. I strongly agree
b. I sort of agree
c. I do not agree or disagree
d. I sort of disagree
e. I strongly disagree

Optional: If you wish to share additional comments about your preferences and opinions about using braille and technology, please add them here.

Thank you very much for completing this survey! Your name has been added to the list of participants eligible for the drawing at the end of the study. 


\section{BIBLIOGRAPHY}

Abner, G., \& Lahm, E. (2002). Implementation of assistive technology with students who are visually impaired: Teachers’ readiness. Journal of Visual Impairment \& Blindness, 96, 98-105.

American Foundation for the Blind (n.d.) AccessWorld: Technology and People Who Are Blind or Visually Impaired. Retrieved from http://www.afb.org/aw/main.asp

American Printing House for the Blind [APH] (2007). Distribution of eligible students based on the Federal Quota Census of January 02, 2006 (Fiscal Year 2007). Retrieved January 30, 2009 from http://aph.org/fedquotpgm/dist07.html

Anstey, M., Bull, G. (2006). Teaching and Learning Multiliteracies: Changing Times, Changing Literacies. Newark, DE: International Reading Association.

Blausell, C.V. \& Klemick, E. (2007). Tracking U.S. trends. In Education Week [Special report]. Technology Counts 2007: The Information Edge, 30, 42-44.

Bogdan, R.C. \& Biklen, S.K. (2007). Qualitative Research for Education: An Introduction to Theories and Methods. Boston: Pearson Education.

Butler, S.E., Crudden, A., Sansing, W.K., \& LeJeune, B.J. (2002). Employment barriers: Access to assistive technology and research needs. Journal of Visual Impairment \& Blindness, 96, 664-667.

Bureau of Labor Statistics, The Editor's Desk (2005). Computer use at word in 2003. Retrieved from http://stats.bls.gov/opub/ted/2005/aug/wk1/art03.htm

CIBER. (2008). Information behavior of the researcher of the future. Retrieved from UCL website: http://www.ucl.ac.uk/infostudies/research/ciber/downloads/

Corn, A., \& Wall, R. (2002). Access to multimedia presentations for students with visual impairments. Journal of Visual Impairment \& Blindness, 96, 197-211.

D’Andrea, F.M. (2009). A history of instructional methods in uncontracted and contracted braille. Journal of Visual Impairment \& Blindness, 103, 585-594. 
Edwards, B.J., \& Lewis, S. (1998). The use of technology in programs for students with visual impairments in Florida. Journal of Visual Impairment \& Blindness, 92, 302-312.

Farnsworth, C. R. \& Luckner, J.L. (2008). The impact of assistive technology on curriculum accommodation for a braille-reading student. RE:view, 39, 171-187.

Fellenius, K. (1999). Computer-based instruction for young braille readers in mainstream education: An evaluation study. Visual Impairment Research, 1, 147-164.

Ferrell, K.A. (n.d.) Issues in the field of blindness and low vision. Retrieved from www.unco.edu/ncssd/resources/issues_bvi.shtml.

Fields, M.A. (2004). Factors correlated with employment outcomes for individuals who are blind or visually impaired (Doctoral Dissertation). Retrieved from ProQuest Dissertations \& Theses: Full Text database. (Publication No. AAT 3123081).

Fowler, F.J. (1995). Improving Survey Questions: Design and Evaluation. Thousand Oaks, CA: SAGE Publications.

Forster, E.M. \& Holbrook, M.C. (2005). Implications of paraprofessional supports for students with visual impairments. RE:view, 36, 155-163.

Gallup (2008). Nearly half of Americans are frequent Internet users. Retrieved January 16, 2009 from http://www.gallup.com/poll/113638/Nearly-Half-Americans-Frequent-InternetUsers.aspx

Gaskins, I.W. (2003). Taking charge of reader, text, activity, and context variables. In A.P. Sweet \& C.E. Snow (Eds.), Rethinking Reading Comprehension. New York: Guilford.

Gravetter, F.J. \& Wallnau, L.B. (2007). Statistics for the Behavioral Sciences, $7^{\text {th }}$ Edition. Belmont, CA: Thomson Wadsworth.

Gray, D.E. (2004). Doing Research in the Real World. Thousand Oaks, CA: SAGE Publications.

Groves, R.M., Fowler, F.J., Couper, M.P., Lepkowski, J.M., Singer, E., \& Tourangeau, R. (2004). Survey Methodology. Hoboken, NJ: Wiley and Sons.

Hatlen, P. (2000). Historical perspectives. In Holbrook \& Koenig (Eds.), Foundations of Education, Second Edition. New York: AFB Press.

Hecker, D.E. (2005). High-technology employment: A NAICS-based update. Monthly Labor Review, pp. 57-72. Retrieved from http://stats.bls.gov/opub/mlr/2005/07/art6full.pdf

International Society for Technology in Education (2007). National Education Technology Standards for Students: The Next Generation. Eugene, OR: International Society for Technology in Education. 
Ito, M., Horst, H., Bittani, M., boyd, d., Herr-Stephenson, B., Lange, P.G., Pascoe, C.J., Robinson, L. (2008). Living and learning with new media: Summary of findings from the Digital Youth Project. John D. and Catherine T. MacArthur Foundation Reports on Digital Media and Learning. Retrieved from http://digitalyouth.ischool.berkeley.edu/files/report/digitalyouth-WhitePaper.pdf.

Kapperman, G., Sticken, J., \& Heinze, T. (2002). Survey of the use of assistive technology by Illinois students who are visually impaired. Journal of Visual Impairment \& Blindness, 96, 106-108.

Karchmer, R.A., Mallette, M.H., Kara-Soteriou, J., Leu, D.J. Eds. (2005). Innovative Approaches to Literacy Education: Using the Internet to Support New Literacies. Newark, DE: International Reading Association.

Kelly, Stacy M. (2008) Correlates of assistive technology use by students who are visually impaired in the U.S.: Multilevel modeling of the Special Education Elementary Longitudinal Study (Doctoral Dissertation). Retrieved from Dissertations \& Theses: Full Text database. (Publication No. AAT 3324867.)

Kennedy, T.L.M., Smith, A., Wells, A.T., \& Wellman, B. (2008). Networked families. Pew Internet \& American Life Project. Retrieved February 17, 2009 from www.pewinternet.org/pdfs/PIP_Networked_Family.pdf

Koenig, A.J., Mack, C.G., Shenck, W.A., \& Ashcroft, C.A. (1985). Developing writing and word processing skills with visually impaired children: A beginning. Journal of Visual Impairment \& Blindness, 79, 308-312.

Levine, P., Marder, C., \& Wagner, M. (2004). Services and supports for secondary school students with disabilities: A special topic report of findings from the National Longitudinal Transition Study-2 (NLTS2). Retrieved from www.nlts2.org/reports/2004_05/nlts2_report_2004_05_complete.pdf

Leu, D.J. (2000). Literacy and technology: Deitic consequences for literacy education in an information age. In M.L. Kamil, P.B. Pearson, \& R. Barr (Eds.), Handbook of Reading Research, Volume III, (pp. 743-770). Mahwah, NJ: Lawrence Erlbaum Associates.

Leu, D.J., Hillinger, M., Loseby, P.H., Balcom, M.L., Dinkin, J., Eckels, M.L., Johson, J., Mathews, K., Raegler, R. (1998). Grounding the design of new technologies for literacy and learning in teachers' instructional needs. In D. Reinking, M.C. McKenna, L.D. Labbo, \& R.D. Kieffer (Eds.), Handbook of Literacy and Technology: Transformations in a Post-Typographic World. Matwah, NJ: Lawrence Erlbaum Associates

Mack, C.G., Koenig, A.J., \& Ashcroft, S.C. (1990). Microcomputers and access technology in programs for teachers of visually impaired students. Journal of Visual Impairment \& Blindness, 84, 526-530. 
MacMillan, D. (2008). Testing for Tech Literacy. [Electronic version]. BusinessWeek, Retrieved October 28, 2008 from http://www.businessweek.com/print/technology/ content/oct2008/tc20081027_279347.htm

Mason, C. \& Davidson, R. (2000). National Plan for Training Personnel to Serve Children with Blindness and Low Vision. Reston, VA: The Council for Exceptional Children.

Merriam-Webster (2003). $11^{\text {th }}$ Collegiate Dictionary. CD-ROM edition.

Mertens, D. (1998). Research Methods in Education and Psychology: Integrating Diversity with Quantitative and Qualitative Approaches. Thousand Oaks, CA: SAGE Publications.

Miles, M.B., Huberman, A. M. (1994). Qualitative Data Analysis: An Expanded Sourcebook, $2^{\text {nd }}$ Edition. Thousand Oaks, CA: SAGE Publications.

Morse, J.M., Richards, L. (2002). Read Me First for a User's Guide to Qualitative Methods. Thousand Oaks, CA: SAGE Publications.

Mullis, I. V. S., Kennedy, A.M., Martin, M.O., Sainsbury, M. (2006). PIRLS 2006 Assessment framework and specifications, 2nd Edition [Progress in International Literacy Study]. Amsterdam, the Netherlands, International Association for the Evaluation of Educational Achievement (IEA). Retrieved December 6, 2008 from http://timss.bc.edu/isc/publications.html

Murphy, J.L., Hatton, D., \& Erickson, K.A. (2008). Exploring the early literacy practices of teachers of infants, toddlers, and preschoolers with visual impairments. Journal of Visual Impairment \& Blindness,102, 133-146.

NEA [National Education Association] (2008). Access, Adequacy, and Equity in Education Technology: Results of a Survey of America's Teachers and Support Professionals on Technology in Public Schools and Classrooms. Washington, D.C: Author.

National Center for Education Statistics. (2000, September). Teachers' Tools for the 21st Century: A Report on Teachers' Use of Technology. (Statistical Analysis Report (NCES 2000-102). Washington, DC: U.S. Department of Education.

National Council of Teachers of English. (2008). The NCTE Definition of $21^{\text {st }}$-Century Literacies. Retrieved from http://www.ncte.org/positions/statements/21stcentdefinition

Nielsen//NetRatings (2004). Three out of four Americans have access to the Internet, according to Neilsen//NetRatings. [Press release.] Retrieved January 14, 2009 from http://www.nielsen-online.com/pr/pr_040318.pdf

Office of Special Education and Rehabilitative Services [OSERS], U.S. Department of Education (2006). Assistance to States for the Education of Children with Disabilities and Preschool Grants for Children with Disabilities Students; Final Rule. (Federal Register, 
71 (156) 46540-46845.) Retrieved from http://edocket.access.gpo.gov/2006/pdf/06-

6656.pdf

OSEP (n.d.) National instructional materials accessibility standards (NIMAS). Retrieved January 29, 2009 from http://nimas.cast.org/about/regulations/osep_summary

Parker, S., Buckley, W., Truesdell, A., Riggio, M., Collins, M., \& Boardman, B. (1990). Barriers to the use of assistive technology with children: A survey. Journal of Visual Impairment \& Blindness, 84, 532-533.

Prensky, M. (2001) Digital natives, Digital immigrants. On the Horizon. Retrieved from http://www.marcprensky.com/writing/default.asp

Presley, I. \& D'Andrea, F.M. (2009). Assistive Technology for Students Who Are Blind or Visually Impaired: A Guide to Assessment. New York: AFB Press.

Reed, P. \& Bowser, G. (2005). Assistive technology and the IEP. In Edyburn, D., Higgins, K. \& Boone, R. (Eds.), Handbook of Special Education Technology Research and Practice. Whitefish Bay, WI: Knowledge by Design.

Rozema, R. \& Webb, A. (2008). Literature and the Web: Reading and Responding with New Technologies. Portsmouth, NH: Heinemann.

Rubin, H.J. \& Rubin, I.S. (2005). Qualitative Interviewing: The Art of Hearing Data. Thousand Oaks, CA: SAGE Publishing.

Smith, D.W. and Kelly, P. (2007). A survey of assistive technology and teacher preparation programs for individuals with visual impairment. Journal of Visual Impairment \& Blindness, 101, 429-433.

Smith, N.B. (2002). American Reading Instruction, Special Edition. Newark, DE: International Reading Association.

Spungin, S.J. \& Taylor, J. (1986). The teacher. In G.T. Scholl (Ed.), Foundations of Education for Blind and Visually Handicapped Children and Youth (pp.255-264). New York: American Foundation for the Blind.

Spungin, S.J. \& D'Andrea, F.M. (2000). Braille literacy. In J. Dixon (Ed.), Braille Into the Next Millennium. Washington, D.C.: The Library of Congress.

Strangman, N. \& Dalton, B. (2005). Using technology to support struggling readers: A review of the research. In D. Edyburn, K. Higgins, \& R. Boone (Eds.), Handbook of Special Education Technology Research and Practice. Whitefish Bay, WI: Knowledge by Design.

State Educational Technology Directors Association [SETDA] (2008). SETDA's National Trends Report 2008. Retrieved December 7, 2008 from www.setda.org 
Taffe, S.W. \& Gwinn, C.B. (2007). Integrating Literacy and Technology. New York: Guilford Press.

Tyner, K. (1998). Literacy in a Digital World: Teaching and Learning in the Age of Information. Mahwah, NJ: Lawrence Erlbaum Associates.

U.S. Department of Education, Office of Educational Technology. (2004). Toward a new golden age in American education: How the Internet, the law and today's students are revolutionizing expectations. Retrieved February 18, 2009 from http://www.ed.gov/about/offices/list/os/technology/plan/2004/site/edlite-default.html

U.S. Department of Education (n.d.) Visions 2020.2: Student views on transforming education and training through advanced technologies. (Joint report from U.S. Department of Education, U.S. Department of Commerce, and NetDay.) Retrieved from http://www.ed.gov/about/offices/list/os/technology/plan/2004/site/documents/visions_20 202.pdf

U.S. Department of Education, Office of Special Education and Rehabilitative Services, Office of Special Education Programs. (2005). 25th Annual (2003) Report to Congress on the implementation of the Individuals with Disabilities Education Act, (Vol.1). Washington, D.C.: Government Printing Office.

U.S. Department of Labor (1999). Futurework: Trends and challenges for work in the $21^{\text {st }}$ century. Retrieved June 14, 2009 from http://www.dol.gov/oasam/programs/history/herman/reports/futurework/report.htm

Newman, L., Wagner, M., Cameto, R., Knokey, A.-M. (2009). The post-high school outcomes of youth with disabilities up to 4 years after high school.: A report from the National Longitudinal Transition Study-2 (NLTS2). [NCSER 2009-3017]. Menlo Park, CA: SRI International.

Wall Emerson, R.S., Corn, A., \& Siller, M.A. (2006). Trends in braille and large-print production in the United States: 2000-2004. Journal of Visual Impairment \& Blindness, $100,197-211$.

Wenglinsky, H. (2005). Using Technology Wisely: The Keys to Success in Schools. New York: Teachers College Press.

Wepner, S.B., \& Bowes, K.A. (2004). Using assistive technology for literacy development. Reading and Writing Quarterly, 20, 219-223.

Willis, J.W. (2007). Foundations of Qualitative Research: Interpretive and Critical Approaches. Thousand Oaks, CA: SAGE Publications.

Withrow, F.B. (2004) Literacy in the digital age: Reading, writing, viewing, and computing. Latham, MD: Scarecrow Education. 